\title{
RADIOBIOLOGY LABORATORY
}

College of Medicine, University of Utah

Salt Lake City 12, Utah

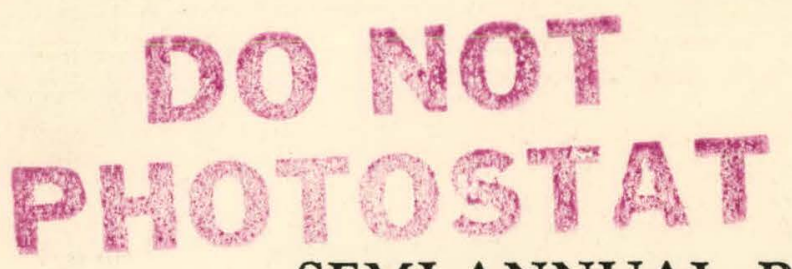

SEMI-ANNUAL PROGRESS REPORT

September 30, 1957

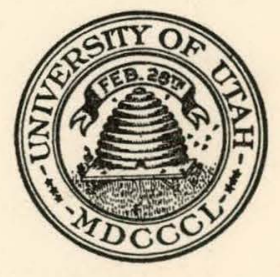

Operated for the Atomic Energy Commission

by

The University of Utah

through the

Department of Anatomy of the College of Medicine

CONTRACT AT(11-1)-119 


\section{DISCLAIMER}

This report was prepared as an account of work sponsored by an agency of the United States Government. Neither the United States Government nor any agency Thereof, nor any of their employees, makes any warranty, express or implied, or assumes any legal liability or responsibility for the accuracy, completeness, or usefulness of any information, apparatus, product, or process disclosed, or represents that its use would not infringe privately owned rights. Reference herein to any specific commercial product, process, or service by trade name, trademark, manufacturer, or otherwise does not necessarily constitute or imply its endorsement, recommendation, or favoring by the United States Government or any agency thereof. The views and opinions of authors expressed herein do not necessarily state or reflect those of the United States Government or any agency thereof. 


\section{DISCLAIMER}

Portions of this document may be illegible in electronic image products. Images are produced from the best available original document. 


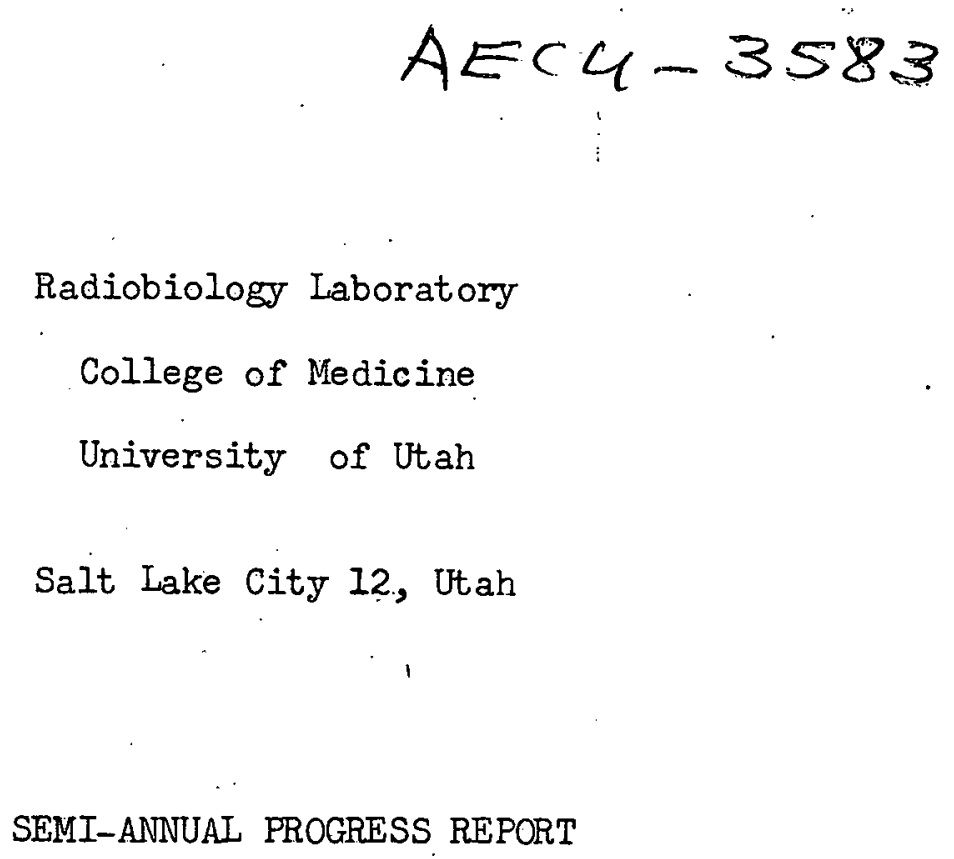

Operated for the Atomic Energy Commission

by

The University of Utah

through the Department of Anatomy of the College of Medicine Contract $\operatorname{AT}(11-1)-119$ 
Injection Tables

Explanation

I. Toxicity Animals

A. Plutonium

B. Radium

C. Mesothorium

D. Radiothorium

E. Strontium

II. Test Animals

A. Plutonium

B. Radium

C. Mesothorium

D. Radiothorium

E. Strontium

F. Aging Controls

Clinical Report

I. Tabular sumnary of deceased dogs

II. Effect of radioactive isotopes upon rate of narrowing of pulp cavities of teeth.

III. Case histories

IV. Current census

Hematology Report

Microradiographic Studies of Cortical Bone of Chronic Toxicity Dogs

The Failure of Plutonium to Deposit in the Osteoid of Rachitic Rats

Biochemistry Report

A Summary of the $\dot{R a}{ }^{228}$ (MsTh) Injection Solutions

Studies of the State of Plutonium, Thorium and Radium in Beagle Blood

Lack of Effect of Dose Level on $\mathrm{Pu}^{239}$ Metabolism in the Beagle

Concentration of $\mathrm{Sr}^{90}$ in Plasma

Absorption of Radium and Thorium Through the Gut as a Function of Chemical Form, IV.

Isotope iBurden and Radiation Dose Rate in Injected Beagles 
K-9 Bark II, An Improved Live Dog Gamma Counter

Measurement of X-Ray Dosage to Dogs

Further Thoron Exhalation Measurements

Further Studies on Radon Retention 
INJECT ION TABLES

Tables I and II list the toxicity and test animals, respectively. Toxicity animals are those animals which will be maintained until sacrifice becomes a clinical necessity; test animals may be sacrificed as needed for special studies.

Dogs are put into the toxicity study in groups of six or seven of the same sex (five or six dose levels plus one control). Litter mates are used whenever. possible. Each animal receives the designated dose of one radioisotope in a single $I_{0}^{\prime} V^{\prime}$. injection. The animals are injected at approximately 18 months of age after skeletal maturity has been demonstrated radiographically. Twelve such groups are planned for each radioisotope.

The five dose levels designated by integers are those specified at the eariy meetings of the consultants, and those designated by non-integers have been added by the local group. Since these dose levels were specified as "retained" doses, (1) the actual injected doses are 4 times the desired "retained" doses of $\mathrm{Ra}^{226}$, $\mathrm{Ra}^{228}$ (Mesothorium), and $\mathrm{Sr} 90$, and 1.11 times the desired "retained" doses of $\mathrm{Pu}^{239}$ and $\mathrm{Th}^{228}$ (Radiothorium). The desired "retained" doses are the same for all the isotopes except $\mathrm{Sr}^{90}$, in which case they are greater by a factor of 10 .

Dose level $I$ is the basis of the scheme, and is 10 times the maximum permissible $\mathrm{Ra}^{226}$ in man. Level $1=0.0143$ "retained" $\mu \mathrm{c} / \mathrm{kg}$

$$
=10 \times \frac{0.1 \mu c \mathrm{ra}^{22.6}}{70}
$$

All other dose levels are simple multiples of level 1 as shown on the following page:

(1) The average fractional radium retention equals 0.25 at 330 days after injection; the average fractional retention of plutonium is 0.90 at. six days after injection, but plutonium retention decreases more slowly during the first year than does radium retention. 


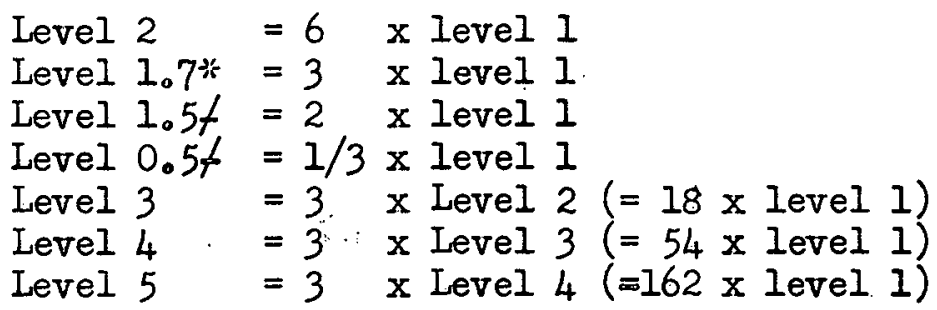

The numbering system for the dogs has been built around the injection program and serves as a code to describe each dog's place in the experiment. The first letter tells the sex of toxicity $\operatorname{dogs}(M=$ male, $F=$ female). When the first letter is $T$, the dog is a test animal. $M, F$, or $T$ is followed by a number which denotes chronological order.

Next comes a code letter for the radioactive isotope. $(P=$ plutonium, $R=$ radium, $M=$ mesothorium, $T=$ radiothorium, $S=$ strontiun). The final number is the dose level number as defined above and with $0=$ control.

Example: MIP5 is a male animal in the first plutonium group at the top dose level.

Although $M \cap P 5, M \cap P 4, M \cap P 3, M \cap P 2, M \cap P 1$, and MIPO constitute a group and were injected at the same time, the tables are arranged according to dose level to. facilitate comparison of all the $\mathrm{P} 5$ animals, all the $\mathrm{P} 4$ animals, etc。

* All the isotopes except $\mathrm{Th}^{228}$.

t. $\mathrm{Th}^{228}$ only. 
TABLE I

\section{TOXIC ITY ANIMALS (AS OF 9-30-57)}

A. Plutonium

\begin{tabular}{|c|c|c|c|c|c|c|}
\hline $\begin{array}{l}\text { Approx. } \\
\text { Retained } \\
\text { Dose } \\
(\mu \mathrm{c} / \mathrm{kg}) \\
\end{array}$ & $\begin{array}{l}\text { Exp. } \\
\text { No. }\end{array}$ & $\begin{array}{l}\text { Age at } \\
\text { Injection } \\
\text { (mos.) }\end{array}$ & $\begin{array}{l}\text { Weight at } \\
\text { Injection } \\
(\mathrm{kg})\end{array}$ & $\begin{array}{c}\text { Injected } \\
\text { Dose } \\
(\mu \mathrm{c} / \mathrm{kg})\end{array}$ & $\begin{array}{c}\text { Date } \\
\text { Injected }\end{array}$ & $\begin{array}{l}\text { Days since } \\
\text { Injection }\end{array}$ \\
\hline 2.5 & $\begin{array}{l}\text { M1P5 } \\
\text { F2P5 } \\
\text { M3P5 } \\
\text { M4P5 } \\
\text { F5P5 } \\
\text { F6P5 } \\
\text { F7P5 } \\
\text { M8P5 } \\
\text { F9P5 }\end{array}$ & $\begin{array}{l}14 \\
38 \\
17 \\
19 \\
23 \\
13 \\
16 \\
16 \\
18\end{array}$ & $\begin{array}{l}8.86 \\
8.75 \\
8.10 \\
9.18 \\
8.77 \\
7.90 \\
8.33 \\
9.55 \\
9.45\end{array}$ & $\begin{array}{l}2.67 \\
3.30 \\
3.00 \\
3.17 \\
2.77 \\
2.57 \\
2.99 \\
2.69 \\
2.73\end{array}$ & $\begin{array}{r}12-1-52 \\
3-2-53 \\
6-1-53 \\
9-16-53 \\
10-14-53 \\
5-12-54 \\
10-25-54 \\
3-15-55 \\
9-9-55\end{array}$ & $\begin{array}{c}\text { (dead at } 1324 \text { d) } \\
(\text { dead at } 1576 \text { d) } \\
(\text { dead at } 499 \text { d) } \\
1475 \\
1447 \\
(\text { dead at } 1194 \text { d) } \\
1071 \\
930 \\
752\end{array}$ \\
\hline 0.81 & $\begin{array}{l}\text { MבP4 } \\
\text { F2P4 } \\
\text { M3P4 } \\
\text { M4P4 } \\
\text { F5P4 } \\
\text { F6P4 } \\
\text { F7P4 } \\
\text { M8P4 } \\
\text { F9P4 } \\
\text { F1OP4 } \\
\text { M11P4 } \\
\text { M12P4 }\end{array}$ & $\begin{array}{l}15 \\
19 \\
16 \\
19 \\
21 \\
14 \\
16 \\
21 \\
18 \\
17 \\
20 \\
20\end{array}$ & $\begin{array}{l}7.61 \\
8.65 \\
9.36 \\
8.74 \\
7.05 \\
9.26 \\
8.45 \\
9.22 \\
8.58 \\
6.48 \\
9.56 \\
11.4\end{array}$ & $\begin{array}{l}0.823 \\
1.03 \\
0.92 .9 \\
0.974 \\
0.872 \\
0.811 \\
0.963 \\
0.887 \\
0.960 \\
0.868 \\
0.927 \\
0.838\end{array}$ & $\begin{array}{r}12-1-52 \\
3-2-53 \\
6-1-53 \\
9-16-53 \\
10-14-53 \\
5-12-54 \\
10-25-54 \\
3-15-55 \\
9-9-55 \\
11-22-55 \\
4-24-56 \\
5-29-56\end{array}$ & $\begin{array}{c}\text { (dead at } 1724 \mathrm{~d}) \\
\text { (dead at } 1556 \mathrm{~d}) \\
\text { (dead at } 1198 \mathrm{~d}) \\
\text { (dead at } 1066 \mathrm{~d}) \\
\text { (dead at } 1245 \mathrm{~d}) \\
1237 \\
1071 \\
930 \\
752 \\
678 \\
524 \\
489\end{array}$ \\
\hline 0.27 & $\begin{array}{l}\text { M1P3 } \\
\text { F2P3 } \\
\text { M3P3 } \\
\text { M4P3 } \\
\text { F5P3 } \\
\text { F6P3 } \\
\text { F7P3 } \\
\text { M8P3 } \\
\text { F9P3 } \\
\text { F1OP3 } \\
\text { M11P3 } \\
\text { M12P3 }\end{array}$ & $\begin{array}{l}14 \\
14 \\
16 \\
20 \\
21 \\
14 \\
16 \\
13 \\
18 \\
20 \\
20 \\
20\end{array}$ & $\begin{array}{l}8.00 \\
6.85 \\
8.74 \\
8.51 \\
8.22 \\
8.38 \\
9.00 \\
9.73 \\
7.67 \\
8.94 \\
10.5 \\
10.2\end{array}$ & $\begin{array}{l}0.261 \\
0.312 \\
0.291 \\
0.292 \\
0.288 \\
0.282 \\
0.314 \\
0.30 \\
0.30 \\
0.298 \\
0.309 \\
0.308\end{array}$ & $\begin{array}{r}12-1-52 \\
3-2-53 \\
6-1-53 \\
9-16-53 \\
10-14-53 \\
5-12-54 \\
10-25-54 \\
3-15-55 \\
9-9-55 \\
11-22-55 \\
4-24-56 \\
5-29-56\end{array}$ & $\begin{array}{c}\text { (dead at } 1476 \mathrm{~d} \text { ) } \\
1673 \\
1582 \\
1475 \\
1447 \\
1237 \\
1071 \\
930 \\
752 \\
678 \\
524 \\
489\end{array}$ \\
\hline 0.086 & $\begin{array}{l}\text { M1P2 } \\
\text { F2P2 } \\
\text { M3P2 } \\
\text { M4P2 } \\
\text { F5P2 } \\
\text { F6P2 } \\
\text { F7P2 } \\
\text { M8P2 } \\
\text { F9P2 } \\
\text { F1OP2 } \\
\text { MIIP2 } \\
\text { MI2P2 }\end{array}$ & $\begin{array}{l}15 \\
14 \\
16 \\
20 \\
20 \\
14 \\
16 \\
13 \\
18 \\
18 \\
20 \\
20\end{array}$ & $\begin{array}{c}7.61 \\
7.73 \\
10.5 \\
9.84 \\
8.12 \\
7.54 \\
8.40 \\
9.73 \\
9.72 \\
7.94 \\
10.3 \\
9.98\end{array}$ & $\begin{array}{l}0.0853 \\
0.112 \\
0.0940 \\
0.0862 \\
0.0846 \\
0.0902 \\
0.0996 \\
0.0957 \\
0.101 \\
0.0968 \\
0.0961 \\
0.100\end{array}$ & $\begin{array}{r}12-1-52 \\
3-2-53 \\
6-1-53 \\
9-16-53 \\
10-11-53 \\
5-12-54 \\
10-25-54 \\
3-15-55 \\
9-9-55 \\
11-22-55 \\
4-24-56 \\
5-29-56\end{array}$ & $\begin{array}{r}1764 \\
1673 \\
1582 \\
1475 \\
1447 \\
1237 \\
1071 \\
930 \\
752 \\
678 \\
524 \\
489\end{array}$ \\
\hline
\end{tabular}


Approx.

Retained

Dose

$(\mu \mathrm{c} / \mathrm{kg})$

0.043

$\begin{array}{ll}M I P 1.7 & 22 \\ \text { F2PI.7 } & 17\end{array}$

M3PI.7. 21

M4PI.? 22

F5P1.7 21

F6P1.7 21

F7P1.7 25

M8P1.7 22

F9PI.7 25

FIOPI.7 24

MIIPI.7 20

MI2PI.7 22

$.0 .0143 \quad$ MIPI 15

F2P1. 14

M3P1 17

M4PI 20

F5PI 20

F6PI

F7P1 17

M8P1 15

F9P1 18

FIOPI 21

MIIPI 20

MI2PI 21

Control MIPO 15

F2PO 14

M3PO $\quad 17$

$\mathrm{M} 4 \mathrm{PO} \quad 14$

F5PO 20

F6PO 14

F7PO 17

M8PO : 19

F9PO 19

FIOPO 22

MIIPO 20

MI2PO 21
8.72

8.62

8.63

8.37

11.6

10.3

9.73

13.6

9.72

10.6

11.6

9.41

9.41

6.85

8.00

9.97

8.80

7.38

6.36

10.6

7.87

12.0

8.90

9.67

9.70

6.36

10.8

10.7

9.75

5.59

6.90

10.9

9.35

11.0

10.3

10.9
Injected

Dose Date Days since $(\mu \mathrm{c} / \mathrm{kg}) \quad$ Injected

Injection

$\begin{array}{rr}0.0475 & 6-26-56 \\ 0.0431 & 11-22-55 \\ 0.0493 & 6-26-56 \\ 0.0484 & 10-10-56 \\ 0.0459 & 6-26-56 \\ 0.0495 & 6-26-56 \\ 0.0481 & 10-10-56 \\ 0.0479 & 10-10-56 \\ 0.0485 & 10-10-56 \\ 0.0495 & 10-10-56 \\ 0.0486 & 4-24-56 \\ 0.0491 & 10-10-56\end{array}$

461

678

461

355

461

461

355

355

355

355

524

355

0.0150 . 12- 1-52

1764

$0.0163 \quad 3-2-53$

$0.0165 \quad 6-1-53$

1673

1582

$0.0139 \cdot 9-16-53$

$0.011_{4} \quad 10-11_{4}-53$

$0.0140 \quad 5-12-54$

$0.0167 \quad 10-25-54$

$0.0172 \quad 3-15-55$

0.0168

9. $9-55$

0.0152

$11-22-55$

$\begin{array}{ll}0.0157 & 4-24-56 \\ 0.0167 & 5-29-56\end{array}$

1475

1447

1237

1071

930

752

678

524

489

1764

1673

1582

1475

1447

1237

1071

930

752

678

524

489 
$-5-$

B. Radium

Approx.

Retained Age at Weight at Injected

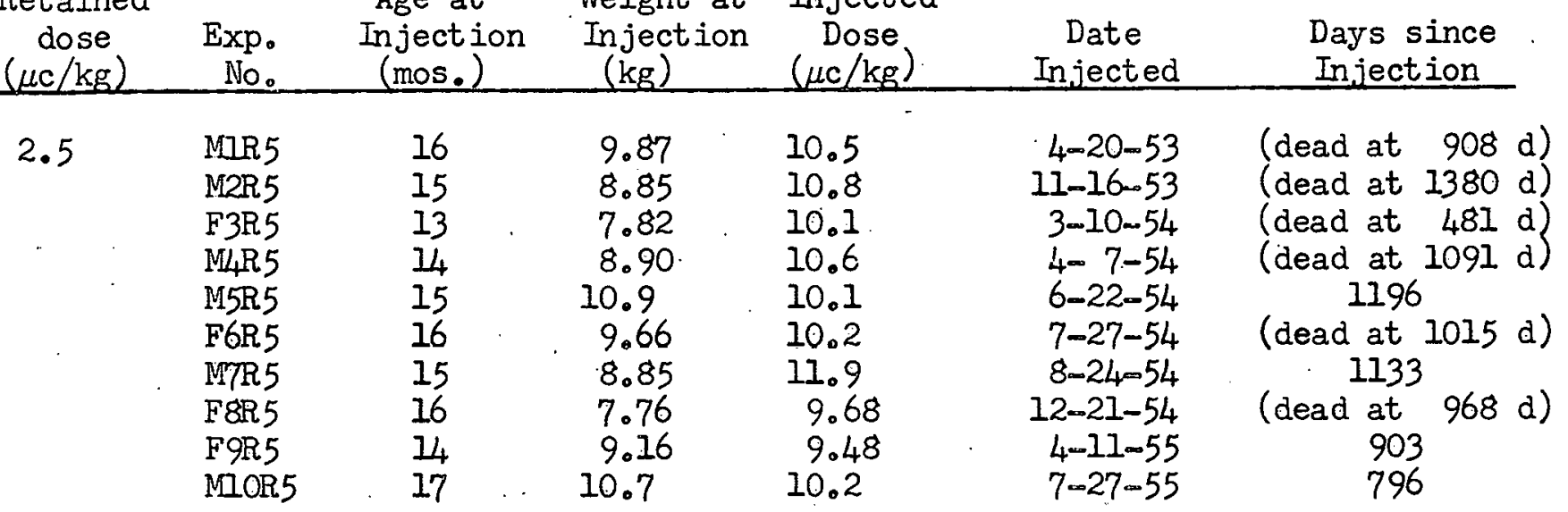

\subsection{1}

NDR4. 16

M2R4 15

F3R 4

\section{3}

F3R4A

$\mathrm{M} 4 \mathrm{R} 4$

M5R4

F6R 4

M7R4

F8R4

F9R $4^{\circ}$

MIOR 4

F11R4

F12R4

0.27

MIR3 16

M2R 3

F3R 3

M4R3

M5R3

F6R3

MiR3

F8R 3

FoR.3

MIOR3

FIIR3

$\mathrm{F}_{2} \mathrm{R}_{3}$

20

15

16

\section{5}

\section{6}

17

16

16

$=$

0.086

$\begin{array}{ll}\text { MIR2 } & 16 \\ \text { MAR2 } & 19 \\ \text { F3R2 } & 18 \\ \text { M4R2 } & 14 \\ \text { M4R2A } & 14 \\ \text { M5R2 } & 15 \\ \text { F6R2 } & 16 \\ \text { M7R2 } & 17 \\ \text { F8R2 } & 19 \\ \text { F9R2 } & 19 \\ \text { MIOR2 } & 17 \\ \text { FIIR2 } & 16 \\ \text { FI2R2 } & 16\end{array}$

15

13

15

\section{6}

17

18

\section{8}

\section{7}

16

16

$-$

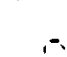

16

$$
9.08
$$

9.53

8.65

7.20

8.83

13.2

8.55

9.55

8.94

8.53

10.8

10.4

9.61

3.51

3.55

3.33

3.10

3.47

2.42

3.44

3.88

3.14

3.02

3.28

2.84

8.91

9.02

7.74

11.7

13.0

9.75

12.3

7.76

8.02

10.1

12.9

11.4

2.81

$4-20-53$

$11-16-53$

3-10-54

$11-30-56$

4- 7-54

6-22-54

$7-27-54$

$8-24-54$.

$12-21-54$

4-11-55

$7-27-55$

$12-20-55$

1-17-56

1.20

I. 21

1.11

1.16

0.846

1.14

1.29

1.03

0.987

1.06

0.938

0.883

$4-20-53$

$11-16-53$

$3-10-54$

4- 7-54

6-22-54

$7-27-54$

8-24-54

$12-21-54$

$4-.77-55$

$7-27-55$

$12-20-55$

1.-17-56

8.74

0.382

8.22

0.387

8.53

10.5

0.347

0.361

10.6

0.306

0.267

0.360

10.6

0.413

11.1
.6 .95

0.331

9.38

0.317

9.30

0.345

0.310

10.3

0.281

4-20-53

11-16-53

$3-10-54$

4- 7- -54

$4-1] \div 55$

6-22- 54

$7-27 \div 54$

$8-24-54$

$12-21-54$

4-11- 55

$7-27-55$

$12-20-55$

$1-17-56$

\section{(dead at 1606 d)} 1414

(dead at $490 \mathrm{~d}$ )

304

1272

1196

1161

1133

1014

903

796

650

622

1624

1414

1300

1272

1196

1161

1133

1014

903

796

650

622

1624

1414

1300

(dead at 328 d)

903

1196

1161

1133

1014

903

796

650

622 
Approx.

Retained Age at Weight at Injected Dose Injection Injection Dose $(\mu \mathrm{c} / \mathrm{kg})$ (kg)

$$
0.043
$$

No. (mos.)

$\begin{array}{ll}\text { MIRI.7 } & 17 \\ \text { M2RI.7 } & 20 \\ \text { F3RI.7 } & 16 \\ \text { MLRI.7 } & 17 \\ \text { MSRI.7 } & 17 \\ \text { FGRI.7 } & 16 \\ \text { MTRI.7 } & 20 \\ \text { FRRI.7 } & 16 \\ \text { FGRI.7 } & 20 \\ \text { MIORI.7 } & 19 \\ \text { FIIRI.7 } & 20 \\ \text { FI2RI.7 } & 19\end{array}$

$0.0143 \quad$ MIRI

M2RI

F3RI

$\mathrm{M}, \mathrm{RI}$

MSRI

F6RI

MTRI

F\&RI

F9RI

MIORI

FIIRI

FI2RI

Control

$\begin{array}{ll}\text { MIRO } & 18 \\ \text { M2RO } & 16 \\ \text { F3RO } & 20 \\ \text { MLRO } & 15 \\ \text { M5RO } & 15 \\ \text { F6RO } & 16 \\ \text { MTRO } & 17 \\ \text { F8RO } & 21 \\ \text { F9RO } & 23 \\ \text { MIORO } & 17 \\ \text { FIIRO } & 18 \\ \text { FI2RO } & 16\end{array}$

$\begin{array}{cc}9.98 & 0.137 \\ 7.85 & 0.163 \\ 13.1 & 0.165 \\ 6.20 & 0.163 \\ 10.1 & 0.151 \\ 7.90 & 0.152 \\ 7.17 & 0.163 \\ 9.50 & 0.154 \\ 7.55 & 0.168 \\ 9.57 & 0.167 \\ 8.17 & 0.165 \\ 8.95 & 0.167\end{array}$

8.48
10.0
8.68

8.60

11.7

7.23

17.4

8.98

9.88

11.5

11.2

9.71

8.03
14.3
11.4
11.0
6.57
8.43
11.0
8.21
11.7
10.9
10.2
8.68

0.618

0.0876

0.0576

0.642

0.0436

0.0484

0.0651

0.0559

0.0521

0.0573

0.0522

0.0444

0

0

0

0

0

0

0

0

0

0

0
Date

Injected

1-17-56

$11-30-56$

$12-20-55$

12-20-55

$12-20-55$

12-20-55.

$11-30-56$

12-20-55

$11-30-56$

$11-30-56$

$11-30-56$

$11-30-56$

$4-20=53$

11-16'-53

$3-10-54$

4- 7-54

$6-22-54$

$7-27-54$

8-24-54

$12-21-54$

4-11- 55

$7-27-55$

$12-20-55$

1-17-56

$4-20-53$

11-16-53

$3-10-54$

$4-70054$

$6-22-54$

7-27-54

$8-24=54$

12- $21-54$

4-11-55

$7-27-55$

$12-20-55$

$1-17-56$
Days since

Injection

622

304

650

650

650

650

304

650

304

304

304

304

1624

1414

1300

1272

1196

1161

1133

1014

903

796

650

622

1624

1414

1300

1272

1196

1161

1133

1014

903

796

650

622 
C. Mesothorium

Approx.

Retained Age at Weight at Injected

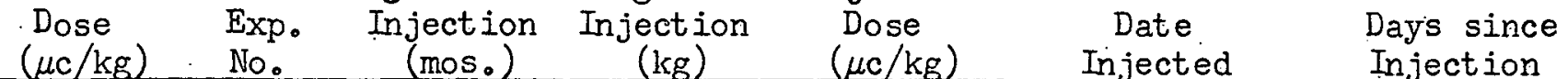

1. Plus 15 per cent radiothorium (on an activity basis)

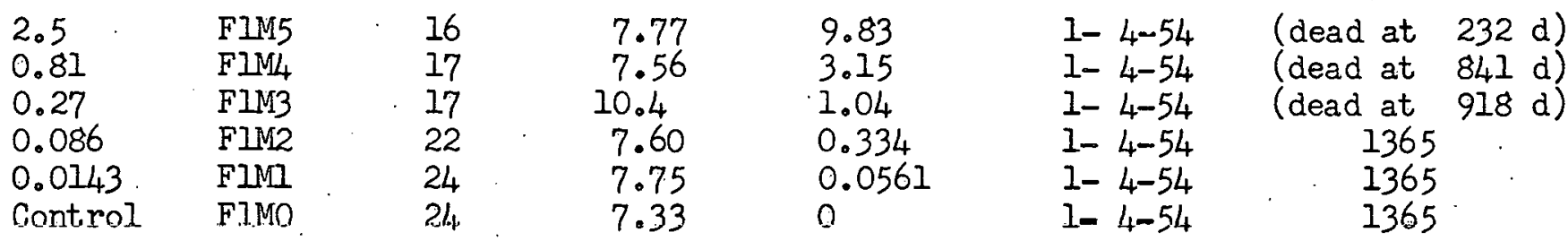

2. Plus 3 per cent radiothorium

\begin{tabular}{|c|c|c|c|c|c|c|c|}
\hline 2.5 & $\begin{array}{l}\text { F2M5 } \\
\text { M3M5 }\end{array}$ & $\begin{array}{l}15 \\
19\end{array}$ & $\begin{array}{l}7.35 \\
8.87\end{array}$ & $\begin{array}{c}10.0 \\
9.93\end{array}$ & $\begin{array}{r}11-29-54 \\
3-13-56\end{array}$ & (dead at & $780 \mathrm{~d})$ \\
\hline 0.81 & $\begin{array}{l}\mathrm{F}_{2} \mathrm{M}_{4} \\
\mathrm{M} 3 \mathrm{M}_{4}\end{array}$ & $\begin{array}{l}15 \\
19\end{array}$ & $\begin{array}{l}6.95 \\
9.65\end{array}$ & $\begin{array}{l}3.41 \\
3.22\end{array}$ & $\begin{array}{r}11-29-54 \\
3-13-56\end{array}$ & $\begin{array}{l}\text { (dead at } \\
\text { (dead at }\end{array}$ & $\begin{array}{l}778 \text { d) } \\
418 \text { d) }\end{array}$ \\
\hline 0.27 & $\begin{array}{l}\mathrm{F} 2 \mathrm{M} / 3 \\
\mathrm{M} 3 \mathrm{M} 3\end{array}$ & $\begin{array}{l}15 \\
19\end{array}$ & $\begin{array}{l}6.70 \\
10.4\end{array}$ & $\begin{array}{l}1.12 \\
0.921\end{array}$ & $\begin{array}{r}11-29-54 \\
3-13-56\end{array}$ & $\begin{array}{r}1036 \\
566\end{array}$ & \\
\hline 0.086 & $\begin{array}{l}\text { F2M2 } \\
\text { M3M2 }\end{array}$ & $\begin{array}{l}17 \\
19\end{array}$ & $\begin{array}{l}8.25 \\
11.0\end{array}$ & $\begin{array}{l}0.355 \\
0.342\end{array}$ & $\begin{array}{r}11-29-54 \\
3-13-56\end{array}$ & (dead at & $965 d)$ \\
\hline 0.043 & $\begin{array}{l}\text { F2MI.7 } \\
\text { M3MI.7 }\end{array}$ & $\begin{array}{l}18 \\
19\end{array}$ & $\begin{array}{l}9.90 \\
11.0\end{array}$ & $\begin{array}{l}0.173 \\
0.172\end{array}$ & $\begin{array}{l}3-13-56 \\
3-13-56\end{array}$ & $\begin{array}{l}566 \\
566\end{array}$ & \\
\hline 0.0143 & $\begin{array}{l}\text { F2MI } \\
\text { M3MI }\end{array}$ & $\begin{array}{l}15 \\
19\end{array}$ & $\begin{array}{l}8.25 \\
13.8\end{array}$ & $\begin{array}{l}0.0593 \\
0.0574\end{array}$ & $\begin{array}{r}11-29-54 \\
3-13-56\end{array}$ & $\begin{array}{r}1036 \\
566\end{array}$ & \\
\hline Control & $\begin{array}{l}\text { F2MO } \\
\text { M3MO }\end{array}$ & $\begin{array}{l}18 \\
19\end{array}$ & $\begin{array}{c}6.94 \\
13.0\end{array}$ & $\begin{array}{l}0 \\
0\end{array}$ & $\begin{array}{r}11-29-54 \\
3-13-56\end{array}$ & $\begin{array}{r}1036 \\
566\end{array}$ & \\
\hline
\end{tabular}

3. Plus 0.6 per cent radiothorium

$\begin{array}{ccccccc}2.5 & \text { M4M5 } & 16 & 7.29 & 9.82 & 1-15-57 & 258 \\ & \text { F5M5 } & 22 & 11.1 & 10.2 & 3-5-57 & 209 \\ & \text { M6M5 } & 19 & 7.53 & 10.1 & 4-23-57 & 160 \\ & \text { F7M5 } & 16 & 7.35 & 9.77 & 6-4-57 & 118 \\ 0.81 & & & & & & \\ & \text { M4M4 } & 20 & 7.84 & 3.07 & 1-15-57 & 258 \\ & \text { F5M4 } & 17 & 9.63 & 3.21 & 3-5-57 & 209 \\ & \text { M6M4 } & 17 & 9.49 & 3.10 & 4-23-57 & 160 \\ & \text { F7M4 } & 18 & 8.40 & 2.92 & 6-4-57 & 118 \\ & \text { M3M4A } & 16 & 7.34 & 2.89 & 6-4-57 & 118 \\ & \text { MLM3 } & 20 & 10.2 & 1.13 & 1-15-57 & 258 \\ & \text { F5M3 } & 17 & 8.51 & 1.13 & 3-5-57 & 209 \\ & \text { M6M3 } & 17 & 9.09 & 1.11 & 4-23-57 & 160 \\ & \text { F7M3 } & 18 & 9.94 & 0.993 & 6-4-57 & 118\end{array}$


Approx.

Retained Age at Weight at Injected

Dose Exp. Injection Injection Dose Date Days since

$(\mu \mathrm{c} / \mathrm{kg}) \quad$ No. $\quad\left(\mathrm{mos}_{0}\right) \quad(\mathrm{kg}) \quad(\mu \mathrm{c} / \mathrm{kg})$ Injected Injection

$\begin{array}{lllllll}0.086 & \text { M4M2 } & 20 & 9.88 & 0.351 & 1-15-57 & 0.358\end{array}$

$8.30 \quad \cdot 0.359$

$\begin{array}{llll}\text { M6M2 } & 17 & 12.4 & 0.357\end{array}$

F7M2 $\quad 18 \quad 10.1$

0.327

$3-5-57 . \quad 209$

$4-23-57 \quad 160$

6- 4-57 118

0.043

\begin{tabular}{|c|c|c|}
\hline MLMI.7 & 20 & 8.94 \\
\hline F5MI.7 & 22 & 12.8 \\
\hline M6MI.7 & 17 & 10.0 \\
\hline FrMI.7 & 18 & 10.2 \\
\hline
\end{tabular}

0.178

0.175

0.168

1-15-57

3- 5-57

4-23-57

6- 4-57

258

209

160

$0.0143 \quad$ MLMI

20

0.160

$1-15-57$

118

F5MI 22

Mi6M1

9.90

0.0600

3- 5-57

258

8.80

F7MI

17
18

10.6

0.0545

4-23-57

209

9.89

$6-4-57$

160

Control M/4MO

$20 \quad 10.3$

F5MO

M6MO

22

11.2

7.56

F7MO

16

13

8.71

0

$1-15-57$

118

$3-5-57 \quad 209$

4-23-57 160

6- 4-57 $\quad 118$ 
D. Radiothorium

Approx.

Age at Weight at Injected
Dose Exp. Injection Injection Dose $(\mu \mathrm{c} / \mathrm{kg}) \cdot$ No. $\left(\mathrm{mos}_{\mathrm{O}}\right) \quad(\mathrm{kg}) \quad(\mu \mathrm{c} / \mathrm{kg})$ Days since

2.5

M7T5 $\cdots \quad 16$

9.48

2.76

2.63

Injected Injection

0.81

M2T5

16

8.22

$2-8-54$

9-28-54

(dead at $212 \mathrm{~d}$ )

M1T4. $\quad 16 \quad 8.32$

M2T4

15

0.882

8.32

7.25

0.916

MLT4

8.81

0.800

20

0.835

$2-8-54$

9-28-54

$6-6-55$

10-18-55

(dead at $97 \mathrm{~d}$ )

0.27

MIT3

M2T3

F3T3

10

9.15

11.9

12.0

0.301

0.301

0.272

M4T3

16

9.69

0.285

2- 8-54

9-28-54

$6-6-55$

10.-18-0.55

(dead at 645 d)

(dead at $833 \mathrm{~d}$ )

(dead at 763 d)

713

0.086

M1T2
M2T2
F3T2
M4T2
M4T2A

16

16

10.2

9.16

0.0976

0.0875

$2-8-54$

9-28-54

7.87

0.0908

19

13.0

21.10 .6

0.0900

$6-6-55$

$10-18-55$

9. $7-56$

(dead at 988 d)

(dead at 859 d)

0.0899

9. 7-56

0.0289

7.95

0.0293

10.3

F3TI. 5

15

0.0303

0.0299

9-28-54

$6-6-55$

$10=18-55$

(dead at. 547 d)

713

(dead at 1282 d)

1098

(dead at 78 d)

388

388

1098

847

713

$0.0143 \quad$ NITI I I

M2TI 23

9.36

0.0146

$2 \infty 8-54$

$9-7-56$

1330

9.27

0.0146

9- 7-56

388

8.84

0.0145

9- $7-56$

388

M4TI

23

8.27

0.0146

$9-7-56$

388

0.00476

$\begin{array}{ll}\text { MITO.5 } & 23 \\ \text { M2TO.5 } & 15 \\ \text { F3TO.5 } & 22 \\ \text { M4TO.5 } & 17\end{array}$

14.3

0.00496

$9-28-54$

388

10.5

0.00490

$6-6-55$

8.59

0.00485

$10-18-55$

1098

847

713

Control MTO - 16

8.24

7.28

$2-8-54$

1330

N2TO

16

17.6

9-28-54

1098

6- 6-55

847

M4TO

19

8.10

$10-18-55$

713 
E。 Strontium

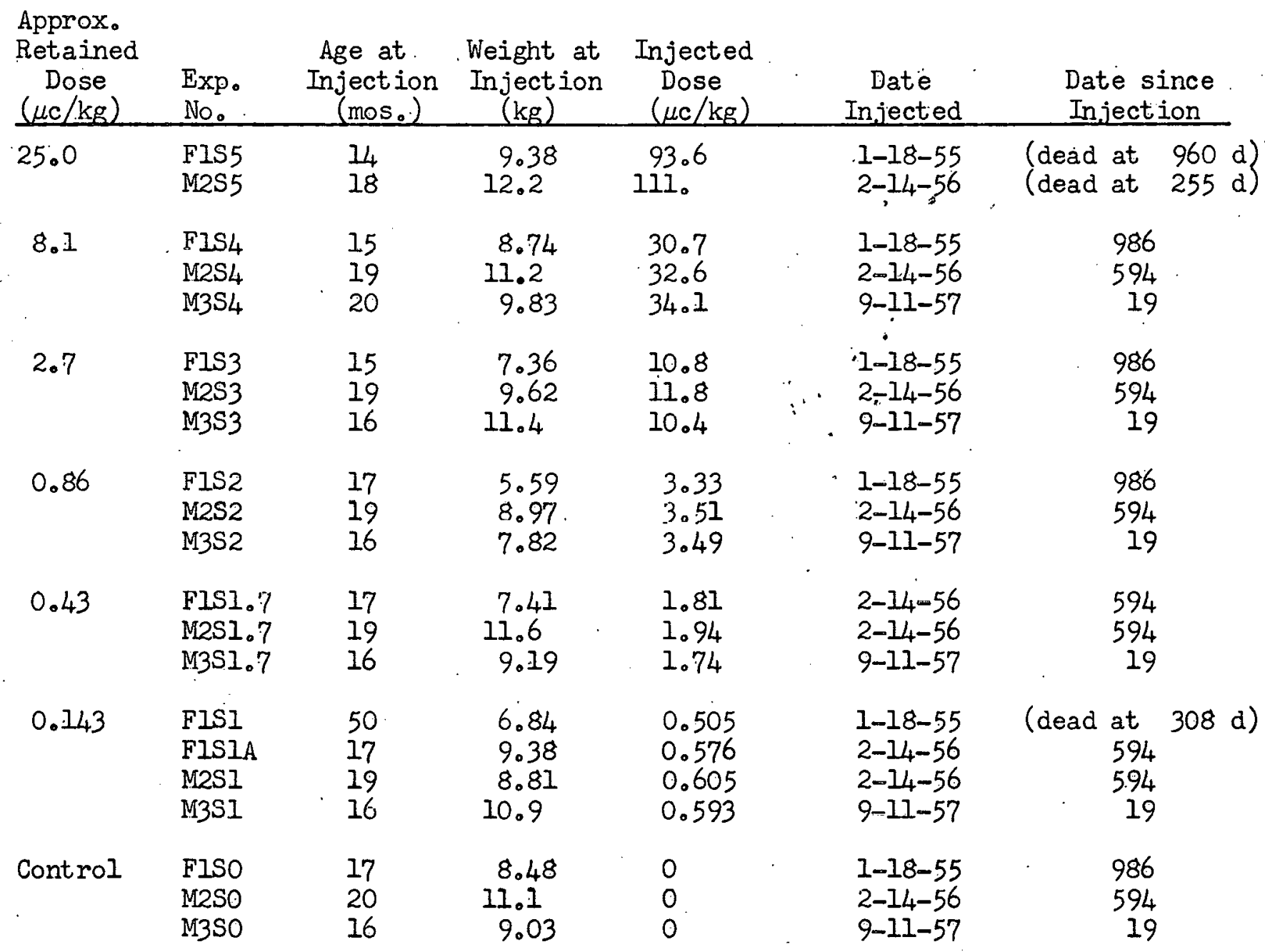


TABLE II

TEST ANIMALS (AS OF 9-30-57)

A. Pl-utonium

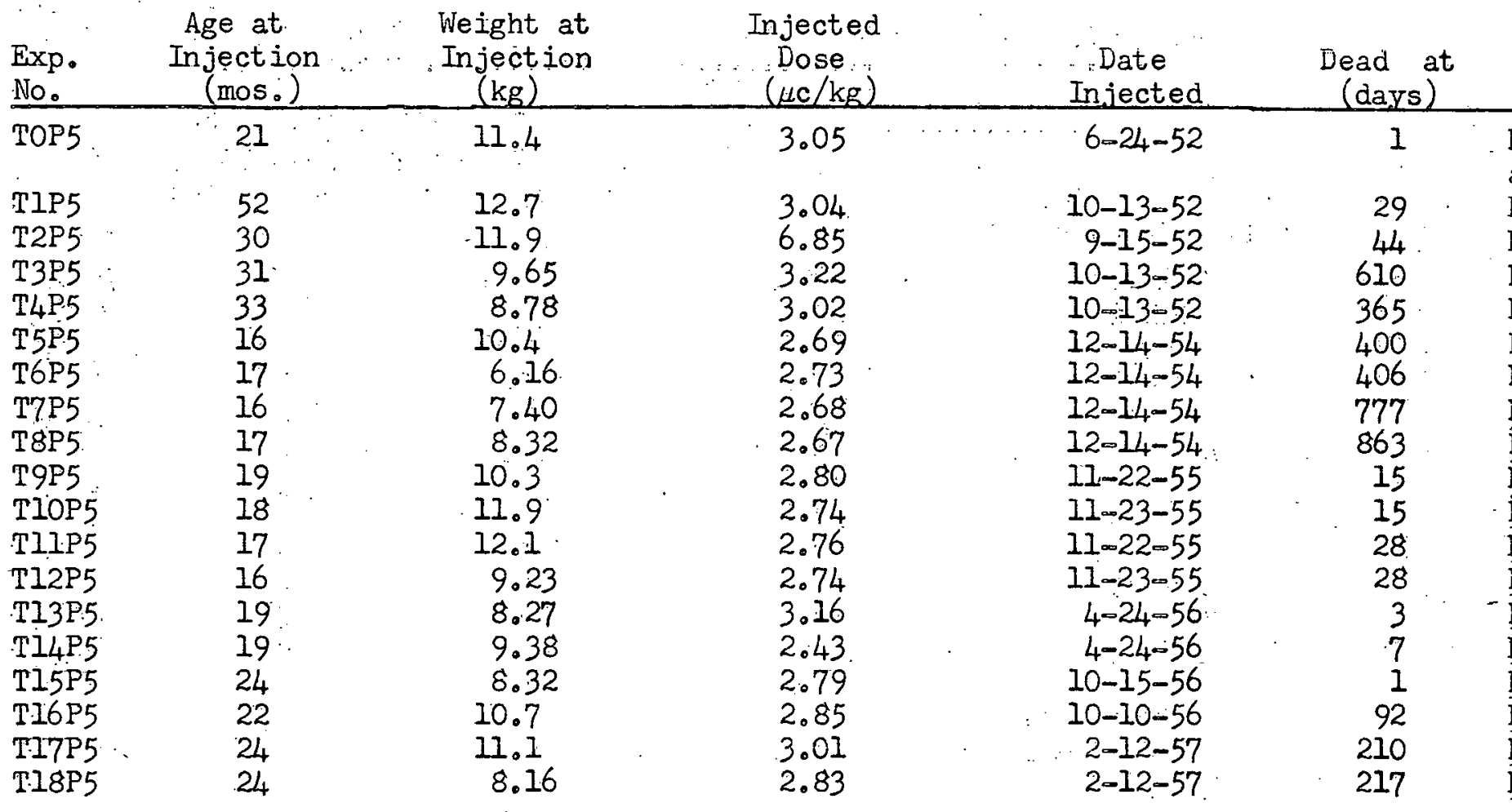

B. Radium

10.3
4.39
4.76
10.6
11.7
11.4
11.8
1.92
1.94
1.98
1.91
9.72
9.76
3.17
3.11
9.68

8.40

8.29

10.0

6.14

6.14

5.52

10.4

1.02

1.58

12.3

7.59

12.03 $12-1-52$
$1-12-53$
$1-12-53$
$7-6-53$
$10-6-53$
$10-6-53$
$10-6-53$
$5-10-53$
$5-10-53$
$5-10-53$
$5-10-53$
$5-9-56$
$5-9-56$
$7-11-56$
$7-11=56$
$7-11-57$

1. $\begin{array}{r}12-1-52 \\ 1-12-53 \\ 1-12-53 \\ 7-6-53 \\ 10-6-53 \\ 10-6-53 \\ 10-6-53 \\ 5-10-53 \\ 5-10-53 \\ 5-10-53 \\ 5-10-53 \\ 5-9-56 \\ 5-9-56 \\ 7-11-56 \\ 7-11=56 \\ 7-11-57\end{array}$

Detailed distribution, radioautographic study.

\section{Retention.}

Retention。

Distribution, excretion.

Distribution, excretion.

Development of bone pathology. Development of bone pathology. Development of bone pathology. Development of bone pathology. Radioautographic studies. Radioautographic studies. Radioautographic studies. Radioautographic studies.

Radioautographic studies. Radioautographic studies. Radioautographic studies. Radioautographic studies. Radioautographic studies. Radioautographic studies.

Retention \& excretion. Retention \& excretion. Retention \& excretion. Distribution.

Distribution $\left(\mathrm{Ca}^{45}\right)$.

Distribution...

Distribution.

In vivo bone radon retention and distribution study.

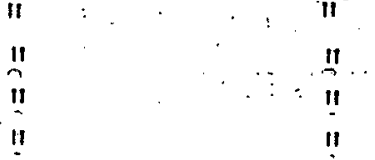

Phantom。

Phantom.

In vivo bone radon retention and distribution study. 
C. Mesothorium

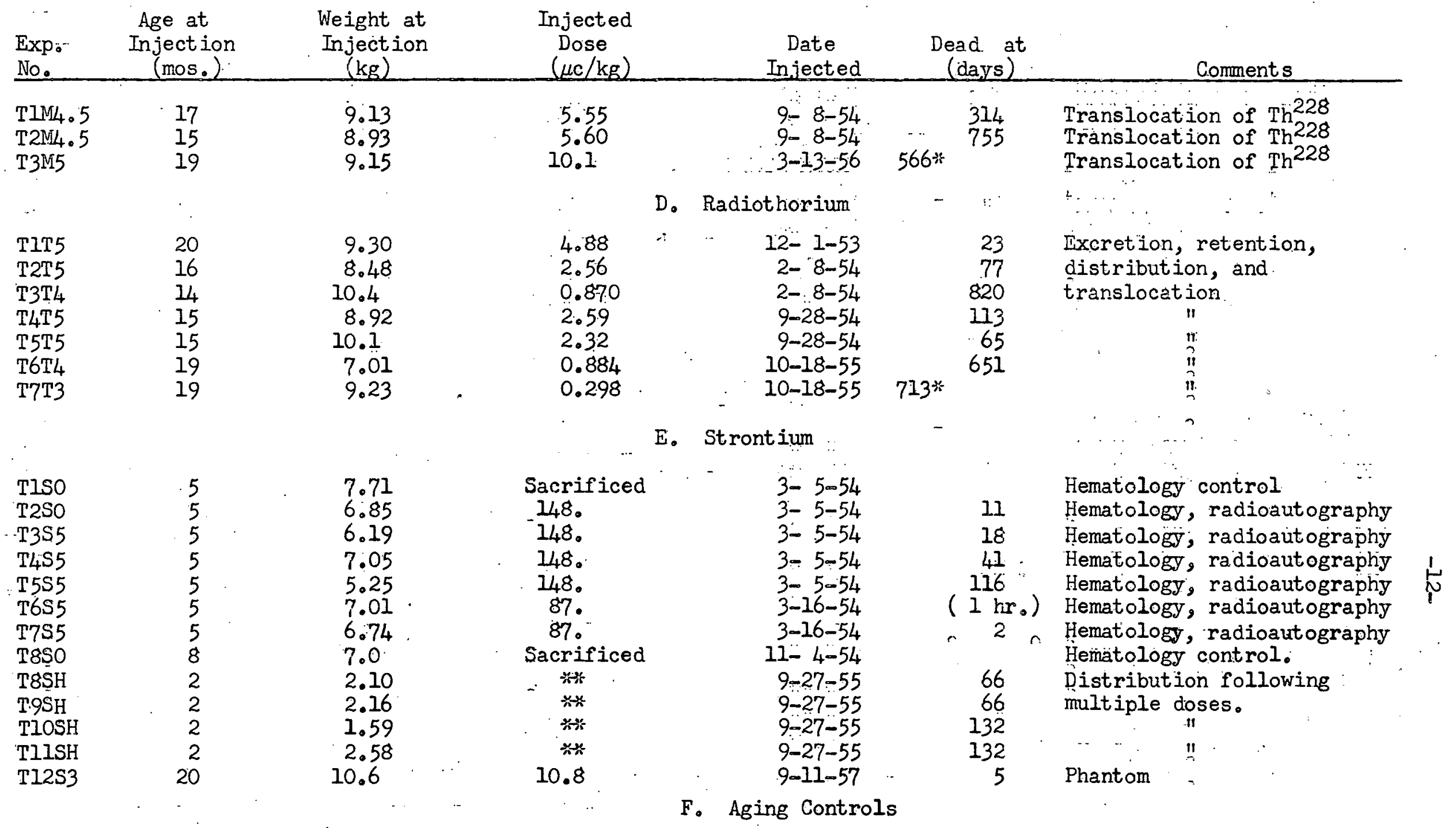

MAC35 Säcrificed 2-17-56, 17 months old.

MAC37 Säcrificed 7-12-56, 11 jears old.

FACI S Sacrificed 5-14-57, 45 months old.

* Days since injection

Doses of $1 \mu \mathrm{c}$ each from 9-27-55 and weekly thereafter for 10 weeks。 
$-13-$

CLINICAL SECTION REPORT

C. E. Rehfeld, G. N. Taylor, W. Fisher, No. B. Nebeker

I. Tabular summary regarding toxicity and test animals that were allowed to live until degenerative changes seriously impaired normal function. This will include that group of dogs. which developed clinically. apparent tumors and another group in which tumor formation. was not apparent and in which death was due to anemia and/or other causes.

II. Effect of radioactive isotopes upon the rate of narrowing of pulp cavities of teeth. This study was made through the use of radiographs. This work was , done by G. N. Taylor in consultation with William ${ }^{R}$. Christensen and. C. E. Rehfeld.

III. Case histories of the dogs which have been sacrificed or have died from various causes in the period March 15, 1957 through September 17, 1957.

IV. Current census of beagle colony. 
I. Summary of Observations on Toxicity Animals and on Test Animals Treated as Toxicity Animals.

Data listed here includes:

1. Days of age when given the radioactive isotope burden.

2. Days following isotope injection when first clinical and/or radiographic evidence obtained for presence of a tumor - latent period of tumor formation.

3. Days following isotope injection when death occurred by euthenasia or spontaneous causes.

4. Anatomical location of tumor which dictated euthenasia; reason for euthenasia other than the presence of a tumor; or cause of death other than by euthenasia.

Radium studies - tumor formation

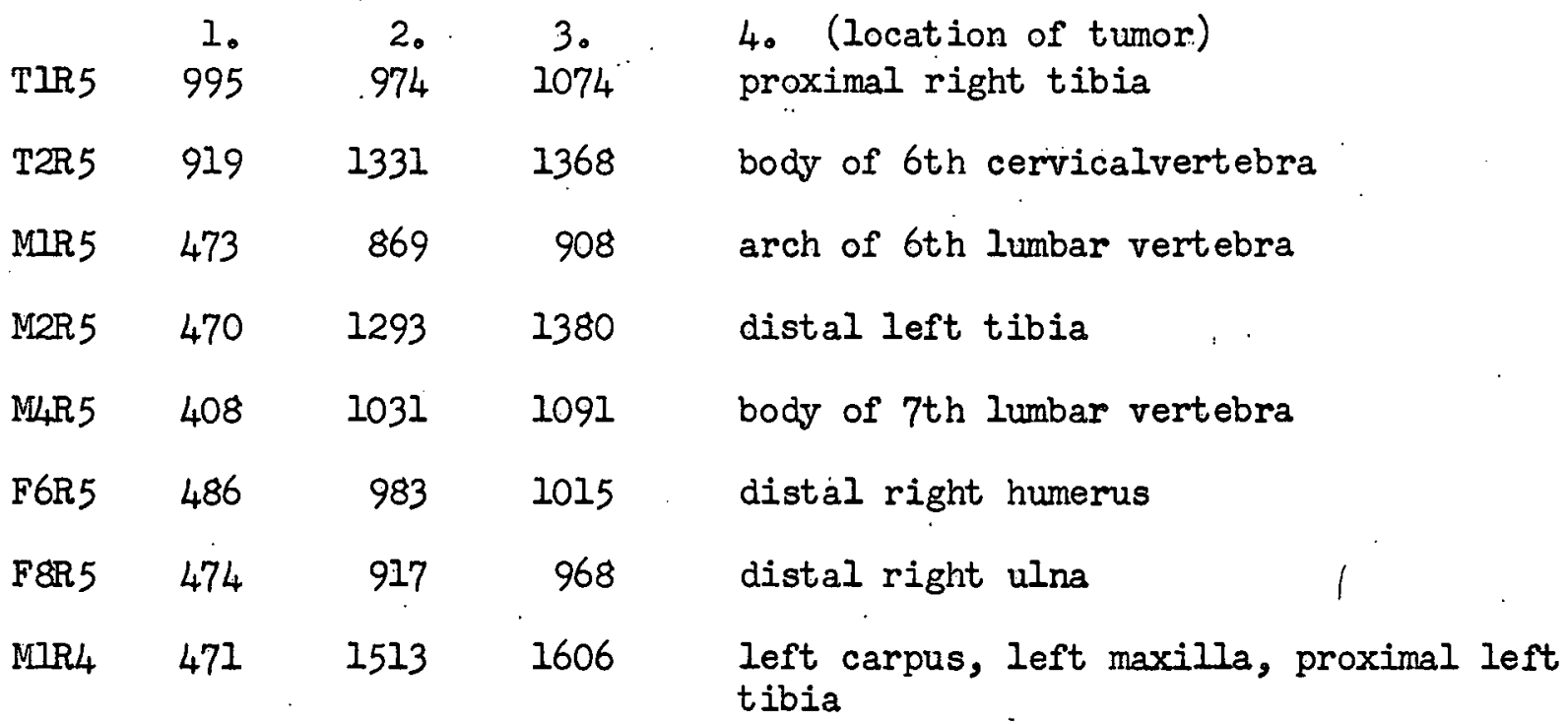

Radium studies - no tumor formation

$$
\text { 1. 2. 3. 40 (reason for death or euthenasia) }
$$

F3R5 $380 \quad 481$ encephalitis

F3R4 $\quad 384 \quad 490 \quad$ encephalitis

M4R2 $\quad 414 \quad 325$ perforated infarcted ileum 
Plutonium studies - tumor formation

\begin{tabular}{|c|c|c|c|c|c|}
\hline & 1. & 2. & 3. & 4. (location of tumor) & \\
\hline $\mathrm{M} \geq \mathrm{P}_{5}$ & 412 & 1288 & 1324 & proximal $1 / 3$ left femur & \\
\hline F6P.5 & 407 & 1129 & 1194 & shaft of right ilium & \\
\hline $\mathrm{M} I P 4$ & 442 & 1701 & 1724 & $\begin{array}{l}\text { proximal right humerus, proximal left } \\
\text { fracture of left mandible. }\end{array}$ & femur, \\
\hline $\mathrm{F} 2 \mathrm{P}_{4}$ & 567 & 1537 & 1556 & sacrum & \\
\hline $\mathrm{M}_{3} \mathrm{P}_{4}$ & 475 & 1171 & 1198 & near head of left tenth rib & \\
\hline $\mathrm{M}_{4} \mathrm{P}_{4}$ & 567 & 1007 & 1065 & neck of right femur & \\
\hline $\mathrm{F} 5 \mathrm{P} 4$ & 650 & 1141 & 1245 & body of 3 rd lumbar vertebra & \\
\hline MIP3 & 417 & 1460 & 1476 & $\begin{array}{l}\text { body of } 4 \text { th lumbar vertebra, body of } \\
\text { cervical vertebra. }\end{array}$ & 5 th \\
\hline
\end{tabular}

Plutonium studies - no tumor formation

1. 3. 4. (reason for death or euthenasia)

F2P5 $1151 \quad 1576 \quad \begin{aligned} & \text { fracture of left mandible, extreme osteo- } \\ & \text { lytic degeneration of ent ire skeleton }\end{aligned}$

M3P5 $515 \quad 499 \quad$ chronic hepatitis and erythropenia

Mesothorium studies - tumor formation

$\begin{array}{lllll} & \text { I. } & 2 . & 3 . & 4 \cdot \text { (location of tumor) } \\ \text { F2M4 } & 460 & 763 & 777 & \text { dorsal process of 13th thoracic vertebra } \\ \text { FIM3 } & 458 & 828 & 918 & \text { body of 3rd lumbar vertebra }\end{array}$

Mesothorium studies - no tumor formation

1. 2. 3. 4. (reason for death or euthenasia).

FIM5 $494 \quad 232$ aplastic anemia and uremia

F2M5 $460 \quad 780$ bilateral fractures of tibiae

FIM4 $\quad 510.841$. multiple fractures

M3M4 579 $\quad 418$ strangulated inguinal hernia

F2M2 517.965 acute hepatitis 
Radiothorium studies - tumor formation

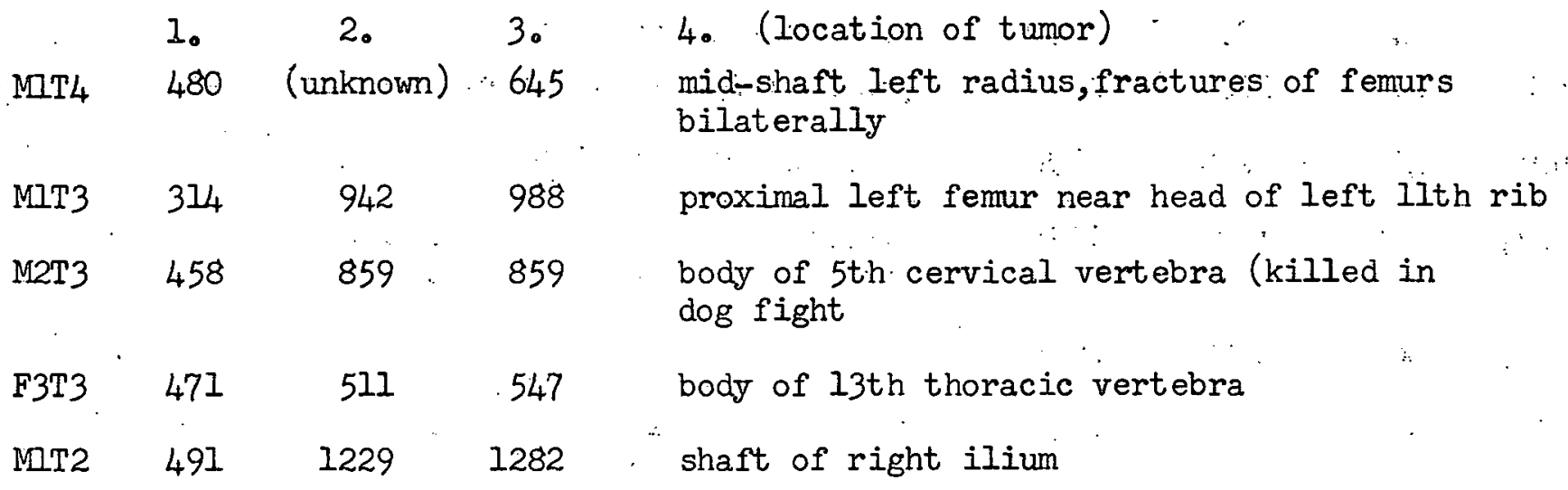

Radiothorium studies - no tumor formation

\begin{tabular}{|c|c|c|c|}
\hline & 1. & 3. & 4. (reason for death or euthenasia) \\
\hline MIT5 & 480 & 212 & febrile uremia, aplastic anemia \\
\hline M2T5 & 483 & 97 & $\begin{array}{l}\text { aplastic anemia, radiation hyperthermia, } \\
\text { bacteremia. }\end{array}$ \\
\hline M2T4 & 458 & 832 & mult iple fractures \\
\hline $\mathrm{F} 3 \mathrm{~T} 4$ & 461 & 763 & aplastic anemia \\
\hline $\mathrm{T} 3 \mathrm{~T} 4$ & 429 & 820 & multiple fractures and acute anemia \\
\hline $\mathrm{T} 6 \mathrm{~T} 4$ & 591 & 651 & multiple fractures \\
\hline $\mathrm{M} 4 \mathrm{~T} 2$ & 553 & 78 & trauma and shock (dog fight)... \\
\hline
\end{tabular}

Strontium studies - tumor formation

$\begin{array}{lllll} & 1 . & 2 . & 30^{\circ} & 4 . \quad \text { (location of tumor) } \\ \text { FIS5 } & 434 & 870 & 960 & \text { distal right femur }\end{array}$

Strontium studies - no tumor formation

\begin{tabular}{|c|c|c|c|c|}
\hline & 1. & 2. & 3. & 4. (reason for death or euthenasia) \\
\hline M2S 5 & 540 & & 255 & strangulated inguinal hernia \\
\hline FISI & 1524 & & 308 & $\begin{array}{l}\text { considered unsuitable for inclusion in } \\
\text { toxicity group because following in jection } \\
\text { it was necessary to perform a hysterectomy } \\
\text { and an orbital enucleation and age at } \\
\text { injection was undesirable. }\end{array}$ \\
\hline
\end{tabular}

Animals which have been replaced, according to research numbers are: F3R4, MLR2, M3M4, M4T2 and FlSl。 
II. Effect of Radioactive. Isotopes upon the Rate of Narrowing of Rulp Cavities of Teeth.

Introduction: Since March 1956, an occlusal film of the left mandible has been included in the semi-annual radiographic studies of each experimental' dog and subsequently this bone and related dental parts have been studied in detail for radiographic changes resultant to the isotope burden. One of the features being investigated is the rate of narrowing of the pulp cavities of the teeth and the influence, if any, of radioactive elements. This study. evaluates this feature in only one tooth root.

Three groups of beagles are used: Control dogs, five level plutonium dogs, and five level radium dogs. The pulp cavity measurements are summarized in graphical form and the significance of changes in the cross-sectional diameter, as the age and treatment vary, is evaluated statistically.

Methods: All of the measurements were made by viewing the films with a binocular dissecting scope with a calibrated eye piece. Only one measurement of the pulp cavity was made and the widest cross-sectional diameter in the anterior root of the first molar of the left mandible was arbitrarily selected for this measurement. This tooth was chosen for the preliminary investigation because of the relatively long period it is retained in the animals mouth, its freedom from radiographic distortion, and its relatively large size.

Cross-sectional measurements were taken from 46 radiographs of control dogs and 42 radiographs of 5 -level plutonium dogs of comparable ages。 In most instances several films are from the same dog but spaced by significant time intervals. Eleven subclasses were formed within each class by arbitrarily grouping the dogs, whose ages ranged from 19 to 84 months, into six-month age groups. The groups were then compared by computing the "F" value at the 95 percent confidence interval, using the method of analysis of variance with disproportionate subclass numbers as outlined by Snedecor. ${ }^{1}$

I Snedecor, George W. Statistical Methods, 4th Edition, The Iowa State College Press, Ames, Iowa. 
The same procedure was used in comparing the 5 level radium dogs with the control group except 53 radiographs of the treated group and 45 radiographs of the control group were used. Also, the ages ranged from 19 to 78 months, being divided into ten six-month age groups.' Mrs. Betty Chamberlain made the statistical computations.

For non-treated dogs we have radiographs of a wider age span, six to 116 months. This is because of the minimum age requirements that are set for injection with the isotope and also the reduced longevity that occurs among the treated groups. Figure $I$ shows the age-diameter relationship of the widest age interval for which we have radiographs. Eighty two occlusal films were used in plotting this curve- all from non-treated beagles.

Results: The "F" values' for the effect of age and treatment on the crosssectional diameter of the lst molar of the left mandible are summarized in the following table.

Source of

Variation

Degrees of

Freedom
"F" value computed from the data
"F" value necessary

to be significant

( $95 \%$ confidence interval)

5-Ievel

plutonium

$1 \& 66$

16.9

252

Age

$10 \& 66$

9.5

.2 .6

5-level

radium

$1 \& 78$

.05

253

Age

$9 \& 78$

6.65

2.77

The above tabulation suggests that the effect of a 5-level quantity of either plutonium or radium administered intravenously by a single injection . is not significant as a factor in causing narrowing of the pulp cavity of the specified root. However, the values for the effect of age on the same root indicate this to be a significant factor. The term "age", presented in the above table under the heading "source of variation", is not used in the sense of a single entity or a process but as an inclusive term indicating the duration of 


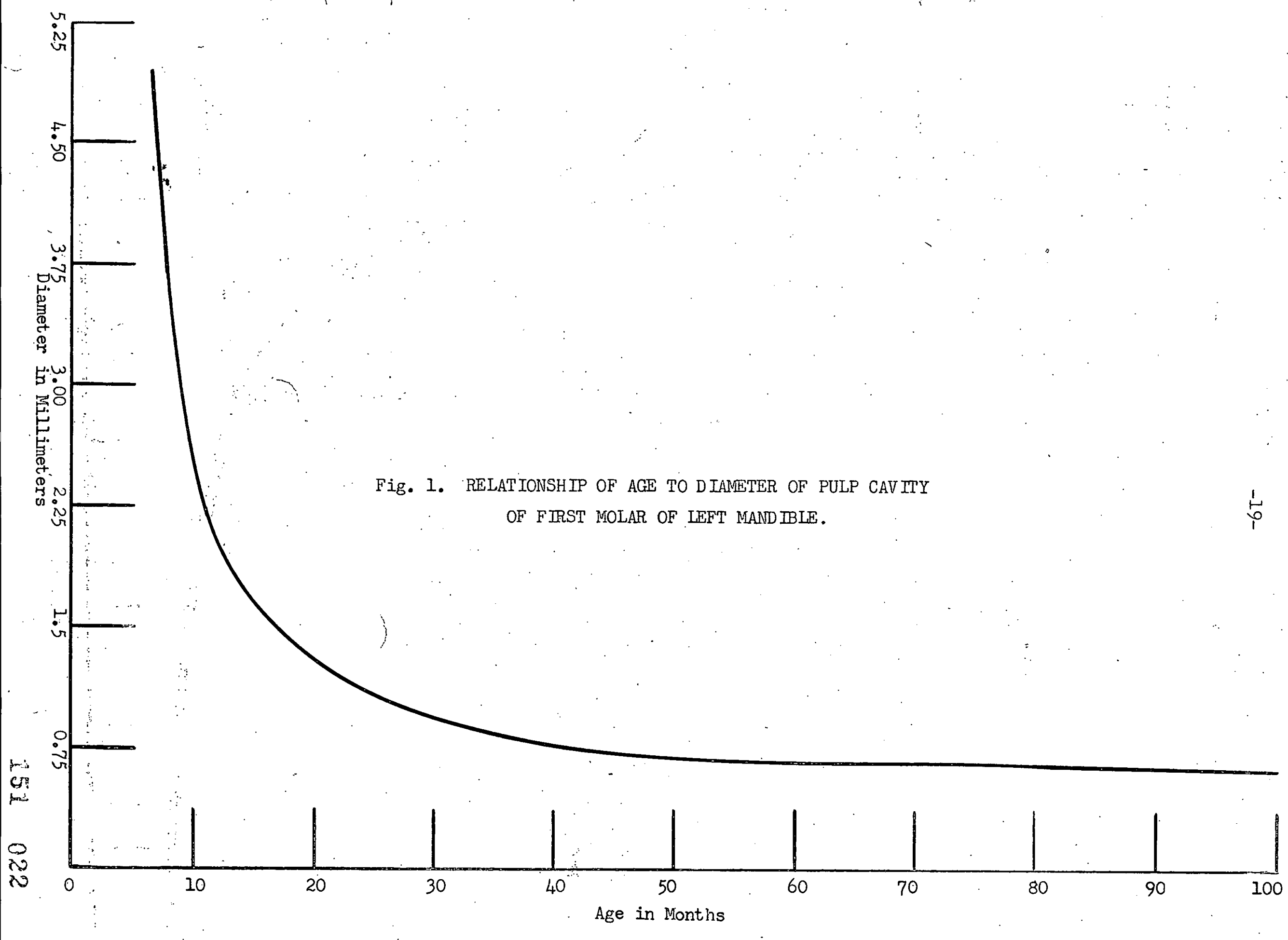




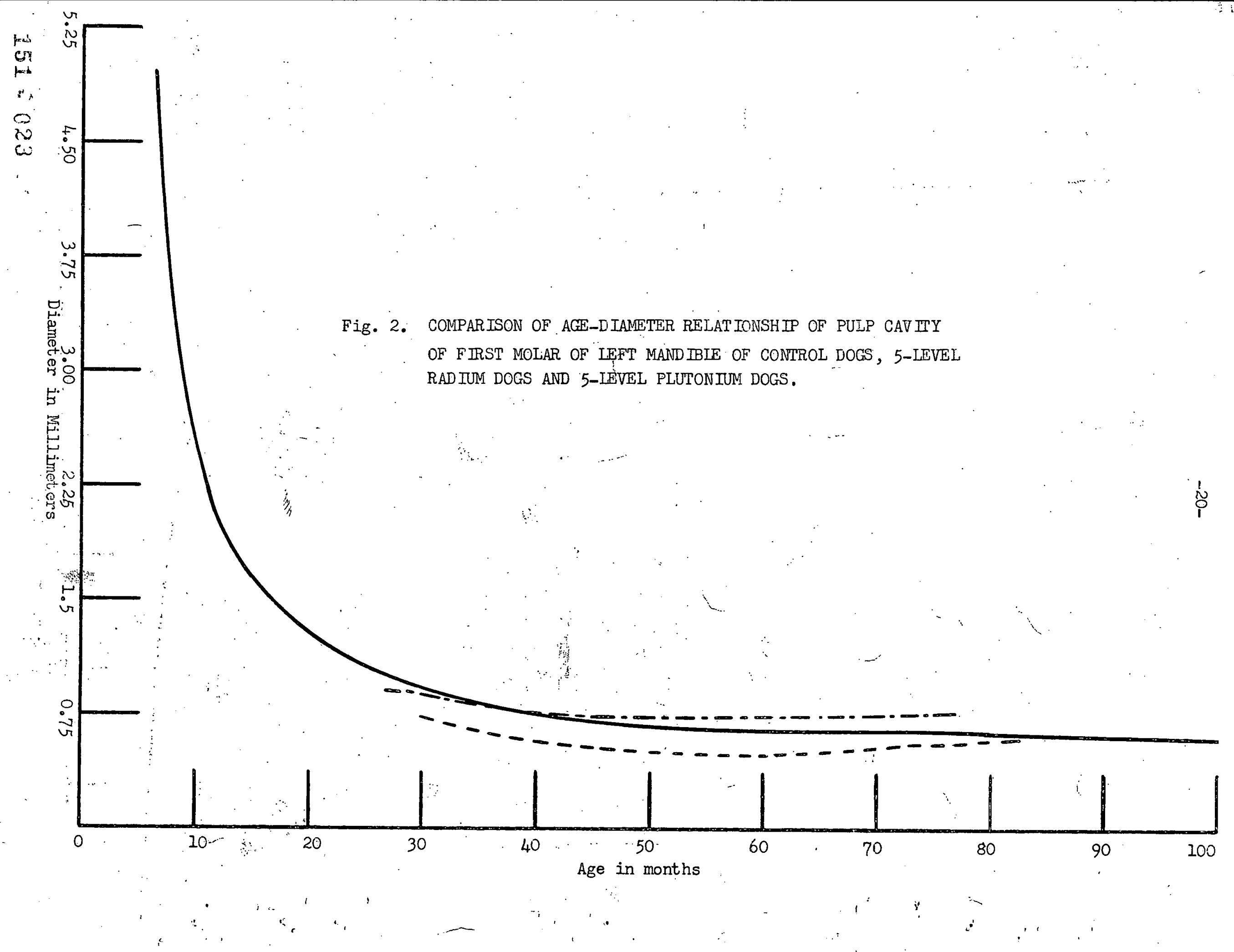


one to many factors.

Figure 2 substantiates the above statistical results. It is even more suggestive of the importance ofthe age factor because it shows the rapid rate of narrowing that occurs between the ages of 6 and 15 months- such period not included in the statistical analysis for reasons already given.

Conclusions: Five level plutonium and radium burdens have no significant effect on the narrowing process of the pulp cavity of the first molar of the mamdible, as observed radiographically. This process appears to be primarily. a function of age. 
III. Case Histories

Included here are brief reviews of pertinent clinical information of all dogs which died or were euthenized since March 12, 1957. The cases are presented in chronological order in reference to time of euthenasia.

M4R5, Tatoo No. 110: This male beagle was one of three siblings born on February 23, 1953. It was injected with $10.6 \mu \mathrm{c} / \mathrm{kg}$ of $\mathrm{radium}{ }^{226}$ on April 7, 1954 when it was 408 days of age. Euthenasia was performed 1091 days after injection because. a tumor of the seventh lumbar vertebra caused urinary and fecal incontinence resulting in acute toxemia.

Review of weight changes: Dog weighed $8.9 \mathrm{~kg}$ at injection and gained $4.99 \mathrm{~kg}$ in the next 706 days, but weighed $8.96 \mathrm{~kg} 385$ days later when euthenized.

Anesthesia: Employed at least 18 times throughout the period of $t$ ime when the dog carried a burden of radium.

Study with other isotopes: Red blood cell life span was studied by means of chromium 51 tagging 709 days after injection of the radium burden.

Fractures revealed by radiology and clinical examination: 693 days postinjection, fractures of the second and third thoracic vertebra involving only the dorsal processes. 727 days, additional fracture of one of the first ribs. 777 days, 1 additional rib fracture. 927 days, fracture of the left humerus. That is, there was a defect in the left humerus which appeared as an old well healed fracture, but there were no clinical symptoms of the fracture at this $t$ ime. 942 days, 1 additional rib fracture. 958 days, fracture of left humerus. 974 days, fracture of right tibia and right fibula. Approximately 48 to 60 days later, the dog developed a urinary and fecal incontinence. This indicated the presence of a tumor arising in the vertebral column. 1085 days, tumor arising from seventh lumbar vertebra confirmed by radiographic examination.

Post-mortem observations: Osteogenic sarcoma of the seventh lumbar vertebra, metastastic processes were seen as follows. There were two closely adjacent to 
the diaphragm and the mediastinum; two nodules in the right ventricle of the heart, one at the atrio-ventricular junction, at the anterior lateral aspect measuring $8 \mathrm{~mm}$ in diameter and the second nodule was more posterior measuring 2 to $3 \mathrm{~mm}$ in diameter. There were also numerous nodules from 1 to 3 and $4 \mathrm{~mm}$ in diameter seen in all lobes of the lung, these were predominantly at the periphery of the lung. T8P5, Tation No. 168: This male beagle was one of five siblings born on July 5, 1953. It was given a plutonium burden of $2.67 \mu \mathrm{c} / \mathrm{kg}$ at 527 days of age. This animal was euthenized 863 days later as one of a series of 5 -level plutonium test dogs. Weight summary:- Injection weight $8.32 \mathrm{~kg}$, autopsy weight $10.62 \mathrm{~kg}$. There was no illness which required that the animal be hospitalized.

Study with other isotopes: This animal was used to study the life span of red blood cells through chromium ${ }^{5 l}$ tagging and also was given a tracer dose of strontium 9024 hours before sacrifice.

Radiology observations: 477 there was definite pathology due to the radioactive material as reflected in architectural changes in the bone. 787 days, two unhealed rib fractures. 863 days, post mortem observations, five rib fractures, one of which was recent and two of which were well healed. The other two rib fractures showed a regular callus formation and false joint formation. The shaft of the left humerus had changes which suggested a fracture had occurred at some time in this bone but was then well healed. However there was no physical disability due to a fracture in this left humerus at any time.

Observations of soft tissues at autopsy:

The heart: There was a peculiar endocarditis involving the first portion of the pulmonary artery immediately above the valves. The valve ring and valves were normal but the endocarditis had manifested itself as small vari-colored nodules, suggesting calcification and varied from less than $1 \mathrm{~nm}$ to $1 \mathrm{~mm}$ in diameter. These nodules did not extend down to the main branches of the pulmonary artery. There were focal yellow calcified nodules and a thickening in the endocardium of the left atrium as well, particularly around the ostia of the pulmonary vein. 
There were glistening nodules $1 / 2$ to $1 \mathrm{~mm}$ in diameter located along the line of closure of the mitral valves. There were focal areas of graded calcified nodules less than $I \mathrm{~mm}$ in diameter located in the sinuses of Valsalva above the aortic valves.

The liver: The liver was characterized by mottled contrasting shades of brown in a fine pattern suggesting a disorganized architecture and fine scaring. There were no weII defined adenomata.

Kidney: The kidney was seen to have as follows; yellow areas of calcification in the mid portion of the papilla which measured less than $1 \mathrm{~mm}$ in diameter and were poorly circumscribed.

M3M4 Tatoo No. 29I: This male beagle was one of 4 siblings born August 12, 1954. The mesothorium burden was given $(3.22 \mu \mathrm{c} / \mathrm{kg})$ at 579 days of age. This dog survived 418 days after injection at which time it died from toxemia resulting from the effects of a strangulated inguinal hernia.

Weight changes: The injection weight was $9.65 \mathrm{~kg}$ and just before the final illness the weight approximated $10.28 \mathrm{~kg}$ and the autopsy weight was $8.18 \mathrm{~kg}$.

Study with other isotopes: II days pre-injection this dog was used for a chromium $^{51}$ red blood cell survival time study. 30,104 and 230 days post-injection. blood volume studies and red cell survival time studies were performed using chromium $^{5 l}$ and lodine ${ }^{131}$.

Health: This dog suffered 2 periods of illness, one occurring at 248 days and the other at 417 days which was the final illness. 248 days, this dog had been under rather close observation for several days prior to this time and was then brought in for hospitalization at 248 days as it had an extremely debilitated appearance and was suffering partial aneorexia. A thorough clinical pathological study yielded no positive results or indication as to the source or cause of its condition. However a change of diet caused some improvement so the dog was released in a better state of health within two weeks. 417 days, it was reported that the dog had a complete lack of appetite and a brief examination soon revealed 
that the animal had a strangulated inguinal hernia. The dog was obviously a very poor surgical risk but surgical intervention is dictated in such cases and was completed within a matter of hours. The dog died the next day at 418 days of acute toxemia and shock and was subritted immediately for post-mortem examination.

Post-mortem observations:

Skeleton: Post-mortem radiographic study. revealed moderate to advanced changes in the skeleton due to effects of the radioactive isotope. There was a moderate amount of pathological remodelling of the bone including some osteolytic rarefraction which was present throughout the cortex of the long bones. In regard to fractures there was a single unhealed fracture of the spinous process of one of the thoracic vertebra and the transverse process of a lumbar vertebra. There was one unhealed rib fracture and two fractures of the fatigue type in the body of the scapula.

Soft tissues: Alterations were limited to changes characteristically resulting from stasis in the gastro-intestinal tract. The premortem toxemia may have obliterated minor changes in other of the soft tissues.

F6R5 Tatoo No. 134: This female beagle was one of six siblings born on March 28, 1953. This animal was given $10.2 \mu \mathrm{c} / \mathrm{kg}^{\text {of }}$ radium ${ }^{226}$ on July 27,1954 when it was 486 days of age. 1015 days after injection, euthenasia was dictated by the presence of a large tumor of the distal right humerus and a fracture of the left mandible which interfered with nọmal ingootion.

Review of weight changes: This dog weighed $9.66 \mathrm{~kg}$ at the time it: was injected and gained a total of $6.3 \mathrm{~kg}$ to its maximum weight and then it lost a total of $7.78 \mathrm{~kg}$ from that maximum weight in the last 475 days of its life.

Anesthesia: The dog was anesthetized between 27 and 30 times in the entire period of its life.

Radiology and clinical observations: 542 days post-injection there was a large amount of pathologic remodelling in the bone structure as well as a fracture of the right sixth rib. 574 days, this dog suffered a fractured left mandible in 
a dog fight as well as multiple bite wounds. The fracture of the mandible was successfully reduced by use of a single heavy wire suture. At this time there was advanced depigmentation of the iris and the choroid had markedly altered in appearance. 615 days, there were 5 fractures of the dorsal processes of thoracic vertebra all unhealed, but some had some callus formation. $658^{\circ}$ days, both fibulae had fractured near the proximal terminations and in addition there were two ribs which had marked enlargements along their length which indicated the possibility of an extra bony growth or of old well healed fractures. Also at this time it appeared that one of the dorsal processes of the thoracic vertebrae had completed healing. 706 days $_{y}$ there appeared to be well healed fractures of the 6th, 8th and 9th rib of the right side. There was abundant callus formation of the dorsal processes of the thoracic vertebrae and appeared to be similar action of the left fibula. All of these had resorted to false joint formation. Advanced osteolysis had occurred at the fracture site in the left mandible and the wire suture was serving no purpose then, so 3 days later this suture was removed. 723 days, two additional well healed fractures of the ribs appeared but there was no indication of fracture at these positions. There was also a fracture of one of the coccygeal vertebrae with no signs of healing. In the left mandible there was a zone of total loss present with a gap of approximately $1 \mathrm{~cm}$ which was radiolucent. 768 days, there developed a definite lameness of the right pectoral limb which proceeded without remissions to develop a characteristic radial paralysis with advanced atrophy of the musculature, and a noticeable difference in the temperature of this limb from the opposite normal limb. 792 days, one of the fibulae had healed completely. 983 days, there was a gross irregular zone of rarefraction with some calcification in surrounding soft tissues present at the distal end of the left humerus. This appearance suggested an osteogenic sarcoma at this position.

Post-mortem observations:

Skeleton: The dorsal processes of the first. five thoracic vertebrae were fractured with no indication of healing and little callus formation and in addition 
the one fibula was still fractured and the coccygeal vertebra showed no signs of healing. Otherwise, healing had occurred with renewed trabecular pattern in the ribs and other fractures, including that of the dorsal process of one of the thoracic vertebrae. The tumor of the right distal humerus had reached dimensions approximately $9 \times 9 \mathrm{~cm}$ in extent.

Soft tissues: The liver contained numerous small pale poorly defined foci or nodules which averaged about $1 \mathrm{~mm}$ to less in diameter. There was a light yellow. discoloration of the inner cortex of rthe kidney and a discoloration of most of the lymph nodes of the body suggesting that they contained hemosiderin deposits.

FACl Tatoo No. 172: This female beagle was born on July 31, 1953 and it was given a strontium 90 burden 24 hours before sacrifice. This animal was euthenized at 1383 days of age to serve as a source of normal tissues. There was nothing remarkable in the history or seen grossly on post-mortem examination. F2P4 Tatoo No. 7: This female beagle (no siblings) was born August 12, 1951. It was given a plutonium burden of $1.034 \mu \mathrm{c} / \mathrm{kg}$ in March 2, 1953 when it was. 567 days of age. This dog survived 1556 days from the time of injection to sacrifice and then was euthenized because of complications caused by an osteogenic sarcoma of the sacrum.

Congenital condition: This dog had suffered no illness prior to the final phase except for a congenital torticollis which caused it to rotate its head slightly to the left.

Review of weight changes: This dog weighed $8.65 \mathrm{~kg}$ at the time it was in jected and attained a maximum weight of $11.53 \mathrm{~kg} 531$ days pre-mortem and then declined gradually to an autopsy weight of $8.53 \mathrm{~kg}$.

Study with other isotopes: This dog was used three times for a study of the life span of red blood cells by means of chromium 51 . It was used once for a blood volume study using chromium ${ }^{51}$ and iodine ${ }^{131}$.

Radiology and clinical observations: 1101 days, first unequivocal evidence of radioactive isotope toxicity affecting the bone causing pathologic remodelling. 
All subsequent radiographs indicated that this condition advanced steadily throughout the study period of the animal. At no time were there any clear cut fractures apparent. 1500 days, mild lameness of the left forelimb which at this time did not require hospitalization. 1537 days, definite indications of mild discomfort in left forelimb and there was some weakness of the rear limbs (pelvic)。 1542 days, marked incoordination of the pelvic limbs and continued lameness of the left forelimb. Soon thereafter the animals appetite failed and sacrifice was recommended.. However, euthenasia could not be arranged immediately and the animal was placed under constant sedation. During the next 10 days real discomfort seemed apparent only when the tail was moved for any purpose. 1382 days, in the pre-mortem examination there was little to see which has not already been described except that there were some minor alterations in the tapetum which indicated destruction of some of the irridiocytes.

Post-mortem observations:

Liver: The liver was studded with poorly circumscribed nodules which varied in size up to $2 \mathrm{~cm}$ in diameter.

Kidney: The kidney had numerous shallow scars over the surface which measured approximately $1 \mathrm{~mm}$ in greatest diameter, and there was a zone of yellowish dis. coloration in the inner cortical region. The aorta showed variable thickness in the wall in the ascending arch but this was not reflected on the surface of the aorta since both surfaces were smooth and unaltered.

F2P5 Tatoo No. 000: This female beagle (number of siblings unknown) was born January 6, 1950. It was given a burden of $3.298 \mu \mathrm{c} / \mathrm{kg}$ of plutonium on March 2 , 1953 when the dog was 1151 days of age. This dog was euthenized 1576 days following injection because of extreme degeneration of the skeleton and a fractured mandible which prevented normal ingestion of food.

Weight changes: The injection weight was $8.75 \mathrm{~kg}$, the dog gained up to a maximum weight of $13.98 \mathrm{~kg}$ and weighed $8.98 \mathrm{~kg}$ at sacrifice. The period of decline as shown by loss of weight from maximum to sacrifice was 571 days. Anesthesia 
was employed approximately 25 times.

Study with other isotopes: At 687 days post-injection a Sr 85 tracer dose was given to the dog. Chromium ${ }^{51}$ was used twice to study the life span of the red blood cells.

Radiology and clinical observation: 711 days post-injection there appeared the first unequivocal evidence of bone pathology due to radioactive material. 842 days, the spinous processes of three thoracic vertebrae were fractured. 1060 days, there was another spinous process fracture and one rib fracture. 1177 days, there were alterations in the body of the left ilium which made it appear that there was a well healed fracture present at that site. 1290 days, the single rib fracture appeared to have healed satisfactorily. 1330 days, there were at least 5 fractures of the ribs and the majority of these appeared to have healed satiso factorily, however, the spinous processes still had not shown signs of healing. The dog was hospitalized at this time for a period lasting 23 days. The animal at this time was rapidly deteriorating in general condition and health as reflected in weight loss, general attitude, appetite and the fact that it was losing hair very rapidly. All clinical pathological studies done at this time were negative but a change in diet appeared to cause much improvement. 1359 days, the animal was again hospitalized for a brief examination, period of treatment, and change in diet, with good results. 1376 days, the dog was again placed under close observation and constant care. The, animal maintained a satisfactory appetite for the remainder of the time it was studied, approximately 202 additional days.

Pre-mortem examination: The iris appeared to be definitely mottled but it could not be said with certainty that this was a depigmentation process. However, the tapetum appeared granular, particularly at the periphery as though some of the irridiocytes had been destroyed in this area. There was also a structure at the distal extremety of the left radius which indicated this might possibly be an osteogenic sarcoma. 
Post-mortem observations: The liver, was grossly abnormal with complete obliteration of the usual lobe formation and had a variable color with small pale nodules presented in contrast to the intervening dark parenchyma. The largest nodules were up to $.5 \mathrm{~cm}$ in diameter and most of them being several $\mathrm{mm}$ in size. These were separated by the intervening scar tissue and parenchyma.

Kidney: There was a yellow discoloration of the inner zone of the cortex of the kidney. The medulla contained a few yellow white streaks throughout extending down towards the papillae. Mammary tissue contained several very well circumscribed nodules which seemed to be fibrous in consistency. Parathyroids were unusual in that they were guite small and had petechlal hemorrhages evenly distributed over their surfaces. Dura mater, the cranial dura mater was closely adherent to the calavarium so that it was freed with considerable difficulty。

F3T4 Tatoo No. 253: This female beagle was one of 5 siblings born March 2, 1954. This dog was given a radiothorium burden of $.8 \mu \mathrm{c} / \mathrm{kg}$ on June 6,1955 when the dog was 461 days of age. This dog was euthenized 763 days after injection because of an anemia so extreme that the volume of pack red cells was only $1 / 3$ normal.

This dog weighed $7.25 \mathrm{~kg}$ at the time it received the radiothorium burden and advanced to a maximum weight $10.79 \mathrm{~kg}$ and from that point declined to $7.19 \mathrm{~kg}$ at the time of euthenasia. The period of decline as shown by a steady loss of weight from the maximum weight was 227 days.

Anesthesia: This dog was anesthetized approximately 11 times, nine of these times for the purpose of obtaining radiographs.

Study with other is stopes: Chromium ${ }^{51}$ was used to study the life span of red blood cells on August 10, 1955, October 20, 1955, April 25, 1956 and June 1, 1956.

Radiology and clinical observations: 262 days, the first evidence of changes in the bone were noted as limited to sub-periosteal new bone formation, and this was confined to the mid-sahft of the tibiae bilaterally. 478 days, there was a spontaneous fracture of the left ulna but this bone promptly healed so the dog could be discharged 63 days later. The dog reached its maximum weight at the end 
of this particular hospitalization period. 641 days, the volume of packed red. cells was reported to be extremely low so treatment was initiated but without success. 660 days, a rather rapid loss of weight, hair coat very dull; considerable alopecia, almost constant production of exudate from the nasal cavity. and rather frequent fluctuation of appetite through poor, indifferent, and normal. The rather constant production of nasal exudate has not been observed in any other animal in this present study to date and it must be noted that there were no other clinical symptoms in connection with it and it never responded successfully to antibiotic therapy. 731 days, one rib fracture; fracture of the right ulna; marked alteration of structure in the shaft of the left radius.

Pre-mortem observation: There was advanced depigmentation of the iris, a marked state of dehydration and an obvious icterus.

Post-mortem observaticn: There was practically no functional bone marrow in the entire skeleton but what there was was located in the shafts of the humeri and the femur. The lymph glands were quite atrophic and the spleen was very light in color and also atrophic.

F2M2 Tatoo No. 166: This female beagle was one of 8 siblings born June 30, 1953. It was given an injection of $.355 \mu \mathrm{c} / \mathrm{kg}$ of mesothorium on November 29, 1954 when it was 517 days of age. This dog died of acute hepatitis 965 days after receiving its mesothorium burden.

This: dog weighed $8.25 \mathrm{~kg}$ when it was injected and reached a maximum weight of $12.87 \mathrm{~kg} 547$ days after injection, and then weighed $10.68 \mathrm{~kg}$ when the autopsy was performed at 965 days.

Anesthesia: This dog was anesthetized 6 times for radiographic study and about 3 times for whole body radiation measurement.

Radiology: There were no marked changes in the bone as shown by radiographic study so the fatal illness was of interest because of its brevity and its unusual nature as seen in our experience here. 
Symptoms, therapy and course of illness: On July 20, 1957 about 10:15.a.m. this dog was observed in the runs to be so weak that it was unable to stand. It was obvious that at least $100 \mathrm{ml}$ of a serosanguinous fluid had drained from the rectum when the dog was found and more was lost similarly during the succeoding several hours. The dog became comatose shcrtly after being found in the weakened condition but was revived with $150 \mathrm{ml}$ of whole blood given intravenously and another $200 \mathrm{ml}$ of supportive fluids given similarly. There was no evidence of an intestinal tract blockage or of an acute gastritis or enteritis obtained by palpation and radiographic examination. There was no vomiting or nausea, there was an icterus and a body temperature of 103 degrees F. The dog responded very rapidly to the treatment given and was walking about quite alertly within two hours. Precaution was taken of giving both orally and rectally a mixture which coats the intestine with an antibiotic and a protective colloid.

Four hours after being found the dog. was still somewhat depressed but very responsive so was given additional supportive fluids intravenously as well as rather large amounts of penicillin and dihydro-streptomycin. In spite of this rather good appearance and cause for optimism the dog died approximately 20 hours after first being seen in the weakened condition in the rans.

Post-mortem observations:

Liver: The liver hadi a rather characteristic so-called morrocomleather appearance and this later proved to be primarily a centra-lobular necrosis. The biliary duct system appeared to be patent. All fatty tissues throughout the body cavities were definitely icteric. Gastro-intestinal tract; the ileum. was dialated about, $5 \mathrm{~cm}$ anterior to the ileocecal valve when first observed but this soon contracted so that it was no greater in diameter than the rest of the ileum. The stomach was distended and about $1 / 2$ filled with a grayish cloudy fluid. The spleen was very dark and filled with a large amount of blood. The lungs were somewhat edematous and the bronchial nodes were very dark and congested. The kidneys had a cooked appearance and the cortex was somewhat darker than normal. 
Brain; although no pressure measurements were taken the fluids in the : ventricles of the brain appeared to under an increased pressure. Bone marrow; the general marrow state of the dog was good and no unequivocal changeo could. be detected in the architecture of the bone. Lymphoid tisṣue; the lymph tissue was very black in color wherever seen and different in this respect from any other dog seen here to date. Particularly striking was the appearance of the Iymphoid tissue of the gastro-intestinal tract, the peyers patches, the lymph nodes in the cecum and the rectum and colon were all a dull black in color, outlining extremely well the presence of and the extent of Iymphoid tissue distribution in the the lower intestinal tract.

T16R5 Tatoo No. 022: This male beagle was purchased for use as a test animal. It was given a 5-level radium burden on July 11, 1957 when it was 604 days of age, weighed $12.39 \mathrm{~kg}$, and was sacrificed when it had carried the burden for 12 days. It weighed $12.22 \mathrm{~kg}$ at sacrifice and a post-mortem examination of the animal revealed it to be grossly normal in all respects. T6T4 Tatoo No. 257: This male beagle was one of 7 siblings born March 6, 1954. It was given a burden of radiothorrium $(.884 \mu \mathrm{c} / \mathrm{kg})$ on October 18,1955 when it was 591 days of age. This dog as a test animal was sacrificed 651 days postinjection following a fairly long period of illness which dictated sacrifice to prevent loss of tissues. He was extremely anemic and had multiple fractures resnonsible for the prolonged final illness.

Summary of weight changes: This dog weighed $7.01 \mathrm{~kg}$ at injection, gained to a maximm weight of $7.90 \mathrm{~kg}$ and then declined to a weight at autopsy of $7.22 \mathrm{~kg}$. The weight had dropped considerably at one time during the illness and then regained to the high point only 11 days before sacrifice.。

Anesthesia: This dog was anesthetized 10 times for radiographic study and 10 times for whole-body radiation counting.

Radiology and clinical observations: 335 days post-injection, there was a pathologic remodelling of the bone and 2 unhealed fractures of the ribs. In 
addition there were 2 irregular zones of increased density localized at the upper end of the ulna bilaterally and there appeared to be a definite enroachment on the medullary canal at this point. 470 days, there was a marked lameness or weakness of the rear limbs, there were a total of at least 8 rib fractures, all unhealed, and in addition there was what appeared to be a healed fracture of the body of the left ilium and perhaps a fracture through the roof of the acetabulum. 487 days, there was definite lameness and tenderness in the left pelvic limb. 490 days, a radiograph demonstrated what appeared to be old fractures of the body of the ilium bilaterally. In the left ilium this appeared to have healed with abundant callus formation but a central irregular zone of osteolytic rarefraction was present. There was also some irregularity and deformity in the region of the pubic synphysis. 514 days, there were a total of at least 11 unhealed rib fractures. There also appeared to have been old fracture injuries of the right foreleg, the body of the ilium bilaterally and the body of the scapula. 529 days, there was a definite limp of the left pectoral limb and also a stilted movement of the rear limbs. Within 10 days it again became very active and alert and there was little abnormality in ambulation, 549 days, there was an additional unhealed fracture of the left ulna. 543 days, the left pectoral limb was not used at all in ambulation. 562 days, the dog was again walking with fair normality and a hard callus was obvious about the fractures which had been noted in both. the radius and the ulna of the left forelimb. This callus became larger and immobilized the leg throughout the next 3 weeks. (It must be noted that the dog resisted a.ll attempts to immobilize this left forelimb by means of supportive casts). 597 days, a summary of fractures included at least 13 rib fractures essentially all unhealed and the unhealed fractures of the right ulna, left radius and ulna and the body of the right ilium. 613 days, it was noted that the dog had rapid involuntary movements of the mandible or a chatter which had been previously noted in other dogs in this stage, particularly those bearing radiothorium and in a debilitated condition. This mandible chatter was stimulated particularly when the dog 
lowered the head from a raised position and the condition continued throughout the remaining 38 days the dog lived.

Pre-mortem examination: The iris was moderately depigmented and the tapetum Iucidum had a coarse granular nature. There was obvious atrophy of the temporal and masseter muscles. There was an advanced abnormal graying over the entire coat of hair and the hair was abnormally long. There was a lateral deviation of the left radius and ulna at mid-point giving the leg a bowed appearance.

Post mortem observations: The muscle tissues were generally atrophic. The wall of the duodenum and the ileum appeared to be thickened and there were numerous petechial hemorrhages in the mucosa in this area. The aorta and vessels in general had normal surfaces but there was intermittent thickening in the. wall of the ascending arch of the aorta.

M12 Tatoo No. 80: This was a male beagle (no siblings) born October 5, 1952. It was injected with $.097 \mu \mathrm{c} / \mathrm{kg}$ on February 8,1954 when it was 491 days of age. Euthenasia was performed 1282 days post-injection because a tumor of the right ilium had advanced sufficiently far into the pelvic vanal to prevent normal elimination.

Summary of weight ehanges: This dog weighed $10.2 \mathrm{~kg}$ at injection time, it attained a maximum weight of $11.96 \mathrm{~kg}$ and declined to a sacrifice weight of 8.46 kg. There was a nearly constant but slow loss of weight during the last 309 days. Anesthesia: This dog was anesthetized 9 times for whole body radiation activity study and 8 times for radiology.

Radiology and clinical observations: 1163 days, there was pathologic remodeling of the bone and gross zones of osteolytic rarefraction were apparent. 1169 days, there was an infection in the right forelimb resulting in marked edema but the condition was corrected in 9 days. 1229 days, the dog had been limping intermittentIy during the previous two weeks (the right pelvic limb) and was hospitalized at this time for closer observation. An examination revealed the possibility of a tumor forming on the shaft of the right ilium which resulted in 
extreme weakness of the pelvic limbs or perhaps a slight paralysis of the $r$ ight pelvic limb. There was also some atrophy of the musculature in this affected limb. A review of radiographs taken 66 days before this had shown that there were gross zones of osteolytic rarefraction apparent in the right side of the pelvis and especially in the region of the right femoral neck. 1232 days, increasing osteolysis of the ilium and the anterior lip of the right ascetabulum. The head and neck:of the femur and the ischial region of the pelvis also appeared involved. There was very little use of the right pelvic limb at this time. 1267 days, the right half of the pelvis with the exception of the wing of the ilium was largely radiolucent so that there appeared to be very little to support the femur in its attachment to the pelvis. There was considerable enroachment on the canal by soft tissue which promised to soon occlude this canal.

Post-mortem observations: There was a generalized icterus. The lung contained small firm nodules 1 to $2 \mathrm{~mm}$ in diameter scattered sparsely throughout all lobes and these were presumed to be metastatic tumors. There was focal thickening of the wall of the descending portion of the arch of the aorta but no evidence of intimal wrinkling in the aorta. The tumor of the right ilium had practically. occluded the pelvic canal. Apart from the pelvis the skeletal tissue showed only minor degenerative changes with no fractures apparent. The bone marrow in mid shaft of the long bones was light pink in color in contrast to the usual finding of a rather deep red marrow in this position in other dogs. The marrow elsewhere as in the vertebral bodies and sternum was normal in appearance.

F8R5 Tatoo No. 195: This female beagle was one of 4 siblings born September 3, 1953. It was injected with $9.68 \mu \mathrm{c} / \mathrm{kg}$ on December 21, 1954 when the dog was 474 days of age. Euthenasia was performed 968 days following injection because a tumor of the right distal ulna had impaired circulation of the carpal and metacarpal region.

Summary of weight changes: The injection weight was $7.76 \mathrm{~kg}$ and the dog gained to a maximum weight of $11.16 \mathrm{~kg} 934$ days post-injection. The sacrifice 
weight was $9.72 \mathrm{~kg}$. There was a steady loss of weight from the maximum attained during the last 34 days of the study period.

Anesthesia: This dog was submitted to whole body radiation measurements twice and was radiographed 12 times.

Study with other isotopes: Total blood volume study was performed on August 1, 1956 by means of chromium ${ }^{51}$ and iodine ${ }^{131}$.

Radiology and clinical observations: 400 days, the skeleton appeared essentially normal. 478 days, there were at least six rib fractures and two fractures of the spinous processes of thoracic vertebrae. In addition there were gross changes in the architecture of the long bones, particularly of the radius and ulna bilaterally. 498 days, there were two additional rib fractures, 517 days, there were now 11 rib fractures and an additional fracture of a spinous process, the other spinous processes had healed and oneor more of the ribs had healed satisa factorily at this time. 646 days, all fractures appeared to have healed satisfactorily except for two of the ribs and one spinous process where there was false joint formation. 664 days, still two unhealed rib fractures and one new rib fracture. 678 days; the most recent rib fracture reported appeared to be healing but there were three additional new rib fractures, none of which were showing signs of repair. 741 days, no new rib fractures seen and the healing had prow gressed very well in all the others even to the extent that one of the ribs which had the appearance of a false joint for several months had now healed satisfactorily. 896 days, there appeared a defect (an interuption in the continuity of a portion of the cortex) in the ulna of the right foreleg at the juncture of the middle and the distal $1 / 3$ of the bone. 917 days, the dog limped heavily on the right forelimb and there was some swelling over the distal lateral surface of the right ulna. This swelling was somewhat sensitive to palpation or pressure at this time and did not change in this respect throughout the next 51 days. 932 days, it was very obvious that the right ulna was showing considerable disorganization in bone structure as well as osteogenesis. 935 days, the tumor of the ulna 
caused some lateral deviation of the foot. Throughout the remainder of the 51 terminal days, the tumor enlarged at a steady rate and caused increasing complications in the circulation of the foot. Otherwise the dog remained normal and quite active. The tumor eventually reached a size which was $51 / 2 \mathrm{~cm}$ by, $6 \mathrm{~cm}$ and roughly oval in shape.

Pre-mortem examination: There was advanced depigmentation of the iris as well as a rather marked destruction of the tapetum cellulosum and the development of a moderate condition resembling albuminuric choroiditis in appearance. The edema of the right fore-foot was extreme.

Post-mortem observations: Skeleton: all fractures had healed satisfactorily with one exception, there was a false joint formation in one rib fracture. Lymph nodes; generally well replaced by fat and none appeared to contain tumors. Kidney; there was a yellow substance stippled on the inner portion of the cortex of the kidney.

F6P5 Tatoo No. 124: This female beagle was one of 6 siblings born March 31, 1953. It was given a burden of $2.57 \mu \mathrm{c} / \mathrm{kg}$ of plutonium on May 12, 1954 when the dog was 407 days of age. It survived 1194 days from the time of injection when a massive tumor originating from the shaft of the right ilium occluded the pelvic canal causing constipation, acute toxemia and death. The autopsy was performed the day following death.

Summary of weight changes: This dog weighed $7.90 \mathrm{~kg}$ at time of injection and achieved a maximum weight of $11.36 \mathrm{~kg}$ at 413 days post-injection, but it was given a reducing diet and reached an optimum weight of $10.23 \mathrm{~kg}$ at 890 days. The dog was then put on a maintainence diet but in spite of this it lost weight to $7.64 \mathrm{~kg}$ at the time of death.

Anesthesia was employed 12 times for radiology.

Study with other isotopes: Chromium ${ }^{51}$ was employed once to determine red cell life span and a combination of chromium ${ }^{51}$ and iodine ${ }^{131}$ was used 3 times for blood volume studies. 
Radiology and clinical observations: 583 days, there were fractures of a first rib and of the dorsal process of one thoracic vertebra." 639 days, this dog developed an intestinal herniation into the left inguinal canal. This hernia was surgically corrected 13 days later and recovery was uneventful. $692^{\circ}$ days, there were fractures of ribs 1 and 4 on the left side and ribs 7 and 8 on the right side. 877 days, there was good healing and union in one rib fracture but there were 2 additional fractures so that now there were fractures at the hot line in ribs 8, 9 and 10 on the right side. 897 days, there was obvious union in some of the rib fractures even at the hot line, and all of them had good callus formation. 1023 days, there began a marked lameness of the left pelvic limb which lasted for 80 days. The cause of this was not diagnosed. 1028 days, fracture at the hot line of the left ninth rib, all other fractures appeared to have resorted to false-joint formation or to have healed satisfactorily。 1034 days, weakness in the pelvic limbs which may have been referable to a defect in the shaft of the left ilium which had the appearance of an old fracture. 1129 days, there was a severe lameness of the right pelvic limb, otherwise the dog appeared quite normal. 1157 days, there were symptoms of a definite arthritis in the right stifle or knee joint. 1185 days, there was acute constipation caused by a partial occlusion of the pelvic canal. Radiographs indicated that there was a tumor arising from the ischium and the pubis of the right side. The constipation caused a toxemia which could not be successfuliy corrected.

Post-mortem observations: Comments upon the soft tissue have little value due to the condition of the dog pre-mortem and the delay in post-mortem examination. (Considerable comment hàs been included regarding the progress of fracture occurrence in this dog so a final status of rib fractures was included.) Ribs 8,9 and 10 on the right side were fractured at the hot line, the llth rib had healed from an early fracture at its hot line and the l2th rib was fractured just above the hot line. There had been a fracture of the 7 th rib near its vertebral attachment but union was so perfect that the fracture site was scarcely demonstrable 
by radiograph. On the left side there was a fracture midway in the first rib, at the hot line in the $3 \mathrm{rd}$ rib also in the $7 \mathrm{th}, 8$ th and loth ribs. While healing had occurred in a previous fracture in the 9th rib. The fracture of the dorsal process of the 3rd thoracic vertebra had proceeded to false joint formation. MIP4 Tatoo No. 3: This male beagle was born September 1951 and was one of the test animals purchased for toxicity studies. It was injected with . $823 \mu \mathrm{c} / \mathrm{kg}$ of plutonium on December I, 1952 when 442 days of age. A fracture of the left mandible, a tumor of the proximal right humerus and a tumor of the proximal left femur dictated euthenasia after a trial period of 1724 days.

Summary of weight changes: The weight at injection was $7.61 \mathrm{~kg}$, and $9.9 \mathrm{~kg}$ at time of euthenasia. It reached a maximum weight of $11.53 \mathrm{~kg}$ at 1095 days, but still weighed $10.6 \mathrm{~kg}$ at 590 days later, only 39 days before sacrifice.

Anesthesia: This dog was anesthetized 15 times for radiographic study, once for surgery and one time for dental work.

Study with other isotopes: This dog was used once for erythrocyte life span study with chromium ${ }^{51}$. Note- At one time prior to September 1955 this dog suffered from severe alopecia, but hair growth was restored after about a year when it had been on a beef fat supplemented diet for several weeks or months.

Radiology and clinical observations: 1316 days, first definite indication of injury to skeletal tissue through changes seen in the architecture of the bone. 1618 days, the dog was observed to tilt his head to the left when eating and the cause proved to be a fracture, at the level of the first premolar, of the ramus of the left mandible and considerable osteolysis in this area. There did not seem to be pain associated with this condition so the diet was changed resulting in the fact that the dog gained about $1 \mathrm{~kg}$ in the next five to six weeks. No swelling was ever apparent at the fracture site. 1665. days, there had been a gradual strophy of the temporalis and the masseter muscles.: 1701 days, the animal started to limp heavily on the left pelvic limb and radiographs indicated an area of osteolysis in the left femur. At this $t$ ime there were also suggestions of a bone 
tumor forming at the proximal end of the right humerus. 1709 days, the left pelvic limb was held in extreme flexion at all times and tumors were now palpable on both the left femur and right humerus. Also at this time there were more definite signs of disorganization in the architecture of the bone of the left proximal femur.

Pre-mortem examination: It should be noted that the appetite was never seriously impaired in this animal. There was a peculiar condition in the fundus of the eye of this animal which made it appear that there were rust colored irridescent cells overlying the tapetum cellulosum. No fractures were ever apparent in this animal, other than in the zone of osteolysis in the left mandible.

Post-mortem observations: There were poorly circumscribed light yellow nodules varying up to $2 \mathrm{~cm}$ in diameter located throughout all lobes of the liver. M2R5 Tatoo No. 54: This male beagle was one of 4 siblings born August 3, 1952. It was injected with $10.8 \mu \mathrm{c} / \mathrm{kg}$ on November 16,1953 when it was 470 days of age. This dog survived 1380 days after injection when it was euthenized because it had developed a massive tumor of the distal left tibia.

Summary of weight changes: The injection weight was $8.85 \mathrm{~kg}$ and maximum weight was $11.93 \mathrm{~kg}$ at 683 days post-injection. This animal fluctuated often in its weight and still weighed $10.65 \mathrm{~kg}$ at 1355 days while the sacrifice weight was $9.89 \mathrm{~kg}$. The period of decline from 10.65 was only 25 days, but this dog weighed as little as $7.2 \mathrm{~kg}$ at 1182 days or 198 days pre-mortem.

Anesthesia: This animal was anesthetized 24 times for the purpose of obtaining radiographs, at least 4 times fro surgery and 10 times for whole body irradiation measurement and once for dental work.

Chronic ear infection: This dog suffered from a chronic ear infection throughout most of its test period. There were three periods of time when more vigorous treatment was necessary than at other times. The first episode lasted from September 14; 1955 to February 10, 1956. "The second episode from May 24, 1956 to July 7, 1956 and the last episode from January 29, 1957 through July 13, 
1957. During the second episode the irritation was so severe as to stimulate violent shaking of the head causing a hematoma to form in each ear, and the one ear required surgical correction. The presence of this ear infection had some significance since there was some correlation between the ear. infection and a poor hemogram appearing in the animals history.

Radiology and clinical observations: 20 days post-injection there was a foot injury which healed without complication: 674 days, there occurred an oblique fracture of the left humerus and it was observed at the same time that there were fractures of the $4 \mathrm{th}, 5 \mathrm{th}$ and $6 \mathrm{th}$ ribs on the left side and the 5 th rib on the right side. 784 days, an additional fracture occurring in the 8 th left rib and - of the dorsal process of the 5th thoracic vertebra. 911 days, all fractures had healed with good bridging except the right 5th rib. 955 days, there were no new fractures but a peculiar formation of the bone on the left 13 th $\mathrm{rib}$ and the right Tth rib made it appear that these ribs had been fractured at one time. 976 days, there was another similar structure indicating old fracture below the previous fracture on the right 5 th $\mathrm{rib}$ and the previously noted fracture of the right 5 th now had a callus formation although good bridging had not occurred. 1114 days, there occurred a fracture of the right femur and there now appeared to be a large osteolytic zone in the proximal left tibia. 1297 days, there was some attempt at bony bridging in the fracture of the right femur. 1353 days, there was obviously an osteogenic sarcoma of the proximal left tibia and the adjacent distal femur.

Pre-mortem examination: The eyes had undergone advanced destructive changes which included a marked depigmentation of the iris and the disappearance of irridiocytes in the tapetum cellulosum. There had developed a condition which is identical in appearance to the condition known as albuminuric choroiditis. Post mortem observations: Comments will be included in another report at a later date. 
FIS5 Tatoo. No. 219: This female beagle was injected with $93.6 \mu \mathrm{c} / \mathrm{kg}$ when it was 434 days of age. Euthenasia was performed 960 days post-injection because of the development of an osteogenic sarcoma of the distal right femur.

Summary of weight changes: The injection weight of FlS5 was $9.38 \mathrm{~kg}$, it reached a maximum weight of $12.73 \mathrm{~kg}$ at 631 days post-injection and then declined to $8.12 \mathrm{~kg}$ at termination. This period of decline as shown by constant loss of weight was 329 days.

Anesthesia: Employed four times for whole body radiation measurements and. ten times for radiology.

Radiology and clinical observations: 24 days post-injection this animal experienced an episode of radiation hyperthermia which was treated successfully so that the dog was apparently normal again within 17 days. Treatment consisted of aureomycin given at the rate of 200 to $400 \mathrm{mlg}$ daily and 10 to $20 \mathrm{ml}$ of nicothiamin given orally daily. The course of the toxicity period was entirely uneventful until 870 days post-injection when a definite lameness of the right pelvic limb with a slight edema or swelling over the stifle or knee joint indicating some disorder in the distal femur. Radicgraphs at this time indicated a large osteolytic area and a roughened cortical margin at the distal femur suggestive of a bone tumor. Succeeding radiographs throughout the next 90 days showed a gradualiy developing characteristic osteogenic sarcoma. At no time was there an impairment of the appetite or other normal functions. The only therapy employed in the course of this 90 day period was the use of analgesics and tranquilizing drugs because this dog was unusual in that there appeared to be obvious pain associated with the formation of the tumor. It should be noted that the pain associated with the tumor was stimulated primarily upon palpation of the tumor at infrequent intervals. There did not seem to be pain associated with ambulation or other normal functions, however, therapy was employed to eliminate the possibility of there being pain associated with this tumor at all times. 
Pre-mortem examination: The lymph nodes in general were somewhat smaller than normal. The tapetum cellulosum in the fundus of the eye was altered sufficiently to indicate that there had been some damage to this organ in that perhaps some of the irridiocytes had been distroyed.

Post--mortem observations: Radiographs of the bones would indicate that osseous tissue was entirely normal with the exception of the tumor growth.

Lungs: normal texture but there were numerous small nodules evident over the surface, these were less than $1 \mathrm{~mm}$ in diameter.

Lymphoid tissue: The right popliteal and-the internal iliac chains of lymph nodes were hemorrhagic and three to four times normal in size. The enlarged lymph nodes were those associated with the tumor bearing limb.

T17P5 Tatoo No. 358: This male beagle was one of three siblings born February 4 , 1955. It was injected with a 5-level burden of plutonium on February 12; 1957 when it was 739 days of age. This animal was euthenized 210 days after injection so as to complete a series of plutonium test animals.

Surmary of weight changes: The injection weight was $11.14 \mathrm{~kg}$ and weight at sacrifice was $10.20 \mathrm{~kg}$.

Clinical observations: At 137 days of age (and pre-injection) this animal experienced a pneumonia and enteritis which was treated successfully in approx imately 11. days. The clinical history during the post-injection period was with out events of importance but a pre-mortem examination indicated that this animal possessed an abnormally large spleen.

Post-mortem observation: The only thing worthy of note here was that the spleen was enormously enlarged so that it weighed just half as much as did the liver or $125 \mathrm{gms}$. This was approximately 3 to 4 times the size normally seen in other dogs.

MnR4 Tatoo No. 16: This male beagle was one of 3 siblings born January 5, 1952. It was injected with $3.51 \mu \mathrm{c} / \mathrm{kg}$ when it was 471 days of age. Euthenasia was employed at 1606 days because tumors had developed on the left maxilla, the left 
carpus and the left proximal tibia.

Summary of weight changes: Injection weight was $9.08 \mathrm{~kg}$ and the dog gained to a maximum weight of $10.68 \mathrm{~kg}$ at 1279 days and then declined to a sacrifice weight of $6.59 \mathrm{~kg}$ at 1606 days. There was a slow and steady decline in weight during the last 327 days.

Anesthesia: Employed three times for whole body radiation measurement, twelve times for radiology and twice for surgery and dental work. $S$

Study with other isotopes: Chromium ${ }^{51}$ was used at 877 days to measure the life span of red blood cells.

Radiology and clinical observations: 1513 days or 93 days before euthenasia this dog was observed to have a swelling over the left carpus which caused little: or no inconvenience. 1535 days the first real abnormality in ambulation was noted and seem referable to the pelvic area, particularly the action of either or both pelvic limbs. This inconvenience was of very short duration and ambulation appeared nearly normal thereafter for some days. 1557 days there developed a fairly large swelling over the left maxillary bone anterior lateral to the left eye. This swelling had all the characteristics of an abscess in connection with one of the upper cheek teeth but there proved to be no connection there. This swelling persisted with little change then for some weeks. 1589 days, there was a pronounced lameness of the left pelvic limb and a quickening increase in the size of the swelling over the left maxillary bone. Thereafter the condition of the animal deteriorated rapidly so euthenasia was recommended immediately and accomplished 16 days later.

Pre-mortem examination: There appeared to be some depigmentation of the iris and there was also some alteration in the tapetum cellulosum. There had been a condition develop in the fundus of the eye which resembled very well that termed aibuminuric choroiditis in the human.

Post-mortem observations: There was little noteworthy to record as seen regarding the gross appearance of the tissues. 
TI2S3 Tatoo No. 418: This male beagle was one of 4 siblings bonr January 27; 1956. It was given a three level burden of strontium September 11; 1957 when it was 593 days of age. This animal was not suitable for use in a regular toxicity group because of the history of illness prior to an age suitable for assignment to a regular group. Euthenasia was performed 5 days post-injection and no autopsy was performed since the animal became than a phantom for use by the physics group.

Clinical observations: 424 days, traumatic injury to the right foreleg causing moderate edema but recovery was entire within 13 days: 444 days, severe bronchitis and possibly pneumonia complicated by a marked edema of the lower portions of all limbs with symptoms of a generalized arthritis or neuralgia. Vigorous treatment with erythromycin required 17 days to cause recovery. 470 days severe "bronchitis and generalized neuralgia, 25 days required for recovery. A markedly elevated and stubborn temperature was characteristic of both of these episodes, that is the 2nd and 3rd episodes. 518 days, severe bronchitis and generalized neuralgia, very similar to the second respiratory episode, dramatic improvement and recovery was accomplished by the use of meticorten or prednisone. 592 days, there again appeared a temperature elevation and a generalized neuralgia so meticorten treatment was initiated immediately. The animal was given a strontium burden the next day. The animal was euthenized 5 days later。 T18P5 Tatoo No. 360: Male beagle one of three siblings born February $4,1955$. It was given a 5-level plutonium burden on February 12, 1957 when it was 739 days of age. It was sacrificed 217 days post-injection to complete a series of test dogs.

Clinical observations: 24 days post injection, there developed a characteristic radiation hyperthermia with a temperature of 105.5 or 4 degrees above normal and other symptoms characteristic of this condition.' This dog was treated successfully with rather masivive doses of aureomycin so that the temperature was reduced to normal range within 4 days. 180 days, approximately, there was incoordination of the pelvic limbs an episode of short duration with apparent 
complete recovery without therapy.

The dog appeared entirely normal in a pre-mortem examination.

IV. Current Census of Beagle Colony

$\begin{array}{lr}\text { Radium } & 75 \\ \text { Test Radium } & 1 \\ \text { Plutonium } & 71 \\ \text { Mesothorium } & 42 \\ \text { Test Mesothorium. . } & 1 \\ \text { Radiothorium } & 21 \\ \text { Test Radiothorium } & 1 \\ \text { Strontium } & 26 \\ \text { Aging Control } & 41 \\ \text { Radiology } & 2 \\ \text { Unassigned } & 38 \% \\ & 319\end{array}$

* Does not include all puppies. 
THIS PAGE

\section{WAS INTENTIONALLY LEFT BLANK}


HEMATOLOGY REPORT

The report from the hematology group includes the following data:

1. Pre-sacrifice hematology values on toxicity dogs sacrificed since the March 1957 Annual Report.

2. Graphs sumnarizing the hematological response to radiothorium and mesothorium for twenty-four months following injection.

3. Bone marrow differential counts on long bones of toxicity dogs autopsied to date.

1. Pre-sacrifice hematology determinations have been made on thirteen toxicity dogs since the last annual report. We were not able to obtain terminal values on three dogs which died unexpectedly on weekends when personnel was not available (dogs F6P5, F2M2, $\mathrm{M} \mathrm{M}_{4}$ 。)

PRE-SACR IFICE HEMATOLOGICAL VALUES OF TOXICITY DOGS

\begin{tabular}{|c|c|c|c|c|c|c|c|c|c|c|c|c|c|}
\hline $\begin{array}{l}\text { Dog } \\
\text { No. }\end{array}$ & Days & VPRC & $\mathrm{Hgb}$. & $\mathrm{RBC}$ & Retic & $\begin{array}{l}\text { Sed. } \\
\text { Rate } \\
\end{array}$ & WBC & $\begin{array}{l}\text { Seg. } \\
\text { Pmn }\end{array}$ & $\begin{array}{l}\text { Non- } \\
\text { Seg. } \\
\text { Pmn } \\
\end{array}$ & $\begin{array}{l}\text { Lymph } \\
\text { cyte }\end{array}$ & $\begin{array}{l}\text { Mono- } \\
\text { cyte }\end{array}$ & $\begin{array}{r}\text { Direc } \\
\text { eos. } \\
\text { Count } \\
\end{array}$ & $\begin{array}{l}\text { Plate- } \\
\text { let }\end{array}$ \\
\hline $\begin{array}{r}\text { Norma } \\
\text { mean }\end{array}$ & & 49.4 & 16.3 & 7.35 & 0.6 & 2.5 & 13.9 & 7.95 & 0.31 & 4.00 & 0.86 & 384 & 419 \\
\hline $\begin{array}{l}\mathrm{Pu} \\
\mathrm{M} 1 \mathrm{P} 4 \\
\text { F2P4 } \\
\text { F2P5 } \\
\mathrm{F} 5 \mathrm{P} 4\end{array}$ & $\begin{array}{l}1724 \\
1556 \\
1576 \\
1245\end{array}$ & $\begin{array}{l}49.5 \\
41.5 \\
33.0 \\
45.0\end{array}$ & $\begin{array}{l}15.9 \\
13.0 \\
10.7 \\
14.4\end{array}$ & $\begin{array}{l}6.67 \\
6.16 \\
4.63 \\
6.15\end{array}$ & $\begin{array}{l}0.1 \\
0.5 \\
0.3 \\
0.6\end{array}$ & $\begin{array}{l}28.0 \\
50.5 \\
55.0 \\
16.0\end{array}$ & $\begin{array}{r}8.3 \\
14.5 \\
12.2 \\
12.5\end{array}$ & $\begin{array}{l}5.98 \\
9.97 \\
8.02 \\
9.75\end{array}$ & $\begin{array}{l}0.21 \\
1.74 \\
1.19 \\
0.13\end{array}$ & $\begin{array}{l}1.47 \\
1.89 \\
2.35 \\
1.59\end{array}$ & $\begin{array}{l}0.58 \\
0.87 \\
0.64 \\
0.81\end{array}$ & $\begin{array}{l}50 \\
19 \\
25 \\
15\end{array}$ & $\begin{array}{l}267 \\
428 \\
221 \\
372\end{array}$ \\
\hline $\begin{array}{l}R a \\
\text { MDR4 } \\
\text { M2R5 } \\
\text { M4R5 } \\
\text { F6R } 5 \\
\text { F8R } 5\end{array}$ & $\begin{array}{r}1606 \\
1380 \\
1091 \\
1015 \\
968\end{array}$ & $\begin{array}{l}42.0 \\
38.5 \\
29.5 \\
35.5 \\
38.5\end{array}$ & $\begin{array}{r}13.8 \\
11.7 \\
9.3 \\
11.1 \\
12.5\end{array}$ & $\begin{array}{l}5.91 \\
5.19 \\
3.97 \\
5.00 \\
5.59\end{array}$ & $\begin{array}{l}0.2 \\
0.5 \\
1.7 \\
1.0 \\
0.5\end{array}$ & $\begin{array}{l}28.5 \\
51.0 \\
61.0 \\
34.0 \\
52.5\end{array}$ & $\begin{array}{r}9.7 \\
21.5 \\
17.4 \\
11.6 \\
9.3\end{array}$ & $\begin{array}{r}7.30 \\
16.39 \\
12.53 \\
6.00 \\
5.63\end{array}$ & $\begin{array}{l}0.12 \\
1.40 \\
2.26 \\
1.33 \\
0.49\end{array}$ & $\begin{array}{l}1.48 \\
1.08 \\
2.04 \\
3.28 \\
1.86\end{array}$ & $\begin{array}{l}0.73 \\
2.63 \\
0.57 \\
0.93 \\
1.33\end{array}$ & $\begin{array}{l}28 \\
15 \\
35 \\
25 \\
9\end{array}$ & $\begin{array}{l}336 \\
138 \\
413 \\
208 \\
484\end{array}$ \\
\hline $\begin{array}{l}\text { RTh } \\
\text { MIT2 } \\
\text { M2T3 } \\
\text { F3T4 }\end{array}$ & $\begin{array}{r}1282 \\
859 \\
763\end{array}$ & $\begin{array}{l}44.5 \\
41.5 \\
18.0\end{array}$ & $\begin{array}{r}14.0 \\
13.5 \\
6.4\end{array}$ & $\begin{array}{l}6.55 \\
5.60 \\
2.37\end{array}$ & $\begin{array}{l}0.7 . \\
0.4 \\
0.8\end{array}$ & $\begin{array}{r}44.0 \\
6.5 \\
77.0\end{array}$ & $\begin{array}{l}9.2 \\
4.9 \\
3.0\end{array}$ & $\begin{array}{l}7.20 \\
3.03 \\
0.59\end{array}$ & $\begin{array}{l}0.12 \\
0.17 \\
1.00\end{array}$ & $\begin{array}{l}0.97 \\
1.29 \\
1.32\end{array}$ & $\begin{array}{l}0.90 \\
0.29 \\
0.10\end{array}$ & $\begin{array}{r}15 \\
62 \\
9\end{array}$ & $\begin{array}{c}266 \\
- \\
47\end{array}$ \\
\hline $\begin{array}{l}\text { Sr } \\
\text { F1S5 }\end{array}$ & 960 & 44.0 & 13.8 & 6.40 & 0.4 & 40.0 & 7.7 & 5.83 & 0.29 & 1.12 & 0.37 & 28 & 159 \\
\hline
\end{tabular}

Comments: As mentioned in previous reports the most consistent findings prior to sacrifice are anemia, increased sedimentation rate, lymphopenia and eosinopenia. 
As the general condition of a dog deteriorates due to fractures, tumors, osteolytic processes in bone, inanition, etc., the white blood cell count (WBC) tends to rise from leukopenic levels to normal or above normal numbers due to an increase in mature as well as immature pmns. The higher level radiothorium dogs (M2T3, F3T4) did not show this rise in pmns terminally but had a deteriorating blood picture from injection to sacrifice. Only three of the above dogs (M2R5, F3T4, F1S5) had low platelet numbers at the time of sacrifice.

2. Preliminary comparison of the hematological response to mesothorium and radiothorium for a period of twenty-four months。

In annual reports the hematological findings on dogs injected with mesothorium or radiothorium have been given at yearly intervals. The graphs on the following page give mean values of WBCs and lymphocytes at one month intervals for the first four groups of dogs on each radioisotope.

Comments: The initial decrease in the leukocyte count of the 5-level mesothorium dogs is comparable in degree to that of the 4-level radiothorium dogs although the time of maximum depresion is later for the mesothorium injected dogs ( 3 months as compared to I month for RdTh). The leukocyte changes shown above are due mainly to changes in pmns. Eosinophils show a similar curve. Dogs injected with the 3- or 4-levels of mesothorium also develop a leukopenia which becomes maximum at three to six months. The leukocyte count remains at subnormal values for the two year period reported here. The leukocyte depression in 2- and 3level radiothorium dogs appears earlier and the count remains low until: toward the end of the second year. 


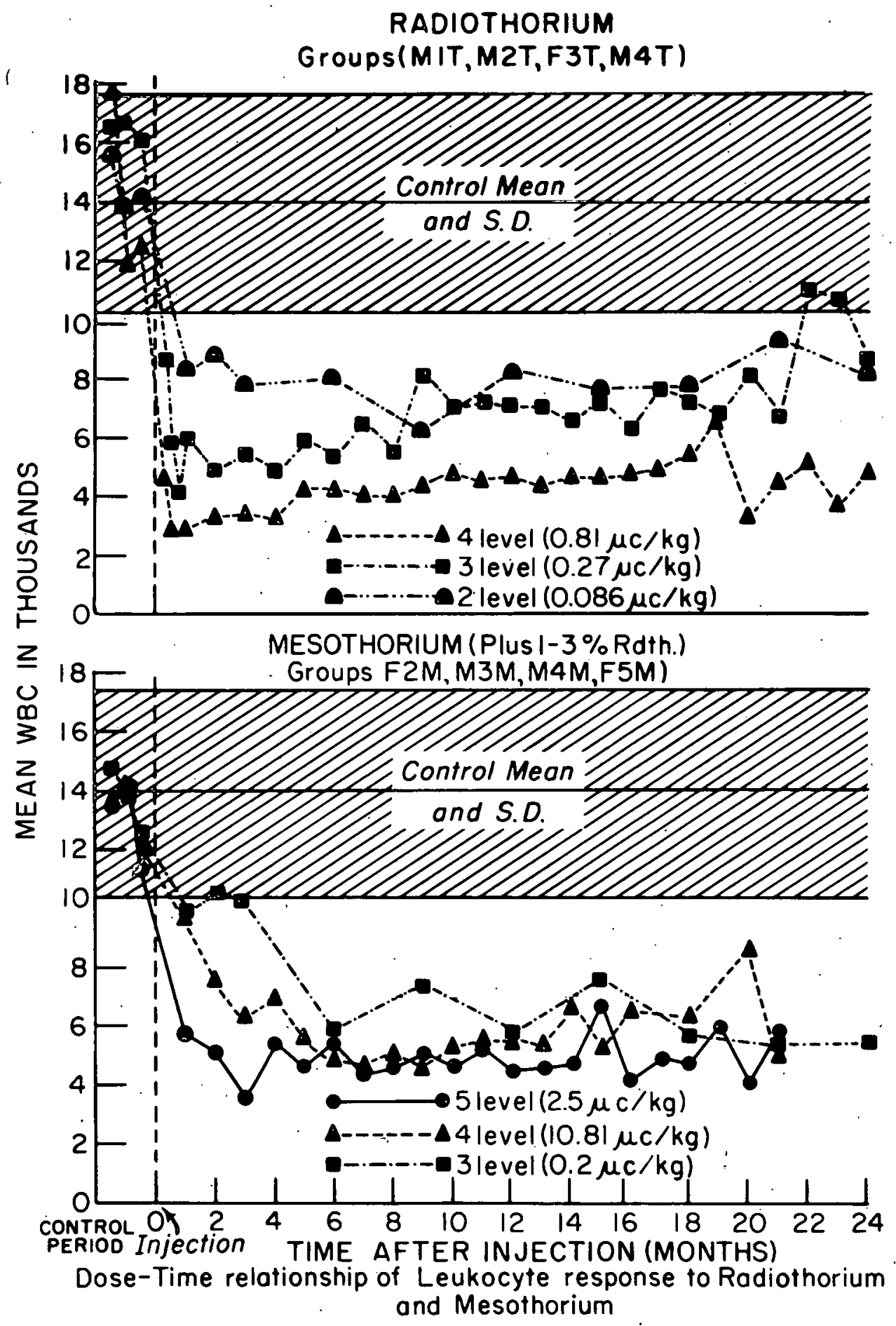




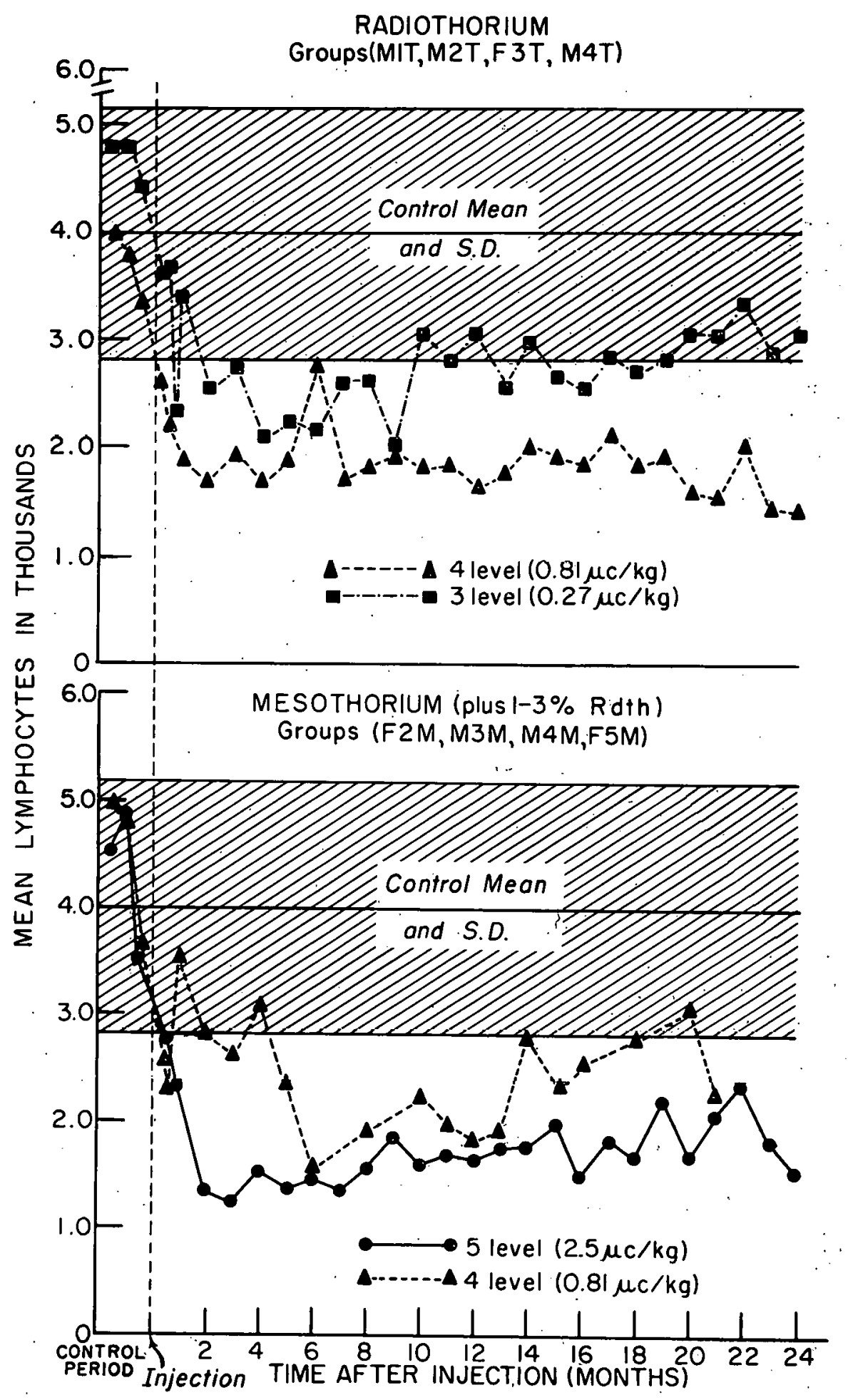

Dose Time relationship of Lymphocyte response to Radiothorium and Mesothorium 
$-53=$

Comments: A decrease in lymphocyte numbers occurs after injection of the highest levels of radiothorium and mesothorium (M3, T4). This lymphopeniz is maximal for both radioisotopes around two months following injection and persists through the two year period shown above. There appears to be a slight decrease in lymphocytes in 3-level radiothorium dogs during the first six months with normal values thereafter. There is a definite drop in lymphocyte numbers in 4level mesothorium dogs at six months with a rise to normal values at about fourteen months.

3. Bone marrow studies on femurs of toxicity dogs autopsied to date. Bone marrow smears are taken at autopsy from various marrow sites ie, rib, sternum, costo-chondral junction, proximal-, mid- and distal-femur and humerus. At least 500 cells are counted (1000 cells are preferable) and a ratio is obtained to express the relative proportion of developing myeloid (white) to erythroid (red) cells, the myeloid/erythroid ratio. It is possible to have a normal myeloid/ erythroid ratio but to have an abnormal distribution of the different types of immature cells. Since the pattern-of radieisotope deposition varies in different. types of bone, it is possible also that the qualitative picture of hematopoiesis may differ from bone to bone and even within the same bone. This has been evident in test-run plutonium dogs reported in the March 1957. Annual Report in which long bones show a different response than flat bones.

In the table on the following page detailed marrow differential counts, are given for the femurs of toxicity dogs. The dogs are grouped according to radioisotope: and in order of increasing time on experiment before sacrifice.

Some general trends appear from analyzing the bone marrow values. The M/E ratio in many of the injected dogs is above normal with the higher values in the dogs which lived the longest. Exceptions to this are dog MIT5 which had extreme bone marrow exhaustion and a very high ratio and dogs having severe regenerative anemias at time of death with stimulation of erythropoiesis and consequently low $\mathrm{M} / \mathrm{E}$ ratios. Developing eosinophils are normal in percentage despite a decrease 


\begin{tabular}{|c|c|c|c|c|c|c|c|c|c|c|c|c|c|c|c|c|c|c|c|}
\hline & & & \multicolumn{5}{|c|}{ Developing Pmins } & \multicolumn{4}{|c|}{ Developing Eosinophils } & \multicolumn{5}{|c|}{ Developing Red Blood Celis } & \multirow[b]{2}{*}{$\begin{array}{l}\text { Total } \\
\text { Misc. } \\
\text { Cells }\end{array}$} & \multirow{2}{*}{$\begin{array}{c}\text { M/E } \\
\text { Ratio } \\
\end{array}$} & \\
\hline & $\begin{array}{l}\text { No. } \\
\text { Dog }\end{array}$ & $\begin{array}{l}\text { No. } \\
\text { Days } \\
\text { Expt. }\end{array}$ & $\begin{array}{l}\text { Myelo } \\
\text { blast }\end{array}$ & $\begin{array}{l}\text { Prongelo } \\
\text { cyte }\end{array}$ & $\begin{array}{l}\text { Myelo- } \\
\text { cyte }\end{array}$ & $\begin{array}{l}\text { Tieta- } \\
\text { myelo- } \\
\text { cyte }\end{array}$ & Seg. & $\begin{array}{l}\text { Pro- } \\
\text { myelo- } \\
\text { cyte }\end{array}$ & $\begin{array}{l}\text { Myelo- } \\
\text { cyte }\end{array}$ & $\begin{array}{l}\text { Heta- } \\
\text { myelo } \\
\text { cyte }\end{array}$ & Seg. & $\begin{array}{c}\text { Total } \\
\text { Yyel oid } \\
\text { Cells. }\end{array}$ & $\begin{array}{c}\text { Pro- } \\
\text { normo- } \\
\text { blest }\end{array}$ & $\begin{array}{l}\text { Baso- } \\
\text { normo- } \\
\text { blast }\end{array}$ & $\begin{array}{l}\text { Late } \\
\text { Normo- } \\
\text { blast }\end{array}$ & $\begin{array}{l}\text { Trythroid } \\
\text { Cells }\end{array}$ & & & \\
\hline & $\begin{array}{c}\text { Control } \\
\text { Range }\end{array}$ & 3 Dogs & $\begin{array}{c}2.3 \\
0.8-3.6\end{array}$ & $\begin{array}{c}3.6 \\
3.0-4.4\end{array}$ & $\begin{array}{c}13.0 \\
8.4-19.0\end{array}$ & $\begin{array}{c}14.7 \\
120-18.0\end{array}$ & $\begin{array}{c}10.2 \\
4.8-18.2\end{array}$ & $\begin{array}{c}0.2 \\
0.0-04\end{array}$ & $\begin{array}{r}0.9 \\
0.6-1.6\end{array}$ & $\begin{array}{c}0.6 \\
0.4-0.8\end{array}$ & $\begin{array}{c}0.5 \\
0.0-1.0\end{array}$ & $\begin{array}{c}46.1 \\
39.0-532\end{array}$ & $\begin{array}{c}0.2 \\
0.0-0.5\end{array}$ & $\begin{array}{c}0.3 \\
0.0-0.8\end{array}$ & $\begin{array}{c}49.9 \\
43.9-57.4\end{array}$ & $\begin{array}{c}50.3 \\
44.0-58.0\end{array}$ & $\begin{array}{c}3.5 \\
2.4-50\end{array}$ & $\begin{array}{l}0.94 \\
.67-1.20\end{array}$ & \\
\hline $\mathrm{Pu}$ & $\begin{array}{l}\text { M4P4 } \\
\text { M3P4 } \\
\text { F5P4 } \\
\text { MIP5 } \\
\text { MIP3 } \\
\text { F2P4 } \\
\text { F2P5 } \\
\text { MIP4 }\end{array}$ & $\begin{array}{l}1065 \\
1198 \\
1245 \\
1324 \\
1477 \\
1556 \\
1576 \\
1724\end{array}$ & $\begin{array}{l}3.0 \\
7.0 \\
0.4 \\
2.4 \\
1.4 \\
0.4 \\
2.4 \\
0.4\end{array}$ & $\begin{array}{l}3.4 \\
7.0 \\
0.2 \\
2.8 \\
2.4 \\
9.4 \\
4.0 \\
9.0\end{array}$ & $\begin{array}{r}18.0 \\
26.8 \\
3.0 \\
12.4 \\
14.6 \\
17.4 \\
114.4 \\
20.0\end{array}$ & $\begin{array}{r}23.4 \\
19.6 \\
7.4 \\
37.4 \\
20.0 \\
26.4 \\
30.0 \\
15.0\end{array}$ & $\begin{array}{r}3.8 \\
2.0 \\
10.2 \\
4.8 \\
3.4 \\
15.2 \\
19.0 \\
23.8\end{array}$ & $\begin{array}{c}0 \\
0.2 \\
0 \\
0 \\
0 \\
0 \\
0.2 \\
0\end{array}$ & $\begin{array}{c}0 \\
0.4 \\
0.4 \\
0.2 \\
0.4 \\
0 \\
0 \\
1.2\end{array}$ & $\begin{array}{c}0.8 \\
0.4 \\
0.2 \\
0 \\
1.4 \\
0.4 \\
0 \\
0.6\end{array}$ & $\begin{array}{l}0.8 \\
0.2 \\
0.8 \\
0 \\
0.4 \\
0.2 \\
0.4 \\
1.0\end{array}$ & $\begin{array}{l}53.2 \\
63.6 \\
22.6 \\
60.2 \\
44.0 \\
69.4 \\
70.4 \\
71.0\end{array}$ & $\begin{array}{c}0.2 \\
0.2 \\
0.2 \\
0 . \\
0 \\
0.2 \\
0 \\
0\end{array}$ & $\begin{array}{c}0.2 \\
0 \\
0.6 \\
0 \\
0 \\
0.2 \\
0.2 \\
0.2 .\end{array}$ & $\begin{array}{l}45.6 \\
36.0 \\
74.0 \\
38.6 \\
56.0 \\
29.8 \\
29.0 \\
27.0\end{array}$ & $\begin{array}{l}46.0 \\
36.6 \\
74.8 \\
38.6 \\
56.0 \\
30.2 \\
29.2 \\
27.2\end{array}$ & $\begin{array}{l}0.8 \\
0.2 \\
2.6 \\
1.2 \\
0 \\
0.4 \\
0.1 \\
1.8\end{array}$ & $\begin{array}{l}1.15 \\
1.76 \\
0.30 \\
1.56 \\
0.79 \\
2.30 \\
2.41 \\
2.61\end{array}$ & \\
\hline $\mathbf{R a}$ & $\begin{array}{l}\text { F3R4 } \\
\text { MRR5 } \\
\text { F8R5 } \\
\text { F6R5 } \\
\text { M4R5 } \\
\text { M2R5 } \\
\text { MRR }\end{array}$ & $\begin{array}{r}490 \\
908 \\
968 \\
1015 \\
1091 \\
1380 \\
1606\end{array}$ & $\begin{array}{l}7.0 \\
0.4 \\
2.2 \\
3.2 \\
0.7 \\
0 \\
0.6\end{array}$ & $\begin{array}{r}13.0 \\
3.4 \\
5.8 \\
3.8 \\
1.1 \\
8.4 \\
8.0\end{array}$ & $\begin{array}{r}46.0 \\
8.5 \\
20.4 \\
19.4 \\
13.7 \\
16.8 \\
24.2\end{array}$ & $\begin{array}{l}7.0 \\
30.9 \\
20.8 \\
29.6 \\
17.4 \\
17.6 \\
16.6\end{array}$ & $\begin{array}{c}0 \\
4.9 \\
19.2 \\
14.4 \\
7.0 \\
15.2 \\
40.0\end{array}$ & $\begin{array}{c}0 \\
0.8 \\
0 \\
0 \\
0 \\
0 \\
0\end{array}$ & $\begin{array}{c}0 \\
1.3 \\
0.2 \\
0.2 \\
0.2 \\
0 \\
0.8\end{array}$ & $\begin{array}{c}0 \\
1.4 \\
0.4 \\
0 . \\
0 \\
0.8 \\
0.2\end{array}$ & $\begin{array}{l}2.0 \\
0.7 \\
0.4 \\
0 \\
0 \\
0.8 \\
0.4\end{array}$ & $\begin{array}{l}75.0 \\
52.3 \\
69.4 \\
70.5 \\
40.7 \\
59.6 \\
90.3\end{array}$ & $\begin{array}{c}0 \\
0.1 \\
0 \\
0 \\
0 \\
0 \\
0\end{array}$ & $\begin{array}{c}0 \\
2.1 \\
0.2 \\
0 \\
0 \\
0.4 \\
0\end{array}$ & $\begin{array}{l}23.0 \\
45.0 \\
29.8 \\
29.2 \\
58.4 \\
36.4 \\
4.8\end{array}$ & $\begin{array}{l}23.0 \\
47.2 \\
30.0 \\
29.2 \\
58.4 \\
36.8 \\
4.8\end{array}$ & $\begin{array}{l}2.0 \\
0.5 \\
0.6 \\
0.2 \\
0.9 \\
3.6 \\
4.4\end{array}$ & $\begin{array}{c}3.3 \\
1.11 \\
2.31 \\
2.42 \\
0.70 \\
1.62 \\
18.9\end{array}$ & $\underset{1}{F}$ \\
\hline $\mathrm{RdTh}$ & $\begin{array}{l}\text { M2T 5*** } \\
\text { MIT 5*** } \\
\text { F3T3 } \\
\text { MIT4 } \\
\text { F3T4 } \\
\text { M2T4 } \\
\text { M1T3. } \\
\text { MIT2 }\end{array}$ & $\begin{array}{r}97 \\
212 \\
547 \\
645 \\
763 \\
832 \\
988 \\
1282 .\end{array}$ & $\begin{array}{c}7.8 \\
4.8 \\
2.0 \\
0.4 \\
1.6 \\
0 \\
0.4 \\
0.8\end{array}$ & $\begin{array}{l}1.2 \\
3.4 \\
4.6 \\
8.4 \\
7.2 \\
5.8 \\
4.6 \\
9.4\end{array}$ & $\begin{array}{r}1.8 \\
25.8 \\
11.8 \\
26.8 \\
33.2 \\
18.8 \\
12.8 \\
24.8\end{array}$ & $\begin{array}{r}7.2 \\
39.9 \\
21.6 \\
41.5 \\
16.4 \\
24.2 \\
8.0 \\
20.6\end{array}$ & $\begin{array}{r}1.4 \\
4.1 \\
2.2 \\
0.6 \\
0.6 \\
31.6 \\
1.0 \\
23.4\end{array}$ & $\begin{array}{c}0 \\
0 \\
0 \\
0.3 \\
0 \\
0 \\
0 \\
0.6\end{array}$ & $\begin{array}{l}1.2 \\
0.4 \\
0.4 \\
0.5 \\
0.2 \\
0.2 \\
0.6 \\
1.2\end{array}$ & $\begin{array}{c}1.4 \\
0.9 \\
1.6 \\
1.4 \\
0.4 \\
0.6 \\
0 \\
0.6\end{array}$ & $\begin{array}{c}0.2 \\
9.4 \\
1.0 \\
2.3 \\
0.6 \\
0.4 \\
0 \\
1.0\end{array}$ & $\begin{array}{l}20.2 \\
88.7 \\
45.2 \\
81.2 \\
60.2 \\
81.6 \\
26.8 \\
82.4\end{array}$ & $\begin{array}{c}0.4 \\
0.4 \\
0 \\
0.5 \\
0.2 \\
0 \\
0 \\
0.6\end{array}$ & $\begin{array}{c}1.8 \\
0.4 \\
0 \\
2.0 \\
1.2 \\
0 \\
0 \\
0.2\end{array}$ & $\begin{array}{r}67.8 \\
0.3 \\
54.0 \\
13.6 \\
28.4 \\
18.4 \\
72.6 \\
14.6\end{array}$ & $\begin{array}{r}70.0 \\
1.1 \\
54.0 \\
16.1 \\
29.4 \\
18.4 \\
72.6 \\
15.4\end{array}$ & $\begin{array}{c}9.8 \\
10.4 \\
0.8 \\
2.7 \\
10.0 \\
0 \\
0.6 \\
2.2\end{array}$ & $\begin{array}{c}0.28 \\
80.6 \\
0.83 \\
5.04 \\
2.02 \\
4.43 \\
0.37 \\
5.35\end{array}$ & \\
\hline MsTh & $\begin{array}{l}\text { FIM5*4 } \\
\text { F2M4 } \\
\text { F2M5 } \\
\text { FIM4 } \\
\text { FIM3 }\end{array}$ & $\begin{array}{l}232 \\
777 \\
780 \\
841 \\
918\end{array}$ & $\begin{array}{l}1.5 \\
2.0 \\
0.4 \\
1.0 \\
2.0\end{array}$ & $\begin{array}{r}10.4 \\
10.4 \\
4.0 \\
4.8 \\
6.4\end{array}$ & $\begin{array}{l}14.3 . \\
17.8 \\
11.0 \\
13.0 \\
14.0\end{array}$ & $\begin{array}{l}48.0 \\
34.0 \\
14.0 \\
31.8 \\
24.6\end{array}$ & $\begin{array}{r}1.7 \\
15.8 \\
13.6 \\
5.4 \\
8.0\end{array}$ & $\begin{array}{c}0.2 \\
0 \\
0.6 \\
0 \\
0\end{array}$ & $\begin{array}{l}\text { C.1 } \\
0.8 \\
c .6 \\
0.4 \\
0.4 \\
0.2\end{array}$ & $\begin{array}{l}0.9 \\
0.6 \\
0.2 \\
0.2 \\
0.6\end{array}$ & $\begin{array}{l}3.7 \\
0.6 \\
1.4 \\
0.2 \\
0.2\end{array}$ & $\begin{array}{l}80.9 \\
72.2 \\
45.8 \\
46.6 \\
56.0\end{array}$ & $\begin{array}{c}0.9 \\
0 . \\
0 \\
0 \\
0\end{array}$ & $\begin{array}{l}0.7 \\
0 \\
0.4 \\
0.6 \\
0\end{array}$ & $\begin{array}{l}16.3 \\
17.4 \\
52.6 \\
42.2 \\
43.0\end{array}$ & $\begin{array}{l}17.8 \\
17.4 \\
53.0 \\
42.8 \\
43.0\end{array}$ & $\begin{array}{l}1.6 \\
8.6 \\
1.2 \\
0.6 \\
1.0\end{array}$ & $\begin{array}{l}4.54 \\
4.71 \\
0.86 \\
1.30 \\
1.30\end{array}$ & \\
\hline $\mathrm{Sr}$ & FIS5 & 960 & 0.2 & 4.8 & 11.6 & 11.6 & 10.2 & $\mathrm{c}$ & 2.0 & 0.2 & 0.2 & 40.8 & 0 & 0.6 & $56.0^{\circ}$ & 56.6 & 2.6 & 0.72 & \\
\hline
\end{tabular}

* From femurs and reported as $\%$ of total cells counted (500 - 1000 Cells)

** Values obtained from humeris in M2T5, MIT5 and FIM5. 
in blood eosinophils. In most of the dogs there is a greater percentage of the early forms of pmns, -promyelocytes, myelocytes and metamyelocytes- than is seen normally (shift to the left) and also an atypical development with premature segmentation, atypical granulation etc. The developing of red cells do not show thịs shift to the left seen in the white cell series. 
MICRORAD IOGRAPHIC STUDIES OF CORT ICAL BONE OF CHRONIC TOXICITY DOGS

Webster S. S. Jee and James S. Arnold*

Microradiograms of bone sections from seven beagles have been examined. Three animals had radium burdens, two had radiothorium burdens, and two had plutonium burdens. Cross sections of the humeral shaft $(25-75 \mu \mathrm{c})$ were prepared by the method of the authors (1). The microradiograms were taken with a $6 \mathrm{Kv}$ Machlett $\mathrm{x}$-ray tube using Lipmann film in an apparatus similar to Engstrom and Wegstedt (2).

The microradiographic appearance of the 4-level radiothorium bones is characterized by abnormal, highly calcified Haversian systems, hypercalcified plugs of central canals of Haversian systems and large areas of resorption (fig. 1). The abnormal hypercalcified Haversian systems exhibited loss of the orderly arrangement of concentric lamellae and lacunae.

The appearance of 5-level radium bones is characterized by few highly calcified Haversian systems, hypercalcified plugs in central canals and large areas of resorption (fig. 2). The 4-level radium bones exhibited Haversian systems with a border of highly calcified bone and large areas of resorption (Figs. 3 and 4). Recently, these identical changes were described in a microradiographic study by Rowland, Jowsey and Marshall (3) in cortical bones of eleven radium patients.

The hypercalcified Haversian systems and highly calcified plugs of central canals are detectable as basophilic staining masses in celloidin sections stained with hematoxylin and eosin.

Correlation of these abnormal sites with isotopic distribution and dose will be studied and reported later.

b..........

* Present address: U. S. Naval Radiological Defense Laboratories, San Francisco, California. 


\section{References}

(1) Arnold, J. S. and Jee, W. S. S., Preparing bone sections for radioautography. Stain Technol.; 29: 49-54, 1954.

(2) Engstrom, A. and Wegstedt, I. Equipment for microradiography with soft roentgen rays. Acta radiol., 35:345-55, 1951.

(3) Rowland, R. E., Jowsey, J. and Marshall, J. H. The microradiographic appearance of radium damaged bones. Abstracts of papers presented before the Radiation Research Soc. Rochester, May 13-15, p55, 1957. 
Figure 1: A microradiogram of the humeral shaft from a beagle which received a burden of $0.88 \mu \mathrm{c} / \mathrm{kg}$ of radiothorium and was sacrificed at 645 days (MIT). Note the large atypical hypercalcified area and the frequent areas of resorption $(x 300)$.

Figure 2. A microradiogram of the humeral shaft from a beagle which received a burden of $10.5 \mu \mathrm{c} / \mathrm{kg}$ of radium and was sacrificed at 908 days (MIR5). Note the arrows pointing to hypercalcified plugs in the central canals of three Haversian systems. Also note large areas of resorption $(x 100)$. 


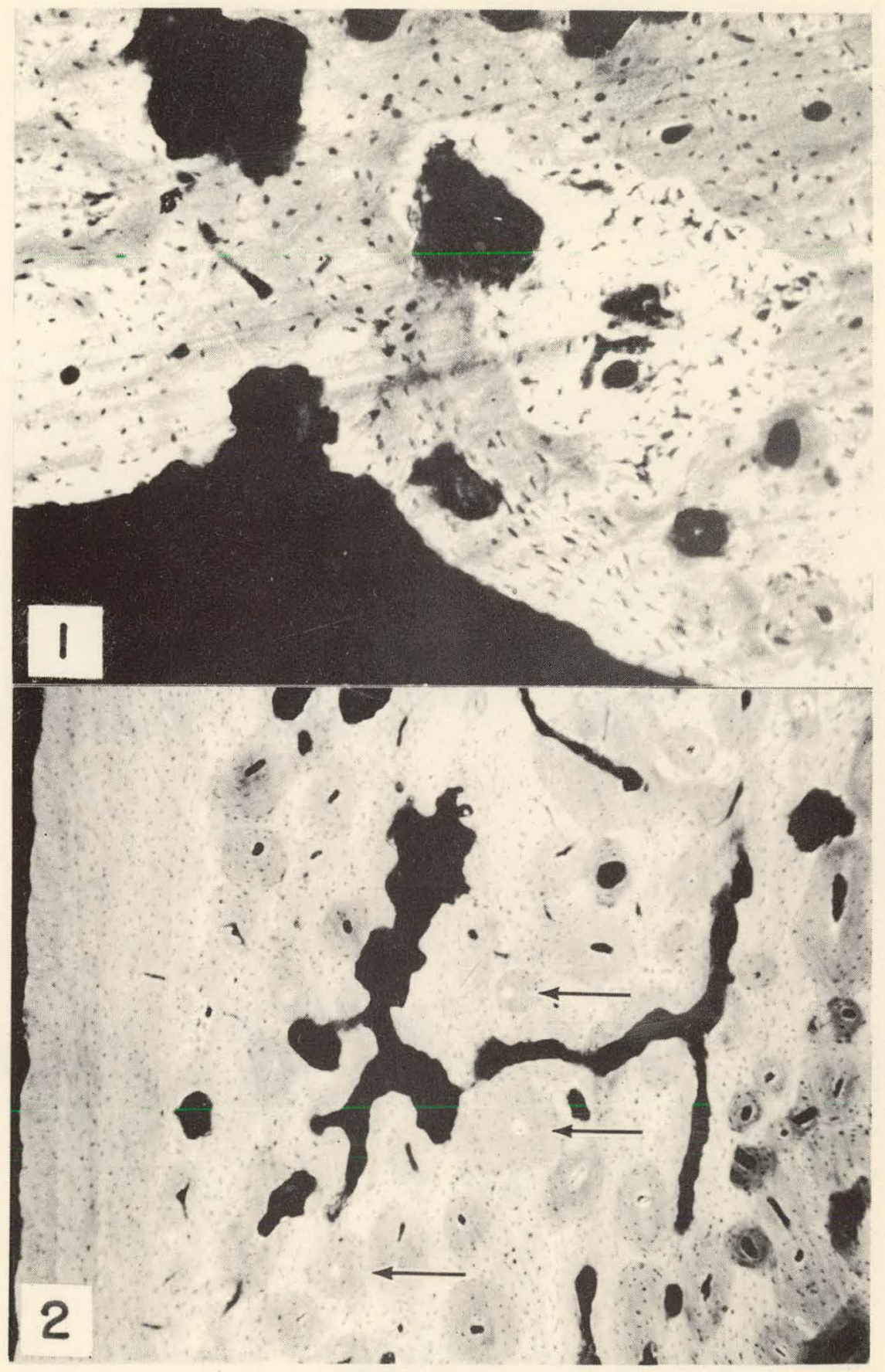


Figure 3. A nicroradiogram of the humeral shaft from a beagle which received a burden of $3.33 \mu \mathrm{c} / \mathrm{kg}$ of radium and was sacrificed at 490 days (F3R4). The arrow points to an abnormal Haversian system with a collar of hypercalcified bone. Note large areas of resorption and the absence of hypercalcified plugs in central canals ( $x l 00)$.

Figure 4. Contact radioautogram of the corresponding area in figure 3. Note the arrow pointing to the site of the abnormal Haversian system where there is no localization of radium $(x \perp 00)$. 

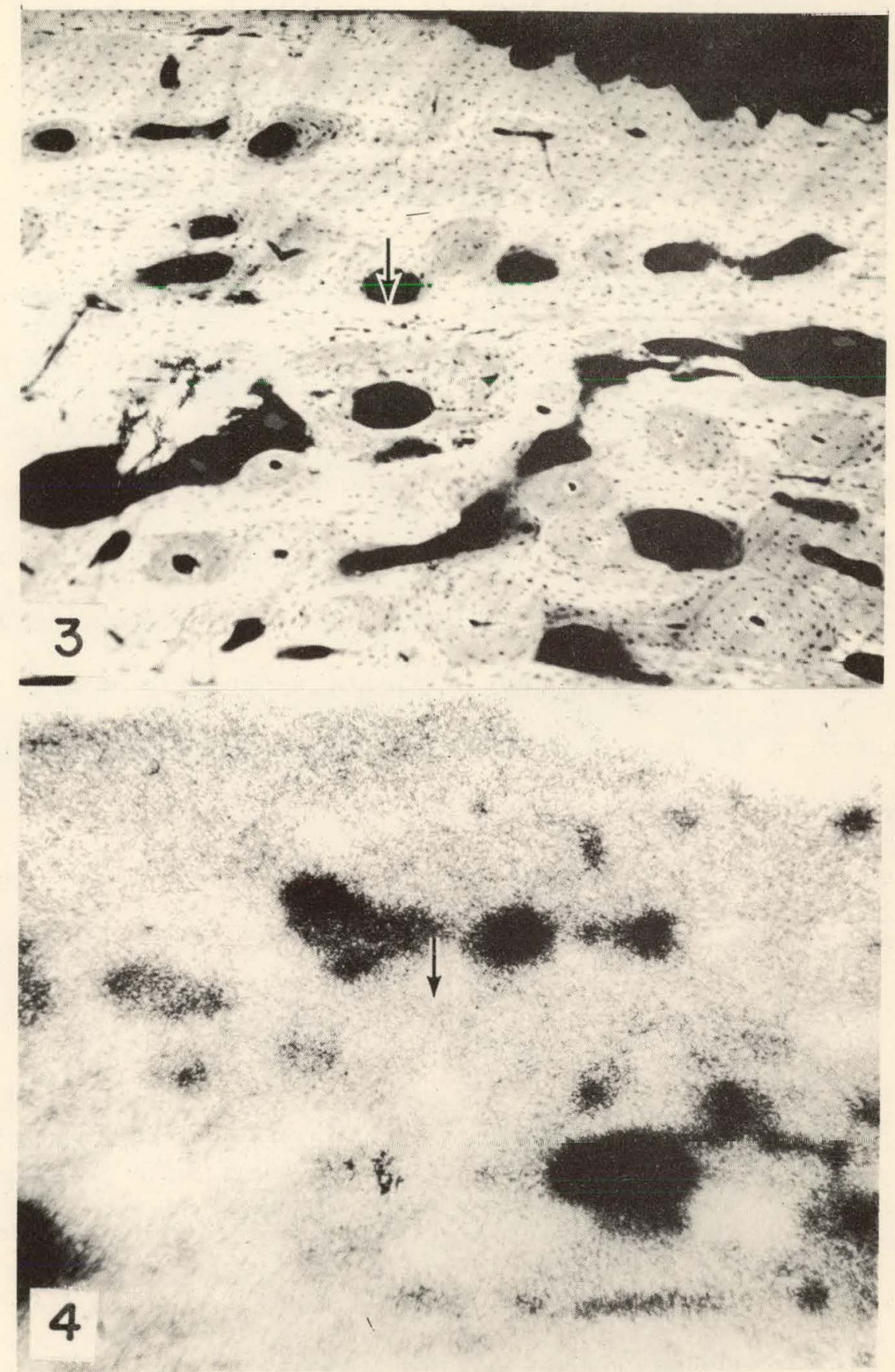
THE FAILURE OF PLUTONIUM TO DEPOSIT IN THE OSTEOD OF RACHITIC RATS W. S. S. Jee, C. R. Mott*, J.S. Arnold** and R. Mical

Abstract: A detailed radioautographic study of rachitic rats injected with plutonium demonstrates that plutonium passed through the osteoid and deposited on the underlying calcified bone surfaces.

Early investigations on the behavior of plutonium 239 demonstrated that it deposits rapidly on bone surfaces $(1,2,3,4)$. In one of these early papers by Copp et.al. (3), these investigators radioautographically localized the plutonium binding to the uncalcified organic bone matrix. Using phosphorous deficient rachitic rats, they stated "plutonium was actively laid down in the uncalcified organic bone matrix below the epiphyseal cartilage and in the endosteum and periosteum". However, Foreman (5) recently demonstrated that the mineral component of bone in various forms concentrates plutonium ions in vitro. With these opposing results in mind, we repeated the experiment of Copp et. al. using standard rachitic rats and more refined radioautographic techniques。

Five three weeks old female Sprague-Dawley rats weighing 45 grams were weaned to the standard rachitogenic diet (6) as follows:

$\begin{array}{lr}\text { Ground yellow corn } & 76 \text { per cent } \\ \text { Wheat gluten } & 20 \text { per cent } \\ \text { Calcium carbonate (USP) } & 3 \text { per cent } \\ \text { Sodium chloride (USP) } & 1 \text { per cent }\end{array}$

At 6 weeks of age, the 5 rachitic rats weighing $90 \mathrm{gm}$. along with 5 control rats of identical age weighing $150 \mathrm{gm}$. were injected intraperitoneally with $1 \mu \mathrm{c} / \mathrm{kg}$ of $\mathrm{Pu}^{239}$ as the citrate (7). All rats were sacrificed after 24 hours. The femurs and tibiae were split, fixed in acetone, embedded in plasticized nitrocellulose and sectioned (undecalcified) at 8 microns. Detailed radioautograms were prepared using strip film and stained with hematoxylin and eosin (8). Adjacent sections, * Late assistant Professor of Biology, Department of Biology, University of Utah. ** Present address: U. S. Naval Radiological Defense Laboratory, San Francisco, California. 
serial when possible, were stained by the von Kossa technique to demonstrate mineralized bone.

In the control rats the plutonium localized selectively on calcified bone surfaces, e.g. beneath the endosteum, periosteum and about vascular channels: In rachitic rats, the plutonium penetrated the osteoid layer and deposited on the underlying calcified bone surfaces as shown in $f$ ig. 1 which is a detailed radioautogram of the femoral shaft of a rachitic rat. The section show in fig. 2 is adjacent to fig. I and is stained with the von Kossa technique to demonstrate mineralized bone. Note that the bone without the von Kossa reaction (blackening) is the broad layer of eosinophilic staining uncalcified organic matrix; the osteoid. The primary spongiosa of the femoral metaphysis in rachitic rats exhibited a broad plate of osteoid with isolated islands of calcified bone containing plutonium." "In the controls, the primary spongiosa contained fine trabeculae with their surfaces lined with plutonium.

Our results and the previous findings by Foreman (4) strongly suggest that the mineral, rather than the organic matrix, is the site where plutonium binds. However, experiments performed by the authors (9) demonstrated that about 50-60\% of the plutonium which deposited in vivo was not removed from acetone fixed bone sections by prolonged and repeated decalcification in $1 \%$ nitric acid. Radioautographs of these decalcified sections showed that about half of the remaining plutonium was in the organic component and the other half showed the original in vivo pattern. A possible explanation of the above observation is that when plutonium is released from dissolved mineral, it is absorbed by the adjacent organic material.

\section{References}

(1) Hamilton, J. H., The metabolism of the fission products and the heaviest elements. Radiology, 49:325-343, 1947 .

(2) Scott, K. G., Axelrod, D. J., Fisher, H., Crowley, J. F. and Hamilton, J. G.; The metabolism of plutonium in rats following intramuscular injection. 
J. Biol. Chem. 176: 283-293, 1948.

(3) Copp, D. H., Axelrod, D. J. and Hamilton, J. G.; The deposition of radioactive metals in bone as a potential health hazard. Amer. J. Roentgenol. 58:10-16,1947.

(4) Arnold, J. S. and Jee,W.'S. S., Bone growth and osteoclastic activity as indicated by radioautographic distribution of plutonium, Amer. J. Anat. in press.

(5) Foreman, H., personal communication.

(6) Hawk, P. B., Oser, B. I.; and Summeson, Assay of Vitamin A and D in Practical Physiological Chemistry, the Blakiston Co.; Inc. New York pp 1261, 1954.

(7) Stover, B. J., Summary of plutonium studies in Second Annual Conference on Radium, Plutonium and Mesothorium pp 18-31, 1954.

(8) Arnold, J. S. and Jee, W. S. S., Embedding and sectioning undecalcified bone and its application to radioautography。 Stain Tech. 29:225-229, 1954.

(9) Arnold, J. S. and Jee, W. S. S., unpublished observations. 
THIS PAGE

\section{WAS INTENTIONALLY LEFT BLANK}


Figure 1. A detailed radioautogram of the femoral shaft from a rat weaned to a rachitogenic diet at three weeks, injected intraperitoneally at six weeks with 1 . $\mathrm{Pu} 239 / \mathrm{kg}$, and sacrificed 24 hours later. Note the deposits of Pu239 on the surface of the calcified bone. The uncalcified osteoid matrix is indicated by arrows ( 5550$)$.

Figure 2. An alternate undecalcified bone section of the radioautogram in figure 1. The section is stained with hematoxylin, eosin and silver nitrate to demonstrate mineralized bone. Note the pale eosinophilic osteoid layer (indicated by arrows) adjacent to the endosteum containing irregular islands of calcified bone ( $x 550)$. 


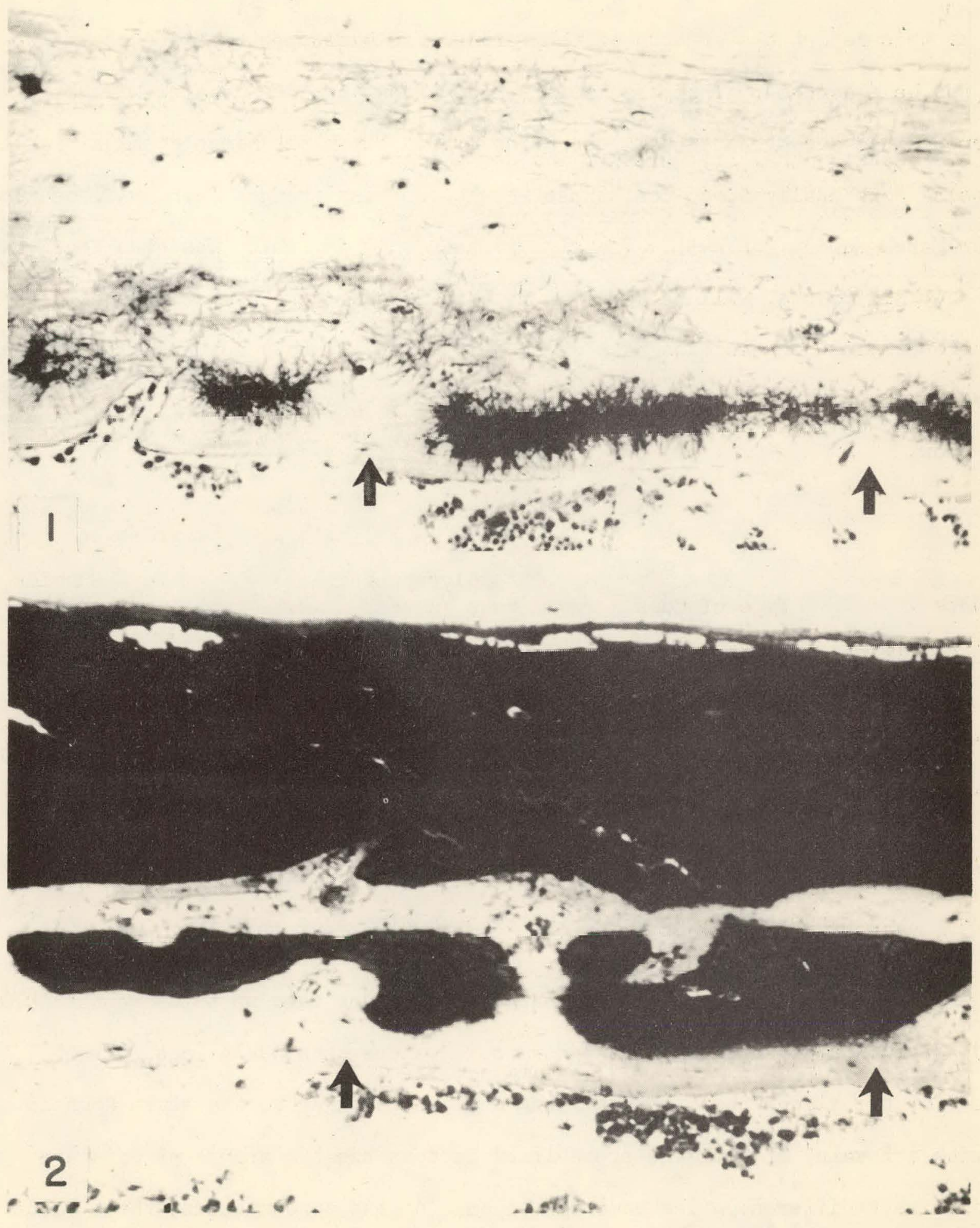




\section{BIOCHEMISTRY REPORT}

\section{H. C. Goldthorpe and Swanson Bennett}

In this report the effects of the various radioisotopes on blood chemistry will not be discussed. There is no reason to think that any changes will have occurred since our March annual report for 1957. The basic blood chemical results are being continually added too, those results and any changes found will be reported in our March report for 1958. The glycoprotein program, which has been accelerated this past six months, will be taken up in this report. The number of analysis of glycoprotein and sero-mucoids have reached 165 each. Many young animals have been added. The addition of these young animals has changed the mean values as Table I will show.

\section{Table I*}

Date Type of dogs

March 31, 1957

68 adult dogs \&

7 young 60 day dogs

Sept. 30, $1957 \quad 103$ adult dogs

Sept. 30, 1957

Sept. 30, 1957
103 adult dogs \&

62 young dogs

62 young dogs
Glycoprotein

Mean Values S.D.

100.3

$\neq 14.2$

$99.6 \quad \neq 15.8$

94.4

$\neq 18.9$

$85.8 \quad \neq 20.5$
Sero-Mucoids Mean Values S.D.

19.3 $\pm 6.5$

8.0 $\$ 7.5$

17.0 $\$ 7.1$ 15.3 $\$ 6.2$

* Under 19 months young dogs, over 19 months adult dogs.

Analysis of the $t a b l e$ shows definately that young dogs up to 19 months (570 days) have lower glycoprotein and sero-mucoid values than adult dogs. The $t$ values for the glycoprotein of the young dogs as compared to the adult dogs is 4.5 with a $P$ value of 0.01 the probability is that the two groups of dogs are significantly different. The same can be said of the sero-mucoids, the $t$ value being 2.3 with a $P$ value of 0.02 . In our March report having only a few values to report for young dogs we could not be sure if the sero-mucoid values for young dogs were lower than adult dogs, but adding to the number of young dogs studied 
we can now be sure that the values for young dogs are lower than for adult dogs. The sero-mucoids make up about the same percentage of the glycoproteins in both sets of dogs namely, 18.0 per cent in normal animals:

The graph shown in the March report of a mixed group of dogs can be enlarged now by adding young dogs. It also shows that the values of both glycoprotein and sero-mucoid are lower in youth, rise to adult values around 19 months of age and stay at a fairly level value through adult life. We do not have enough values for old dogs to determine if the values remain constant, rise or fall in that group. Values for individual dogs are shown in Table II. These are young dogs, male and female. The average values of the six dogs are shown on Table III. These tables show the rise in glycoprotein and sero-mucoid values of serum from youth to adult life.

Table II

Individual Dogs

$\begin{array}{lrcc}\text { Dog } & \text { Days } & \text { Glyco } & \text { Sero } \\ & & & \\ 423 \mathrm{M} & 60 & 84 & 17.8 \\ 423 \mathrm{M} & 445 & 128 & 18.2 \\ & & & \\ 425 \mathrm{M} & 60 & 93 & 20.9 \\ 425 \mathrm{M} & 445 & 131 & 18.5 \\ & & & \\ 427 \mathrm{M} & 60 & 87 & 14.4 \\ 427 \mathrm{M} & 446 & 123 & 19.2 \\ & & & \\ 429 \mathrm{M} & 60 & 85.5 & 13.1 \\ 429 \mathrm{M} & 451 & 112.0 & 37.7 \\ & & & \\ 424 \mathrm{~F} & 60 & 88.5 & 23.4 \\ 424 \mathrm{~F} & 445 & 136 & 18.5 \\ 426 \mathrm{~F} & 60 & 84.0 & 21.8 \\ 426 \mathrm{~F} & 445 & 133 & 19.2\end{array}$

Table III

$\begin{array}{cccc}\text { Days } & \text { Dog } & \text { Glyco } & \text { Sero } \\ 60 & 6 & 87 & 18.6 \\ 445 & 6 & 127.1 & 21.9\end{array}$


Individual values for adult dogs. We have gathered together values for individual dogs, made a table for female dogs and one for male dogs.

Table IV

Nine Adult. Female Dogs

\begin{tabular}{|c|c|c|c|}
\hline D॰g & Days & Glyco & Sero \\
\hline $\begin{array}{l}\text { F2PO } \\
\text { F2PO }\end{array}$ & $\begin{array}{l}1648 \\
1860\end{array}$ & $\begin{array}{r}96.9 \\
100.5\end{array}$ & $\begin{array}{l}20.3 \\
15.7\end{array}$ \\
\hline $\begin{array}{l}\text { FIMO } \\
\text { FIMO }\end{array}$ & $\begin{array}{l}1668 \\
1840\end{array}$ & $\begin{array}{l}94.5 \\
96.9\end{array}$ & $\begin{array}{l}13.1 \\
20.3\end{array}$ \\
\hline $\begin{array}{l}\text { F6PO } \\
\text { F6PO }\end{array}$ & $\begin{array}{l}1227 \\
1505\end{array}$ & $\begin{array}{r}99.6 \\
136.0\end{array}$ & $\begin{array}{l}18.5 \\
14.4\end{array}$ \\
\hline $\begin{array}{l}\text { F3R0 } \\
\text { F3R0 }\end{array}$ & $\begin{array}{l}1520 \\
1689\end{array}$ & $\begin{array}{l}108.5 \\
123.9\end{array}$ & $\begin{array}{l}24.8 \\
34.1\end{array}$ \\
\hline $\begin{array}{l}\text { F9RO } \\
\text { FGRO }\end{array}$ & $\begin{array}{l}1272 \\
1424\end{array}$ & $\begin{array}{l}100.2 \\
* 76.0\end{array}$ & $\begin{array}{l}18.5 \\
10.8\end{array}$ \\
\hline $\begin{array}{l}\text { FACl3 } \\
\text { FACl3 }\end{array}$ & $\begin{array}{l}1641 \\
2106\end{array}$ & $\begin{array}{r}99 \\
110\end{array}$ & $\begin{array}{l}18.7 \\
17.5\end{array}$ \\
\hline $\begin{array}{l}\mathrm{FACl}_{4} \\
\mathrm{FACl}_{4}\end{array}$ & $\begin{array}{l}1671 \\
2064\end{array}$ & $\begin{array}{r}99 \\
113\end{array}$ & $\begin{array}{l}22.8 \\
21.8\end{array}$ \\
\hline $\begin{array}{l}\text { FACl5 } \\
\text { FACl5 }\end{array}$ & $\begin{array}{l}1488 \\
1976\end{array}$ & $\begin{array}{r}93 \\
105\end{array}$ & $\begin{array}{l}16.3 \\
16.8\end{array}$ \\
\hline $\begin{array}{l}\text { FACl7 } \\
\text { FACl7 }\end{array}$ & $\begin{array}{l}1238 \\
1847\end{array}$ & $\begin{array}{r}* 110 \\
107\end{array}$ & $\begin{array}{l}27.6 \\
23.0\end{array}$ \\
\hline
\end{tabular}

151. 071 
Ten Adult Male Dogs

\begin{tabular}{|c|c|c|c|}
\hline Dog & Days & Glyco & Sero \\
\hline $\begin{array}{l}\text { MAC6 } \\
\text { MAC6 }\end{array}$ & $\begin{array}{l}3299 \\
3664\end{array}$ & $\begin{array}{r}109 \\
65\end{array}$ & $\begin{array}{r}23.4 \\
9.1\end{array}$ \\
\hline $\begin{array}{l}\text { MAC7 } \\
\text { MAC7 }\end{array}$ & $\begin{array}{l}2292 \\
2649\end{array}$ & $\begin{array}{l}136 \\
74.5\end{array}$ & $\begin{array}{l}24.2 \\
17.9\end{array}$ \\
\hline $\begin{array}{l}\text { MAC8 } \\
\text { MAC8 }\end{array}$ & $\begin{array}{l}1984 \\
2340\end{array}$ & $\begin{array}{l}99 \\
56\end{array}$ & $\begin{array}{r}17.5 \\
9.3\end{array}$ \\
\hline $\begin{array}{l}\text { M3PO } \\
\text { M3PO }\end{array}$ & $\begin{array}{l}1653 \\
1975\end{array}$ & $\begin{array}{l}112.5 \\
102 .\end{array}$ & $\begin{array}{l}13.1 \\
19.0\end{array}$ \\
\hline $\begin{array}{l}\text { MIRO } \\
\text { MIRO }\end{array}$ & $\begin{array}{l}1738 \\
2017\end{array}$ & $\begin{array}{r}115.5 \\
* 117.0\end{array}$ & 16.6 \\
\hline $\begin{array}{l}\text { M/RO } \\
\text { M/4RO }\end{array}$ & $\begin{array}{l}1366 \\
1522\end{array}$ & $\begin{array}{r}125.7 \\
83.0\end{array}$ & $\begin{array}{l}28.0 \\
12.8\end{array}$ \\
\hline $\begin{array}{l}\text { MSRO } \\
\text { MSRO }\end{array}$ & $\begin{array}{r}923 \\
1550\end{array}$ & $\begin{array}{r}108.2 \\
92.8\end{array}$ & $\begin{array}{l}42.8 \\
20.2\end{array}$ \\
\hline $\begin{array}{l}\text { MIORO } \\
\text { MIORO }\end{array}$ & $\begin{array}{r}994 \\
1254\end{array}$ & $\begin{array}{l}109.4 \\
* 113 .\end{array}$ & $\begin{array}{l}22.4 \\
13.2\end{array}$ \\
\hline $\begin{array}{l}\text { M8PO } \\
\text { M8PO }\end{array}$ & $\begin{array}{l}1197 \\
1316\end{array}$ & $\begin{array}{l}114.1 \\
* 120.1\end{array}$ & $\begin{array}{l}32.8 \\
18.3\end{array}$ \\
\hline $\begin{array}{l}\text { MITO } \\
\text { MITO }\end{array}$ & $\begin{array}{l}1297 \\
1492\end{array}$ & $\begin{array}{r}109.5 \\
93.0\end{array}$ & $\begin{array}{l}15.1 \\
18.6\end{array}$ \\
\hline
\end{tabular}

* Three exceptions show an increase。

The female dogs with two exceptions seem to have an increase in glycoprom tein values with time as the factor, the average increase being $7.5 \mathrm{mg} / 100 \mathrm{ml}$ serum. Nothing can be said in regard to the seromucoids, there is a slight average decrease of $0.7 \mathrm{mg} / 100 \mathrm{ml}$ serum but this is not significant. Table $\mathrm{V}$ for the adult male dogs shows a difference in that male dogs, with three exceptions, show a decline in the average values of $22.5 \mathrm{mg} / 100 \mathrm{ml}$ for the glycoproteins and with an average decline if $7.6 \mathrm{mg} / 100 \mathrm{ml}$ in the seromucoid values. Whether these findings are "real" for female and male dogs is not definite for upon making up separate tables for male and female dogs over 19 months old the differences shown for the 
individual dogs does not show up to any great extent for the two groups.

Table VI

Adult dogs over 19 months old

$\begin{array}{lccccc} & \text { No. Dogs } & \text { Glyco values } & \text { S.D. } & \text { Sero values } & \text { S.D. } \\ \text { Male } & 42 & 97.7 & \$ 18.6 & \ddots .18 .2 & 8.0 \\ \text { Female } & 58 & 100.8 & \neq 15.2 & 17.7 & 7.3\end{array}$

The females have a slightly higher glycoprotein value and a slightly lower seromucoid value as indicated by the tendency in individual dogs as show in Tables IV and $V$. However, applying the t test to the values of table VI gave 0.9 for the male with a $P$ value of 0.3 and 0.3 for the females with $P$ value of 0.7 . Neither being significant as different groups.

THE EFFECT OF ENVIRONMENTAL TEMPERATURE UPON GLYCOPROTEIN AND SEROMUCOID VALUES. Another factor which may effect the values of these two groups of proteins is environmental temperature. We have gathered together the values found for all dogs for the months of June, JuIy, August and the first four days of September and compared them with values from dogs whose blood was drawn during the months of November December, January and February. All were adult dogs, male and female.

Table VII

Effect of Environmental Temperature

\begin{tabular}{|c|c|c|c|c|c|}
\hline . & No. Dogs & $\begin{array}{l}\text { Glyco } \\
\mathrm{mg} / \mathrm{I} 00 \mathrm{ml}\end{array}$ & $S . D$. & $\begin{array}{l}\text { Sero } \\
\mathrm{mg} / \mathrm{l} 00 \mathrm{ml}\end{array}$ & S.D. \\
\hline Sunmer & 40 & 96.6 & $\neq 12.1$ & 16.6 & $\$ 4.0$ \\
\hline Winter & 21 & 101.5 & 11.3 & 19.8 & $=8.6$ \\
\hline
\end{tabular}


From table VII it appears that higher values are found both for glycoprotein and seromucoid during the winter months. Applying the $t$ test to glycoprotein gives a value of 1.5 with a $P$ value of $>0.1$ the results therefore not being too signific cant while the seromucoids upon comparison give a t test value of 1.9 and a $P$ value of <0.I making them significant. This will be checked again when more values for the two periods are available. 
A SUNMARY OF THE Ra228(MisTh) INJECTION SOLUTIONS

Betsy J. Stover and David R. Atherton

Abstract: Injection of the F7M group on June 4, 1957 completes our current Ra 228 injection program, and a description of the ehemistry and radioactivity of the various $\mathrm{Ra}^{228}$ injection solutions appears below. .

\section{A. FlM group.}

The FIM group's injection solutions were prepared by diluting the $\mathrm{Ra}^{228}$ stock solution with isotonic $\mathrm{NaCl}$ solution which had been adjusted to $\mathrm{pH}=2$ with $\mathrm{HCl}$, (the same method used for the $M I R$ and $M 2 R$ groups). The determination of $\mu \mathrm{c}^{\prime} \mathrm{s} R \mathrm{a}^{228}$ and $\mathrm{Th}^{228}$ injected was based on Dr. Grove's original measurements of the stock solution. $\mu \mathrm{c}^{\prime} \mathrm{s} \mathrm{Th}^{228}$ injected $=0.15 \mu \mathrm{c}$ 's $\mathrm{Ra}^{228}$ injected.

B. F2M and $\mathrm{M} 3 \mathrm{M}$ groups.

For the F2M and M3M groups' injection solutions, $\mathrm{Th}^{228}$ was separated from $\mathrm{Ra}^{228}$ a month prior to the injection. For the F2M group, Th228 was extracted with TTA (thenoyltrifluoracetone) in benzene; for the M3M group, $\mathrm{Th}^{228}$ was coprecipitated with $\mathrm{La}(\mathrm{OH})_{3}$ Citric acid, sodium citrate buffer solution, $\mathrm{pH}=3.5$ and $\Sigma$ citrate $=0.08 \mathrm{M}$, served as the diluting fluid in both cases. The determination of $\mu c^{\prime} s \mathrm{Ba}^{228}$ and $\mathrm{Th}_{2} 28$ injected was based on gamma measurements made by M. A. Van Dilla which were standardized using ampoules of $\mathrm{Ra}^{2} 2 \mathrm{~L} 8\left(+\mathrm{Th}^{228}\right)$ and $\mathrm{Th}^{228}$ which had been evaluated by Dr. Grove. $\mu c^{\prime} s \mathrm{Th}^{228}$ injected $=3 \times 10^{-2} \mu \mathrm{c}^{\prime} \mathrm{s} \mathrm{Ra}^{228}$ injected.

C. M4M, F5M, M6M, F7M groups。

For these groups' injection solutions, $\mathrm{Th}^{228}$ was separated six days prior to

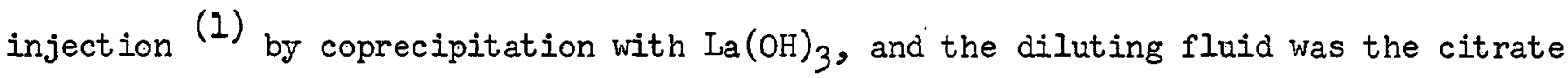
buffer described above. Determination of $\mu \mathrm{c}^{\prime} \mathrm{s} \mathrm{Ra}^{228}$ and $\mathrm{Th}^{228}$ injected was based on absolute beta counting $(2)$ and alpha counting $(1) \cdot \mu \mathrm{c}^{\prime} \mathrm{s} \mathrm{Th}^{228}$ injected $=6 \times 10^{-3}$ $\mu c^{\prime} s \mathrm{Ra}^{228}$ injected. 
D. Comparison with $\mathrm{Th}^{228}$ dose levels.

Since $\mathrm{Th}^{228}$ is retained to a much greater extent than $\mathrm{Ra}^{228}$, the "contamination" dose of $\mathrm{Th}^{228}$ becomes quite significant even when the contamination is minimized. This is illustrated by the following example.

Let $A(n)=$ "desired retained" $\mu \mathrm{c} / \mathrm{kg}$ for dose level $\mathrm{n}$,

$W=$ weight of $\mathrm{dog}$, and

$\mathrm{k}=$ fractional contamination $\left(=\mu \mathrm{c}^{\prime} \mathrm{s} \mathrm{Th}^{228} / \mu \mathrm{c}^{\prime} \mathrm{s} \mathrm{Ra}^{228}\right)$ in injection solution.

Then the injected dose for a mesothorium dog of dose level Mn is $4 \mathrm{~A}(\mathrm{n}) \mathrm{W} \mu \mathrm{c} \mathrm{Ra}^{228}+k 4 \mathrm{~A}(\mathrm{n}) \mathrm{W} \mu \mathrm{c} \mathrm{Th}^{228}$.

Remembering that the injected dose for a radiothorium dog of dose level in is $1.11 \mathrm{~A}(\mathrm{n}) \mathrm{W} \mu \mathrm{c} \mathrm{Th}^{228}$,

it is seen that dog Mn will be injected with as many $\mu c^{\prime} s \mathrm{Th}^{228}$ as is dog $\mathrm{Tn}$ when $k=1.11 / 4=0.28$.

Consider an M5 dog for which $k=0.03$. The injected dose is $4 \times 2.5 \times$ W $\mu \mathrm{c} \mathrm{Ra} 228+$ $0.03 \times 4 \times 2.5 \mathrm{~W} \mu \mathrm{c} \mathrm{Th}^{228}=10 \mathrm{~W} \mu \mathrm{c} \mathrm{Ra} 228+0.3 \mathrm{~W} \mu \mathrm{c} \mathrm{Th}{ }^{228}$.

The injected dose for a T3 dog is $1.11 \times 0.27 \mathrm{~W} \mu \mathrm{c} \mathrm{Th}{ }^{228}=0.3 \mathrm{~W} \mu \mathrm{c} \mathrm{Th}^{228}$, which is equal to the contamination $\mathrm{Th}^{228}$ given the M5 dog.

The following table relates the injected doses of $\mathrm{Th}^{228}$ received by the mesothorium dogs to the injected doses of $\mathrm{Th}^{228}$ of the radiothorium dogs. The purpose is to provide a guide for those in the biological groups who wish to make rough comparisons of early effects of various isotopes.

\section{TABLE I}

Injected $\mathrm{Th}^{228}$ Equivalence

\begin{tabular}{|c|c|c|c|}
\hline Dose Level & $k=0.15$ & $k=0.03$ & $k=0.006$ \\
\hline M5 & $1 / 2 \mathrm{~T} 5$ & T3 & $2 / 3 \mathrm{~T} 2$ \\
\hline & $1 / 2 \mathrm{~T} 4$ & T2 & $2 / 3 \mathrm{Tl} .5$ \\
\hline $\begin{array}{l}\text { M3 } \\
\text { M2 }\end{array}$ & $\begin{array}{l}1 / 2 \text { T3 } \\
1 / 2 \\
\text { T2 }\end{array}$ & $\mathrm{TI}_{\mathrm{T}} .5$ & $2 / 5 \mathrm{Tl}$ \\
\hline M2 & $1 / 212$ & $2 / 3 \mathrm{Tl}$ & $2 / 5 \mathrm{TO} .5$ \\
\hline MI & $1 / 2 \mathrm{TI}$ & $1 / 3 \mathrm{~T} 0.5$ & $1 / 15$ T0. \\
\hline
\end{tabular}


1. B. J. Stover et.al, Chemistry group report, Annual Progress Report, March 31, 1957, pp 135-136.

2. M. A. Van Dilla, Absolute assay of $\mathrm{Ra}^{228}$, Annual Progress Report, March 31, 1957, pp. 149-150. 
STUDIES OF THE STATE OF PLUTONIUM, THORIUM AND RADIUM IN BEAGLE BLOOD

Betsy J. Stover and Nancy Keller

Abstract: Sera from $\mathrm{Pu}^{239}$ and $\mathrm{Th}^{228(\mathrm{RdTh})}$ dogs have been dialyzed against a variety of solutions. In beagle sera $\mathrm{Ra}^{224}$ is almost completely diffusible while $\mathrm{Pu}^{239}$ and $\mathrm{Th}^{228}$ are almost completely bound. Citrate ion forms a more stable complex with both plutonium and thorium than do the blood proteins, but the protein complexes are more stable than several others investigated.

I. $\quad P^{239}$

The binding of plutonium by plasma proteins was observed early in the study of plutonium metabolism. Painter, et al. (1), who studied plutonium in dogs, dialyzed heparinized plasma against $0.075 \mathrm{M}$ veronal buffer, $\mathrm{pH} 8.6$, and serum against $0.02 \mathrm{M}$ maleate buffer, $\mathrm{pH} 7.4$. In both cases, most of the plutonium remained in the sack after dialysis. In addition, the proteins were separated using a Tiselius electrophoresis apparatus. Most of the plutonium moved with the fraction containing $\beta$ globulin and fibrinogen, some with $\gamma$ globulin and fibrinogen, but very littie with the albumin and a globulin fraction. Their conclusion is that most of the plutonium in the blood is bound to globulins. Also, their studies show that the complex of plutonium with the protein is more stable than possible complexes which could be formed with the buffers used.

We have dialyzed sera from our $\mathrm{Pu}^{239}$ dogs against eight different solutions to compare the strength of the protein complex with the strengths of diffusible plutonium complexes. These studies are summarized in Table I. The sera used were collected at times ranging from one hour to one day after injection, and storèd at $2^{\circ} \mathrm{C}$.

:The serum sample, in Visking sausage casing, was suspended in the dialyzing solution, and the plutonium concentration of the solution was measured as a function of time. The dialysis systems were kept in the refrigerator (about $2^{\circ} C_{0}$ ) to minimize evaporation and growth of molds and bacteria. The first dialysis listed in Table. I, $\mathrm{D}-1$, using isotonic saline, showed that little, if any, of the serum plutonium existed 
as a diffusible complex. The F9P3 and F9P4 outside solutions showed no significant increase during the five days, while the F9P5 solution plutonium did increase. The result is borderline, and the possibility of a small leak in the dialysis bag cannot be excluded.

\section{TABLE I}

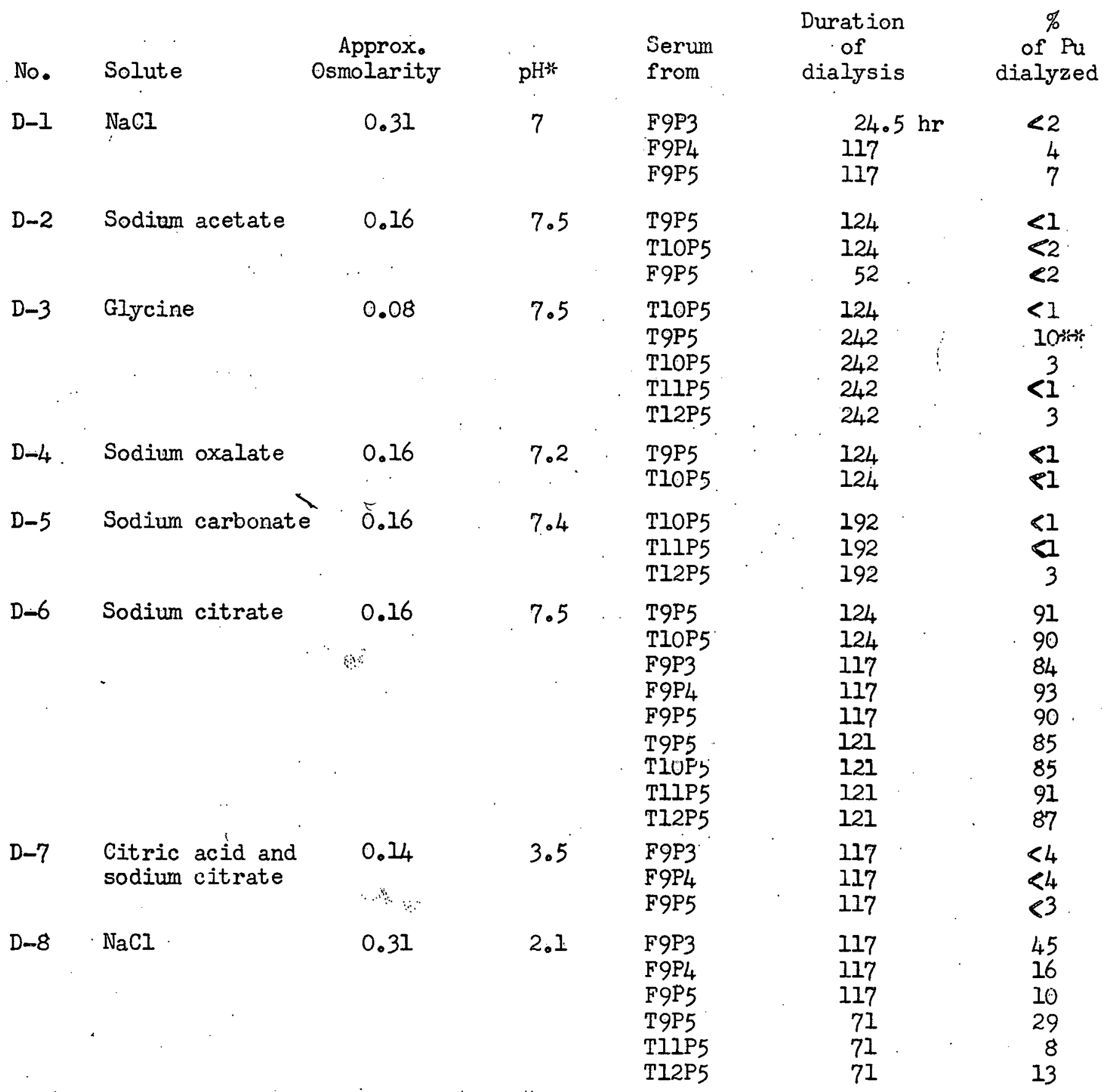

* $\mathrm{pH}$ adjusted with $\mathrm{NaOH}$ or $\mathrm{HCl}$, whichever appropriate. ** "buggy". 
Acetate (D-2), oxalate (D-4), and bicarbonate (D-5) ions all proved to be unsuccessful competitors for serum plutonium, as did glycine (D-3). The combination of glycine and serum proved an excellent culture medium. Plutonium in the outside solutions was negligible until the solutions became obviously "buggy". Then the plutonium began to diffuse out; two samples were left in the refrigerator 35 days, and at that time $77 \%$ and $57 \%$ of the plutonium appeared to be diffusible. This could result from some metabolic product of the organisms or from break-down of the proteins:

In contrast, citrate ion at $\mathrm{pH} 7.5$ (D-6) forms a stronger plutonium complex than does the protein. After five days dialysis, an average of $90 \%$ of the plutonium had been converted to a diffusible complex. The material remaining in the bag was also measured, and the concentration of plutonium was slightly higher than that of the outside solution. An average of $94 \%$ of the initial plutonium was accounted for.

Combining the results from the five different sera, a half-period of about nine hours for the appearance of plutonium in the outside solution was calculated. The plutonium concentration of the outside solution, $C_{t}$, is given by the following equation.

$$
C_{t}=\frac{0.9 P_{0} V}{V+V i} \quad\left(1-e^{-0.077 t}\right)
$$

where $P_{\odot}$ is the initial serum concentration, $V$ and $V$ the serum and citrate solution volumes, respectively, and $t$ is in hours. At $\mathrm{pH} 7.5$ almost all the citrate is present as $\mathrm{Cit}^{-3}$, and $\mathrm{PuCit}^{+}$may be the complex formed.

A citrate buffer of $\mathrm{pH} 3.5(\mathrm{D}-7)$ was also tried and the plutonium remained with the protein. This buffer is the one used to prepare the injection solutions and the citrate is present mainly as $\mathrm{H}_{2} \mathrm{Cit}-$ Dialyses of $\mathrm{Pu}^{239}$ injection solutions against this buffer at room temperature have shown the plutonium to be completely diffusible, and to appear in the outside fluid with a half-period of about two hours. This may indicate that the strengths of the plutonium complexes decrease in this order:

\section{$\mathrm{Cit}^{-3}>$ Protein $>\mathrm{H}_{2} \mathrm{Cit}^{-}$.}

Since the isoelectric points of the serum proteins lie between $\mathrm{pH} 3.5$ and 7.5 , the D-7 results may merely be the effect of the decreased $\mathrm{pH}$ on the protein. Sodium chloride of $\mathrm{pH} 2(\mathrm{D}-8)$ was also tried to see if $\mathrm{H}^{+}$. would displace plutonium from 
the protein. A variable but significant amount of plutonium was dialyzed from each serum sample. At the end of the dialyses the $\mathrm{pH}$ of the saline had increased to about 3. All of the plutonium could not be accounted for in the "inside plus outside" solutions indicating that some had been displaced from the protein and then adsorbed on various surfaces.

In conclusion, an exploratory study of the binding of plutonium by serum proteins shows that at $\mathrm{pH} 7$ to 7.5 , citrate forms a stronger $\mathrm{Pu}$ complex than the proteins, but acetate, glycine, oxalate, and carbonate do not。 At low $\mathrm{pH}_{2} \mathrm{H}^{+}$may displace Pu。

II. $\mathrm{Th}^{228}$ and $\mathrm{Ra}^{224}$

One set of dialysis experiments has been done using serum drawn from $\mathrm{T} 6 \mathrm{~T} 4$ and T7T3 at one hour after injection and four of the solutions used in the plutonium studies. These dialyses were also done at $2^{\circ} \mathrm{C}$; the outside solutions were sampled daily for five days and analyzed for both $\mathrm{Th}^{228}$ and $\mathrm{Ra}^{224}$.

The sampling schedule proved to be a poor guess for the results from the second day on were essentially the same. The dialyses are sumnarized in Table II. As expected, the $\mathrm{Th}^{228}$ results are quite similar to those for $\mathrm{Pu}^{239}$. (Other studies indicate that $\mathrm{Th}^{228}$ also is bound by the blood proteins.) Citrate at $\mathrm{pH} 7.5$ forms a stronger complex with thorium than the serum proteins do. The first day samples indicate that the half-period for the appearance of thorium in the outside solution is not far different from the 9 hours observed for plutonium.

TABIE II

\section{Solute}

1 Citric acid and sodium citrate

2 Sodium citrate

3 Sodium chloride

4 Sodium chloride
Approx. Osmolarity

$$
0.14
$$$$
0.16
$$

0.31

0.31
$\mathrm{pH}$

3.5

7.5

7

2
Serum

from

T6T4

T7T3

$\mathrm{T} 6 \mathrm{~T} 4$

T7T3

T6T4

T7T3

T6T4

T7T3 of Th dialyzed

$\% \mathrm{Ra}$ dialyzed

$\begin{array}{rc}10 & \sim 100 \\ 13 & \sim 100 \\ \sim 100 & - \\ 100 & - \\ 2 & \sim 100 \\ 13 . & \sim 100 \\ 15 . & \sim 100 \\ \sim 16 & \sim 100\end{array}$


The results with the two $\mathrm{NaCl}$ solutions are also similar to the plutonium results in that small variable amounts of thorium passed through the membrane. In the experiments with $\mathrm{pH} 3.5$ citrate buffer, plutonium and thorium do differ since some of the serum thorium is dialyzed. While $\mathrm{H}_{2} \mathrm{Cit}^{-}$is the main form present at $\mathrm{pH}$ 3.5, there is also a significant amount of HCit $=$ (and $\mathrm{H}_{3} \mathrm{Cit}$ ), and perhaps the HCit= ion is removing thorium from the proteins. Comparison of plasma concentrations of $\mathrm{Th}^{228}$ and $\mathrm{Pu}^{239}$ during the first day after injection suggests that the plutonium protein complex is stronger than the thorium complex. $\mathrm{Ra}^{224}$ diffused rapidly into the $\mathrm{pH} 3.5$ citrate and the two NaCl solutions in agreement with the almost complete diffusibility observed at Rochester ${ }^{(2)}$ for radium in rat blood. With $\mathrm{pH} 7.5$ citrate the results are not definitive since $\mathrm{Th}^{228}$ diffused out, too: However, the one day samples had more Ra 224 than would be expected from the $\mathrm{Th}^{228}$, and it is probable that radium is almost completely diffusible in this system, too.

In conclusion, a few dialysis studies give results for $\operatorname{Th}^{228}$ similar to those for $\mathrm{Pu}^{239}$, and show that $\mathrm{Ra}^{224}$ is almost completely diffusible.

\section{References}

1. Clinical physiology of dogs injected with plutonium, E. Painter, E. Russell, C.I. Prosser, M. N. Swift, W. Kisieleski, G. Sacher。 AECD 2042 , June 1946. 2. T. Putnam, Ph.D. thesis, University of Rochester. 
LACK OF EFFECT OF DOSE IEVEL ON Pu239 METABOLISM IN THE BEAGIE

Betsy.J. Stover, D. R. Atherton, No Keller, and D. S. Buster

Abstract: The $\mathrm{Pu}^{239}$ plasma concentration and excretion rate data through four years after injection have been examined for dose level effect. There appears to be no significant difference in retention at four years among the various dose levels.

A. General

Two kinds of dose effects are possible in the metabolism of inorganic radioactive isotopes. The first can be considered a chemical effect which results from a limited number of sites available to bind the isotope. When the number of inorganic ions introduced is less than the number of sites, the fractional retention is constant; when the sites are saturated, the fractional retention decreases. If a chemical effect exists, it will be observed early. An excellent example is Schubert 's study comparing carrier-free $\mathrm{Pb}^{210}$ and $\mathrm{Pb}^{210}$ with carrier $\mathrm{Pb}$. At 25 minutes after intravenous injection of carrier free $\mathrm{Pb}^{210}$ into rats, essentially all of the $\mathrm{Pb}^{210}$ in the blood was in the cells. At the same time after injection of $\mathrm{Pb}^{210}$ with carrier $\mathrm{Pb}$, only $20 \%$ of the blood $\mathrm{Pb}^{210}$ was in the cells and $80 \%$ in the plasma, showing a saturation of the cellular binding sites.

The second kind of dose level effect can be considered a biological one which results from damage occurring in proportion to the amount of irradiation. This effect is more easily observed when a short-lived daughter isotope is involved. An example is the decrease in $\mathrm{Ra}^{224}(\mathrm{ThX})$ excretion with increase in dose level in our $\mathrm{Th}^{228}$ (RdTh) dogs. (2) However, an effect on parent retention was observed by Norris et al, (3) who observed that $\mathrm{Ra}^{226}$ retention in rats increases with injected dose for injected doses greater than $10 \mu \mathrm{c} / \mathrm{kg}$ 。

B. Plasma concentration

The Pu239 concentration in plasma of $\mathrm{P} 4$ and $\mathrm{P} 5$ dogs has now been measured to 4.5 years after injection. The data for the period from 21 days to 4.5 years appear 
in Fig. 1, and the equation, $\mathrm{P}_{2}=7.33 \times 10^{-4} t^{-0.293}$, does not differ significantly from the last one reported. (1) Each point in Fig. 1 is the average of two or more measurements, except for the last two. A total of 80 samples from 24 dogs (P5 and P4) were measured. Since the injection weights of the dogs ranged from 6.5 to 11.4 $\mathrm{kg}$, some of the scatter of the points may result from differences' in total: plasma volumes.

In Fig. 2, the $\mathrm{P} 5$ and $\mathrm{P} 4$ data are treated separately. Most of the $\mathrm{P} 4$ points are lower than the P5 points, and the equations are; for P5, $P_{2}^{\prime}=9.95 \times 10^{-4}+t_{-0.327}$ and, for $\mathrm{P}_{4}, \mathrm{P}_{2}^{\prime \prime}=4.26 \times 10^{-4} t^{-0.235}$.

Since the $\mathrm{P}_{4}$ points are quite consistently lower, this may be a dose level effect. On the otherhand, there were only $32 \mathrm{P} 4$ samples compared with $48 \mathrm{P}^{\prime} \mathrm{s}_{\mathrm{g}} \mathrm{P}^{\prime} \mathrm{s}$ are harder to measure, and the decrease with $t$ ime is so slow that scatter. is accentuated.

\section{Excretion}

The lack of effect of dose level on early Pu ${ }^{239}$ excretion has been reported before. (5) To review, (s.ee also Table II) the total amount excreted during the first 22 days after injection was measured for 19 dogs, 3 each at dose levels P1, P2, P3, and $P_{4}$, six at $P 5$, and one at twice the P5 level; there was no significant correlation between dose level and total amount excreted.

Excretion measurements from 23 days to 4 years after injection have been made for 12 dogs, 3 each at dose levels P5, P4, P3, and P2, (except at 4 Jears, when measurements have been completed for only seven dogs to date). During the period 23 to 42 days some measurements on P1 dogs and some additional:measurements on $\mathrm{P} 5$ dogs were made. These data have been separated according to dose level, and equations for $X_{2}$ and $R$ have been calculated and appear in Table $I_{0}$ Inspection of the power functions which describe the excretion rates shows that both the coefficient and exponent increase as dose level decreases from P5 to P3. P2 does not follow this trend. 
CONCENTRATION OF Pu IN PLASMA $\mathrm{Pu} \geq 21$ days (JULY 1957.)
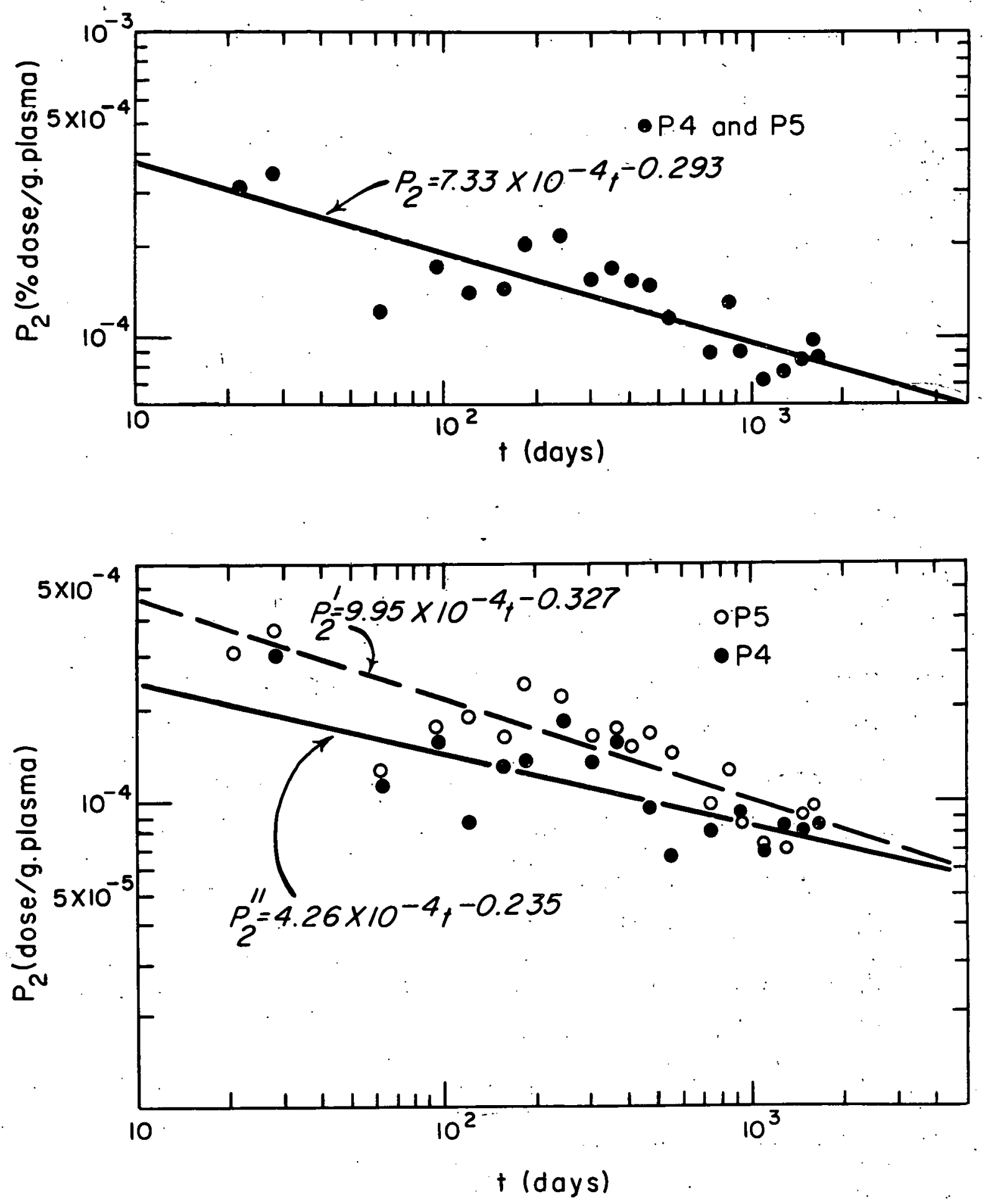
Table I

Equations for $\mathrm{X}_{2}$ arid $\mathrm{R}$

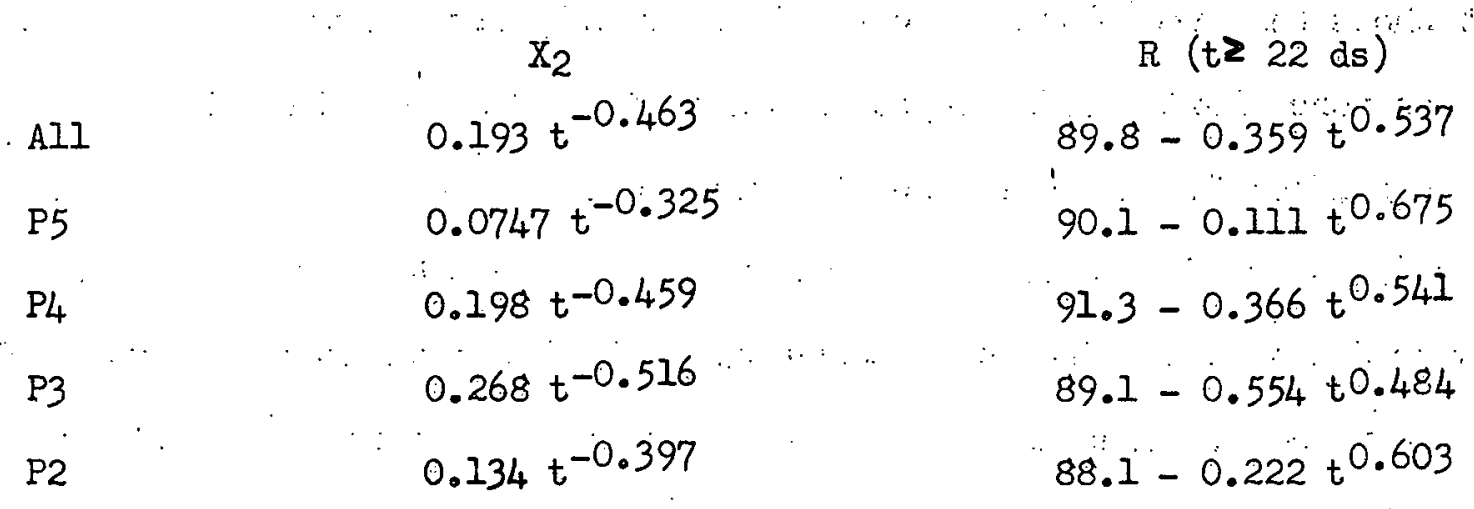

The average total excretion during the first 22 days is reviewed in Table II. Also included are the cumulative excretion for the interval 22 days to 4 years and the retention at 4 years calculated from the equations of Table I. These calculations show that; while the excretion equations for the various dose levels differ markedly $\neq$, all the excretion rates are so low and decrease so slowly with time that the cumulative excretions do not differ significantly.

Table II

Pu Excretion by Dose Level

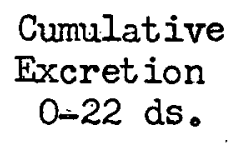

AII

P5.

$\mathrm{P} 4$

P3

P2

PI

$* \sigma=2.1$
$12.1 \% *$

10.8

10.6

13.4

13.3

4.2

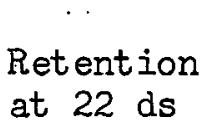

$87.9 \%$

89.2

89.4

86.6

86.7

85.8
Cumulat ive

Excretion

22 ds to 4 yris

$16.1 \%$

14.3

.16 .9

16.4

16.5
70.2

Retention at 4 yrs

$71.8 \%$

74.9

72.5

70.2 
D. Conclusion

Examination of plasma concentration and excretion rate data for dose level effect shows that the plasma concentration is slightly higher and the excretion rate decreases more slowly for P5 dogs. However, the effect on the retention at 4 years is not significant. At this time, 4 years appears to be about the average length of time P5 and Pi dogs survive after injection. Hence the possible dose level effect need not be considered in calculating the total amounts of energy delivered to the $\mathrm{Pu}^{239}$ dogs. (The division of this energy between skeleton and soft tissues needs further study, since most of our tissue and bone measurements have been made on P5 dogs.)

\section{References}

1. J. Schubert and M. R. White, Effect of sodium and zirconium citrates on distribution and excretion of injected radiolead, J. Lab. and Clin. Medicine, 39, $260-266$ (1952).

2. B. J. Stover et al, Chemistry group report, Annual Progress Report, March $3 I_{2}$ 1957, pp. 141-143.

3. W. P. Norris et al, Studies on Ra metabolism in rats. ANL-5288, pp. 79-82 (1954).

4. B. J. Stover et al, Annual Progress Report, March 31, 1957, p 140。

5. B. J. Stover et al, Excretion of plutonium by the beagle, Quarterly Progress Report, December 31; 1953, pp 4-6. 
Measurements of $\mathrm{Sr}^{90}$ in plasma have now been extended to two years after injection. The early samples were measured directiy using a well-type plastic scintillator $(1)$. Since $1 \mathrm{ml}$ was the maximum volume permitted by the direct method, the $\mathrm{Sr}^{90}$ in later samples was concentrated by co-precipitation with $\mathrm{CaC}_{2} \mathrm{O}_{4}$. The same beta detector was used for these samples (with an appropriate standardi)。 Precautions were taken to insure $\mathrm{Sr}^{90}$ - $\mathrm{Y}^{90}$ equilibrium.

The data have been divided into two time groups, $t \leq I$ day and $t Z I$ day, and a power function has been fitted to each group. The results are shown in Figs. I and 2. Since the radium data ${ }^{(2)}$ cover the same periods and were treated in the same way, the equations can be compared without qualifications. The four power functions are listed in Table $I_{0}$

\section{Table I}

Interval

$t \leq 1$ day

$t \geq 1$ day
$\mathrm{Sr}$

$P_{1}=0.114 t-0.371$

$P_{2}=5.03 \times 10^{-3} t-1.25$
$\mathrm{Ra}$

$P_{1}=0.0918 t^{-0.454}$

$P_{2}^{1}=2.64 \times 10-3 t-1.24$
Units $\%$ dose/g. pl, mins: $\%$ dose/g. pl., days

The calculated one minute value for strontium is about $20 \%$ higher than that for radium. Throughout the first day the strontium concentration decreases more slowly than radium, and at one day strontium is about twice radium. Thereafter, this ratio is maintained and the plasma concentrations of the two decrease at the same rate. Since $P_{2}$ a $\frac{d R}{d t}$, these results indicate that $\frac{\mathrm{Sr} \text { Retention }}{\mathrm{Ra} \text { Retention }}=$ const. $\leqslant 1$

The concentration ratio of about two may well result from greater binding of strontium by plasma proteins. Assuming that all plasma: radium is diffusible (see p. 81 ) and that the concentration of diffusible strontium equals that of diffúsible radium, the "bound" fraction of strontium is 0.48 . Strontium dialysis studies are 


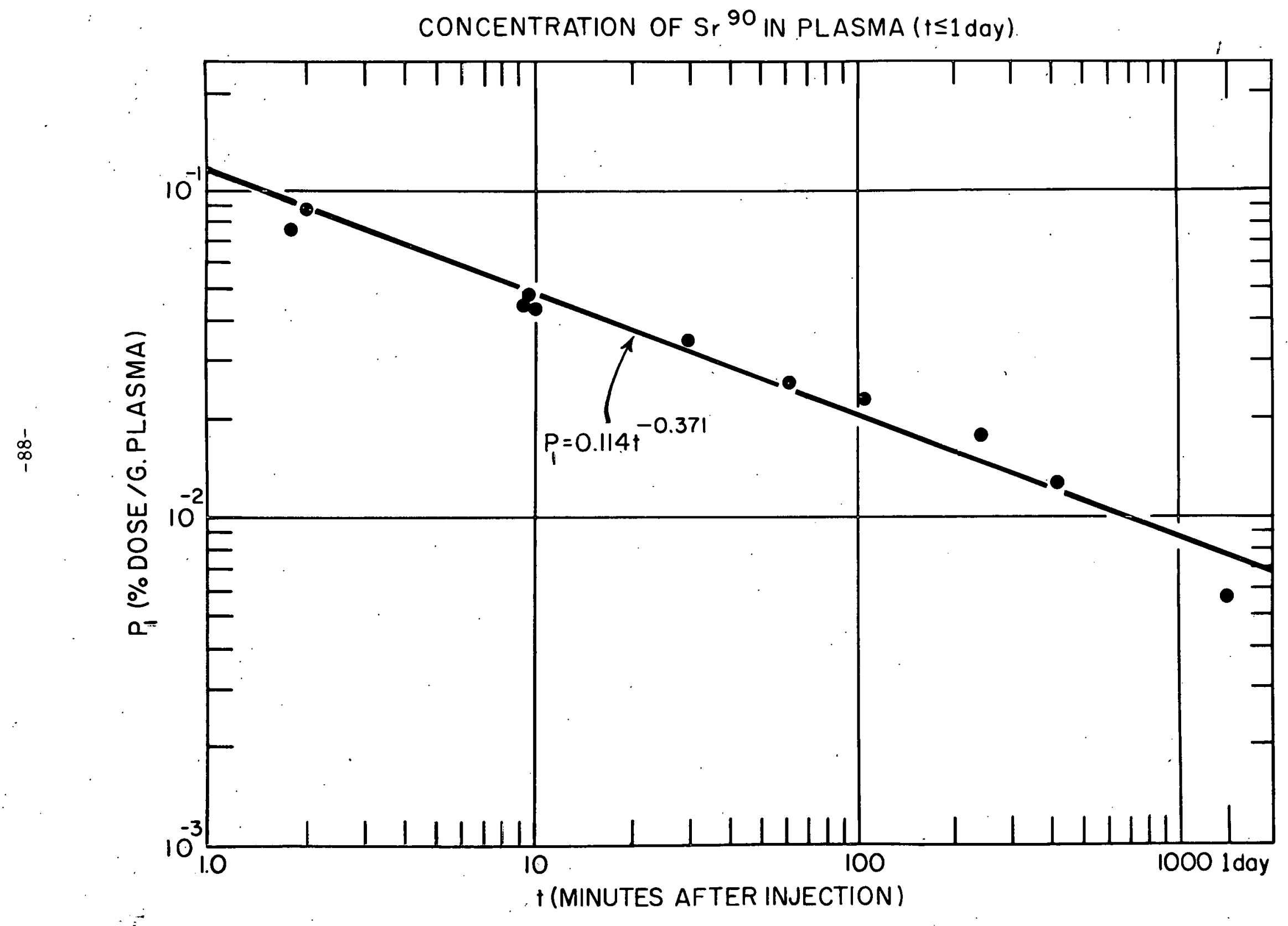




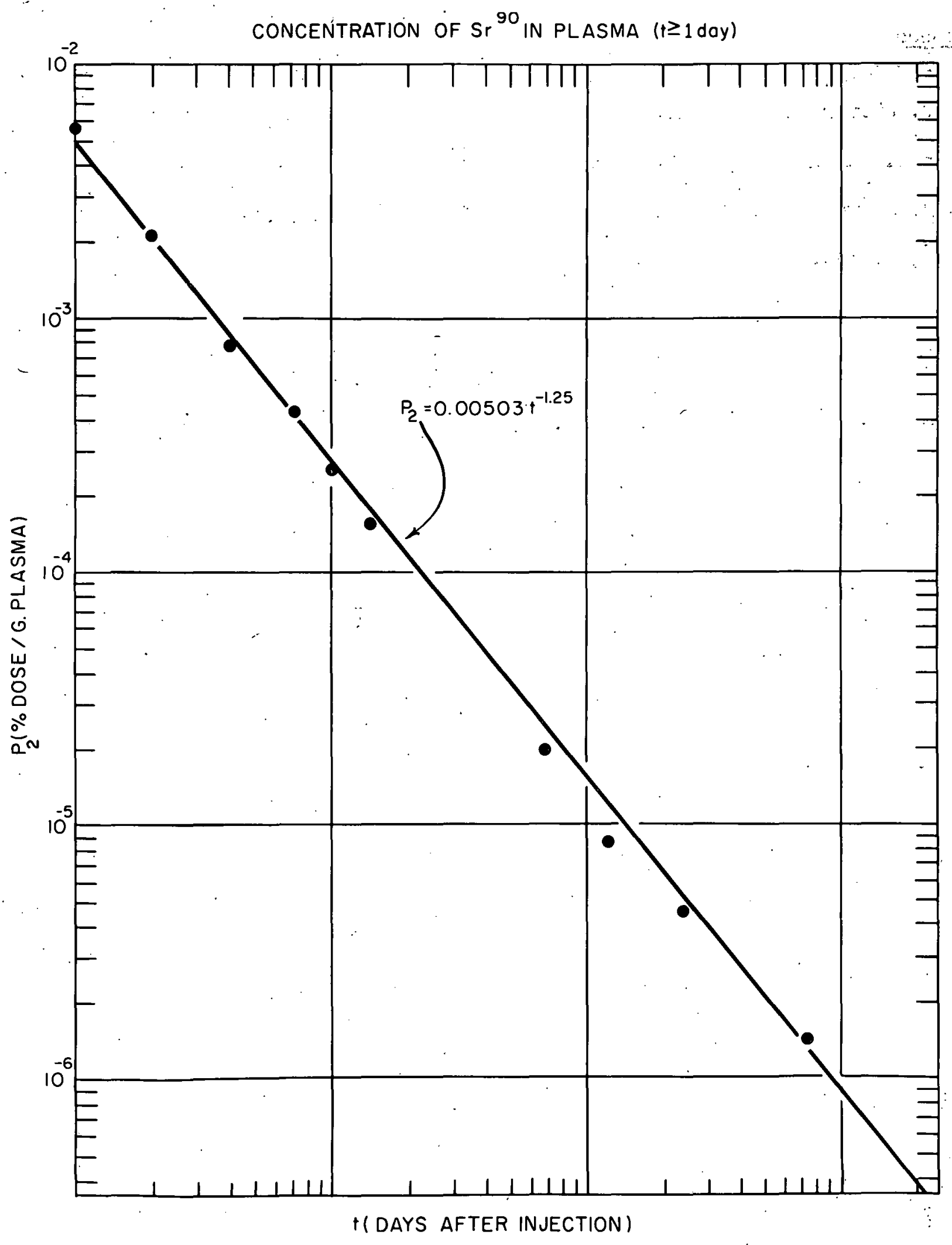


planned to check on this. (Strontium excretion studies are under way.)

\section{References}

1. B. J. Stover and D. R. Atherton, $\mathrm{Sr}^{90}$ plasma concentration - a preliminary report. Annual Progress Report, March 31, 1956, pp. 107-108.

2. B. J. Stover et al, Chemistry group report, Annual Progress Report, March $3 I_{\text {, }}$ 1957 , p. 140 . 
ABSORPTION OF RADTUM AND THORIUM THROUGH THE GUT AS A FUNCTION OF CHEMICAL FORM, IV.

D. R. Atherton, B. J. Stover, and M. A. Van Dilla

\begin{abstract}
Analyses of the guinea pigs fed "home-made dial paint" show a greater. relative absorption of radium than thorium. A summary of the three studies, (rat, monkey, and guinea pig, ) shows considerable variation in the relative absorption, which appears to be related both to the chemical state of the radium and thorium and to the condition of the animals.
\end{abstract}

The studies on absorption of radium and thorium through the gut, previously rew ported $(1,2,3)$, have been concluded with a study in which "Dial Paint"(2) was fed to guinea pigs. Four guinea pigs were used in this study. Each was placed in a separate cage following administration by catheter of a capsule containing $8 \mu \mathrm{c} \mathrm{Ra} 226$ and $24 \mu \mathrm{c}, \mathrm{Th}^{228}$ (the same preparation as was given to the monkeys (2)). Two hours after. administration of the paint the animals were measured in $K-9^{(4)}$ and it was determined that the activity was inside the animals. Measurements were made at intervals over' the eleven days of the experiment, and at the end of the experiment the excreta contained over $98 \%$ of the administered dose.

On the eleventh day of the experiment the animals were killed. Following the rout'ine described previously ${ }^{(2)}$, three samples of each animal, skeleton., gut and liver-spleen, were taken for analysis. The samples were ashed, dissolved in $\mathrm{HNO}_{3}$, and measurements were made by Pogo $(5)$, and thoron techniques ${ }^{(6)}$. The results appear in Table I. A summary of all the gut absorption experiments appears in Table II. 
Table $I^{-}$

$\begin{array}{cccc}\text { Skeleton } & \begin{array}{c}\mathrm{Ra}^{226} \\ \% \text { Dose }\end{array} & \begin{array}{c}\mathrm{Th}^{228} \\ \% \mathrm{Dose}\end{array} & \mathrm{Ra}^{226} / \mathrm{Th}^{228} \\ 1 & 0.33 & 1.7 \times 10^{-3} & 180 \\ 2 & 0.24 & 0.76 \times 10^{-3} & 320 \\ 3 & 0.42 & 1.7 \times 10^{-3} & 250 \\ 4 & 0.64 & 2.3 \times 10^{-3} & 310 \\ \text { Average } & 0.41 & 1.6 \times 10^{-3} & 260\end{array}$

Gut

$\begin{array}{cccc}1 & 0.15 & 0.16 & 0.94 \\ 2 & 0.024 & 0.032 & 0.75 \\ 3 & 0.031 & 0.030 & 1.03 \\ 4 & 0.36 & 0.39 & 0.92 \\ \text { Average } & 0.14 & 0.15 & 0.93\end{array}$

Liver and Spleen

1

$1.6 \times 10^{-4}$

2

$1.1 \times 10^{-4}$

3

$3.6 \times 10^{-4}$

$0.92 \times 10^{-4}$

3.9

Table II

Skeletal Retention at 10 Days

Rat

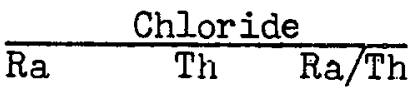

$\frac{\text { Citrate }}{\text { Ra } \quad \text { Th } R a / T h}$

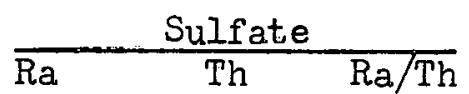

$8.7 \quad 0.6 \quad 14$

16.30 .069240

$0.0017 \quad 0.024$

0.071

Monkey

$\begin{array}{lll}0.017 & 0.0059 \quad 28\end{array}$

Guinea Pig

$0.41 \quad 0.0016 \quad 260$ 
One of the goals of the series of studies involving the monkey: and guinea pigs was to observe whether or not a species difference could be demonstrated. Certainly there was a marked difference in the absorbed material; the guinea pig/monkey ratio was 2.5 for thorium and 24 for radium. It is felt that this cannot properly be assigned to a species difference because of the fact that, while the guinea pigs appeared to continue in their usual phlegmatically contented mode of Iife, the in monkeys were in a state of continual fright which seemed to be reflected in a skimpy appetite and what appeared to be a mild diarrhea. If these animals did indeed have a diarrhea it could very well account for their absorbing less of the activity than did the guinea pigs.

As in the monkey experiment, the guinea pig experiment shows considerable scatter in the $\mathrm{Ra} / \mathrm{Th}$ ratio of skeletal burden, 180 to 320 with an average value of 260 , but certainly it is evident that with the "clean chemistry dial paint" the radium is much more readily absorbed, even though radium is absorbed to less than $1 \%$.

It is of passing interest to note that the gut samples, while having a spread of a factor of 10 , exhibit $R a / T h$ ratios of very close to $1.0(0.75-1.03)$ indicating that this material is residual paint that has been delayed in making its exit.

As was observed in the monkeys, the guinea pig liver-spleen samples are very low compared with the skeleton.

The results of the guinea pig experiment appear to substantiate our previous observations that chemical form is very critical; that absorption of thorium dominates only when it is in a relatively more soluble form than is the radium.

\section{References}

1. 2nd Annual Conference, June 1954, pp.65-67.

2. Annual Progress Report, March 31, 1955, pp. 14-16.

3. Annual Progress Report, March 31, 1956, pp. 79-81.

4. K-9; A large $4 \Pi$ Gamma-Ray Detector, M. A. Van Dilla, R. I. Schuch and E. S. Anderson, Nucleonics 12 No. 9, 22-27 (1954).

5. Annual Progress Report, March 31, 1956, p. 77.

6. Ioid., p. 82 . 
ISOTOPE BURDEN AND RADIATION DOSE RATE IN INJECTED BEAGLES

C. W. Mays, B. J. Stover, D. R. Atherton, and M. A. Van Dilla

Abstract: Normalized body burden as a function of time after injection is presented by isotope for the average toxicity beagle injected between 16 and 18 months of age. Dose rate to the bone has been computed for a 1-level dog in each injection group.

INTRODUCTION: Retention data from previous progress reports has been sifted and brought up to date. Relations represent the best estimates as of September 1957 and not final measurements. This information should be useful in relating radiation effects to dose.

DEFINIT ION:

$$
\text { Normalized Body Burden }=\frac{\mu \mathrm{c} \text { OF RETATNED ISOTOPE AT TIME }(t)}{\mu \mathrm{C} \text { OF PARENT AT INJECTION }(t=0)}
$$

GENERAL: The isotopes we inject locate mostly in the skeleton. Body burden changes with time after injection due to natural radioactive decay and biologic excretion. PLUTONIUM: As plutonium is not readily excreted, dosage rate decreases only slightly after injection. About $26 \%$ of the body burden is in the liver and about $73 \%$ in the skeleton, and in the dog, these percentages do not seem to change greatly with time at'ter injéct1on.

RADIUM: Radium is rapidly excreted at first, but more and more slowly later on. Due to its chemical similarity to calcium nearly all the body burden is in the inorganic. (mineral) part of bone.

Radon is the only daughter of radium which is appreciably excreted. Being a chemically inert gas, most radon atoms are able to diffuse into the blood, where they are carried to the lungs and exhaled before decaying in the body. Increasing fractional radon retention combines with a decreasing radium burden to give a constant radon burden through the lifetime of our dogs.

Lead 210 activity builds up slowly due to its 20 year half life and contributes 
very little damage the first few years after injection. Excretion of lead 210 is believed to be small.

RADIOTHORIUM: The skeletal burden of thorium stays at about $73 \%$ of the injection dose (corrected for decay) while the thorium excreted seems to come from soft tissue fraction. The 1.9 year half life of thorium is much more effective in decreasing body burden than is the small biologic excretion.

The daughters of radiothroium are not readily excreted and the amount excreted decreacos with time.

MESOTHORTMM: As mesothorium $\left(\mathrm{Ra}^{228}\right)$ is an isotope of radium, it locates in the mineral part of bone, is excreted rapidly at first, and then more slowly later on. Most of the radiation dosage comes not from beta-emitting mesothorium, but from its alpha-emitting daughters in the radiothorium decay series. Ingrown radiothorium is not appreciably excreted, and the excretion of its daughters is even less than the small excretion of the daughters of injected radiothorium.

The lag in buildup of ingrown radiothorium causes the dose rate to increase for the first few years after injection in contrast to the decreasing dose rates in, all other injection series.

STRONT IUM 90 : Due to its chemical similarity to calcium and radium, strontium locates in mineral bone. Data to date indicates that strontium retention is slightly less than radium retention in dogs. Ingrown yttrium seems about 100\% retained.

Fractional body burden vs. time is graphically presented. A simplified decay scheme is included on each graph with average alpha $(\alpha)$ and beta $(\beta)$ energies given in million electron volts (MEV) for each transition. Energy of the recoil nucleus is rincluded. with alpha energy. Average beta energy is about $1 / 3$ maximum beta energy. 
NORMALIZED BODY BURDEN EQUATIONS ARE LISTED FOR AVERAGE

DOSE LEVEL AND 16-18 MO. INJECTION AGE

Isotope

PLUTONIUM

$$
\mathrm{Pu}^{239}=.90-.0036 t^{+.54}
$$

RADIUM

$$
\begin{array}{ll}
\mathrm{Ra}^{226} & =.8 t^{-.2} \\
\mathrm{Rn}^{222} & =.045 \\
\mathrm{~Pb}^{210} & =.045\left(1-\mathrm{e}^{-. .000095 t}\right)
\end{array}
$$

\section{RAD IOTHOR TUM}

$$
\operatorname{Th}^{2} 28
$$

$\mathrm{Ra}^{224}$

$=.93 t^{-.023} e^{-.001 t}$

$\operatorname{Tn}^{220}$

$=\left(.93 t^{-023}-.47 t^{-.031}\right) e^{-.001 t}$

$=\left(.93 t-.023-.47 t^{.031}-.06 t^{-.15}\right) \mathrm{e}^{-.001 t}$

MESOTHOR IUM

$$
\begin{aligned}
\operatorname{Ra} 228 & =.8 t^{-.2} e^{-.0284 t} \\
\operatorname{Th}^{228} & =.0008 e^{-.001 t} \int_{.06}^{t} t^{-.2 e^{+.000716 t} d t}
\end{aligned}
$$

STRONT TUM

$$
\begin{aligned}
& \mathrm{Sr}_{r} 90=.7 \mathrm{t}^{-.23} \\
& \mathrm{Y} 90=.7 \mathrm{t}^{-.23}
\end{aligned}
$$

Source

File, R.J. Stover

P.R. March 56, pg 74

P.R. Sept. 57, pg 119

Calculated assuming no $\mathrm{Pb} 210$ excretion.

P.R. Sept. 55, pg 38

P.R. March 57, pg 141

P.R. Sept. 57:; pg 113

$\mathrm{Ra}^{226}$ Retention equation

Calculated assuming ingrown Th228 not excreted

K-9 II,whole dog counter

P.R. March 55, pg 22

Note: $t$ is the number of days after injection.

Normalized body burden depends on both biologic excretion and natural radioactive decay. 
$-97=$

PLUTONIUM BODY BURDEN VS. TTME

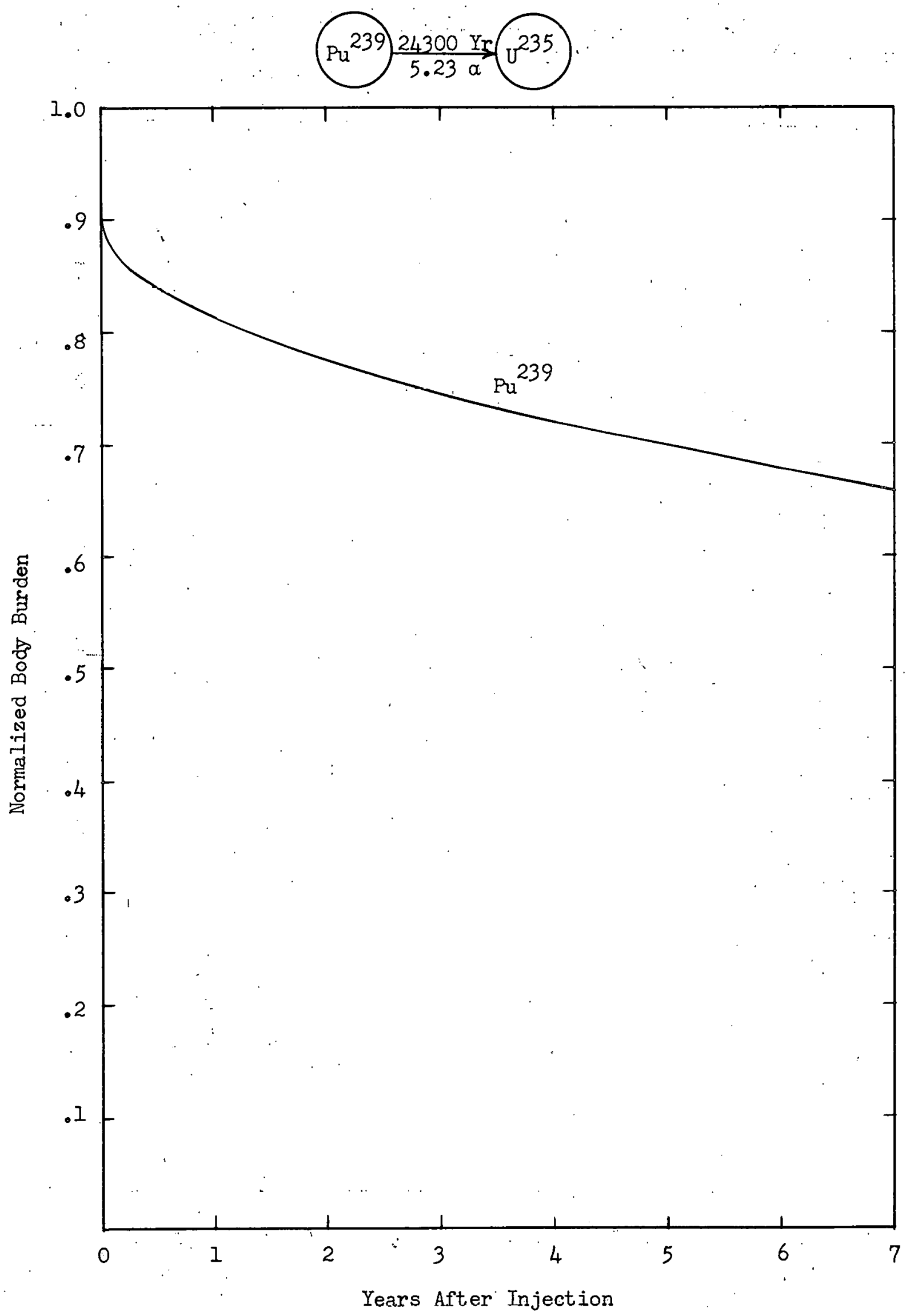


$-98=$

RAD TUM AND DAUGHTERS BODY BURDENS VS. TTME
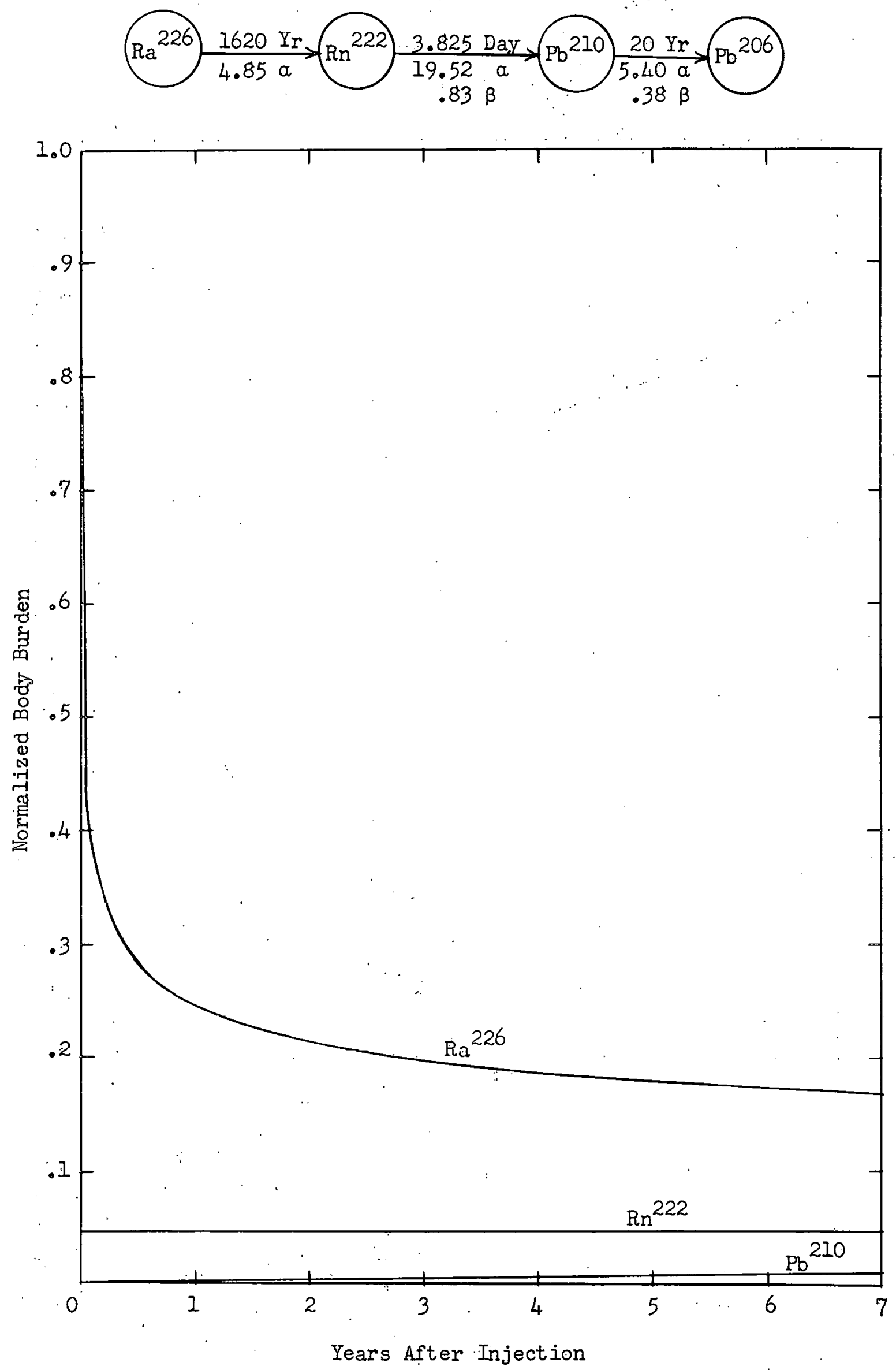

$\begin{array}{ll}151 & 099\end{array}$ 
RADIOTHORIUM AND DAUGHTERS BODY BURDENS VS. TIME
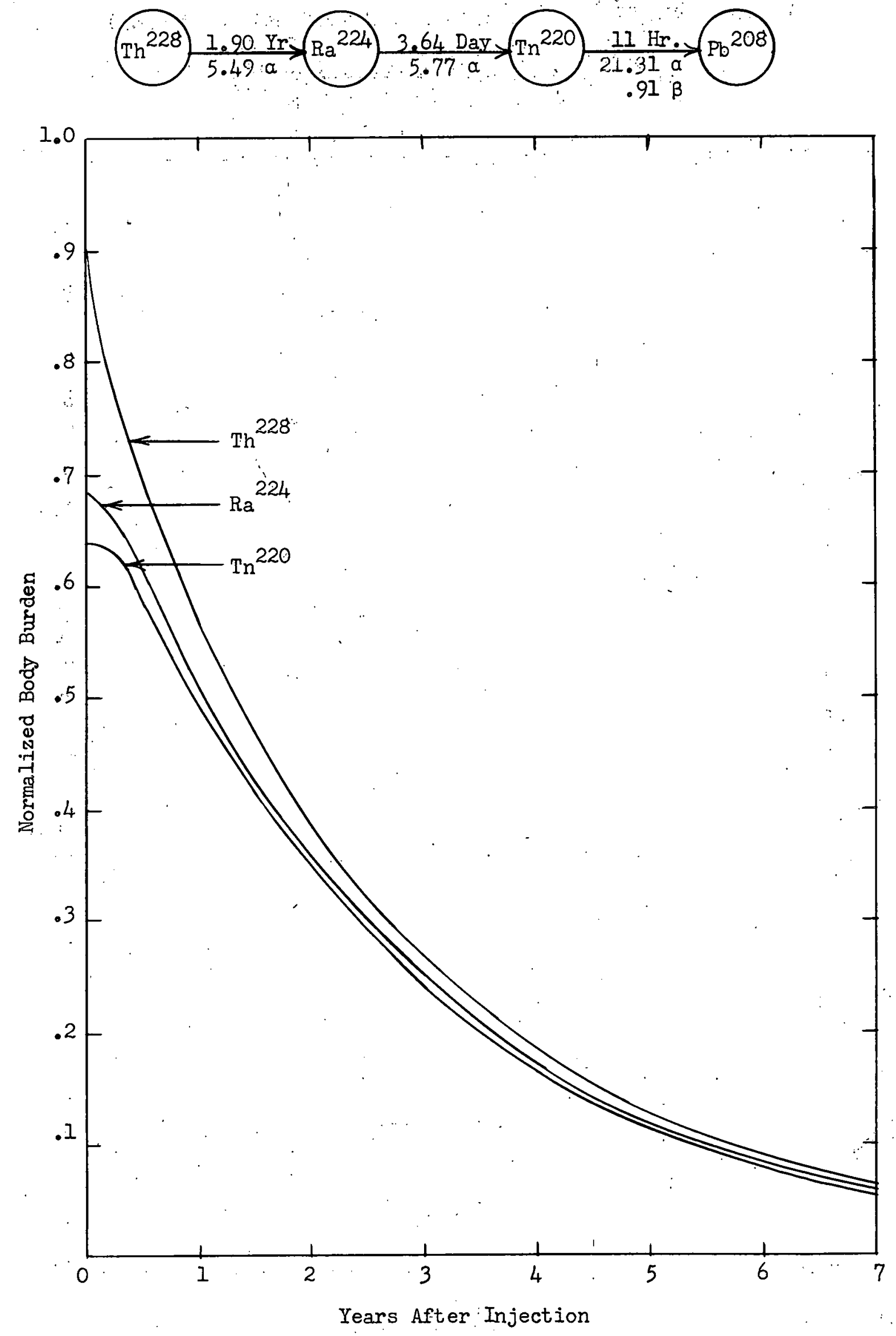


$$
-100-
$$

MESOTHOR IUM AND DAUGHTER BODY BURDENS VS. TTME (Assuming no $\mathrm{Th}^{228}$ contamination in the injection solution)
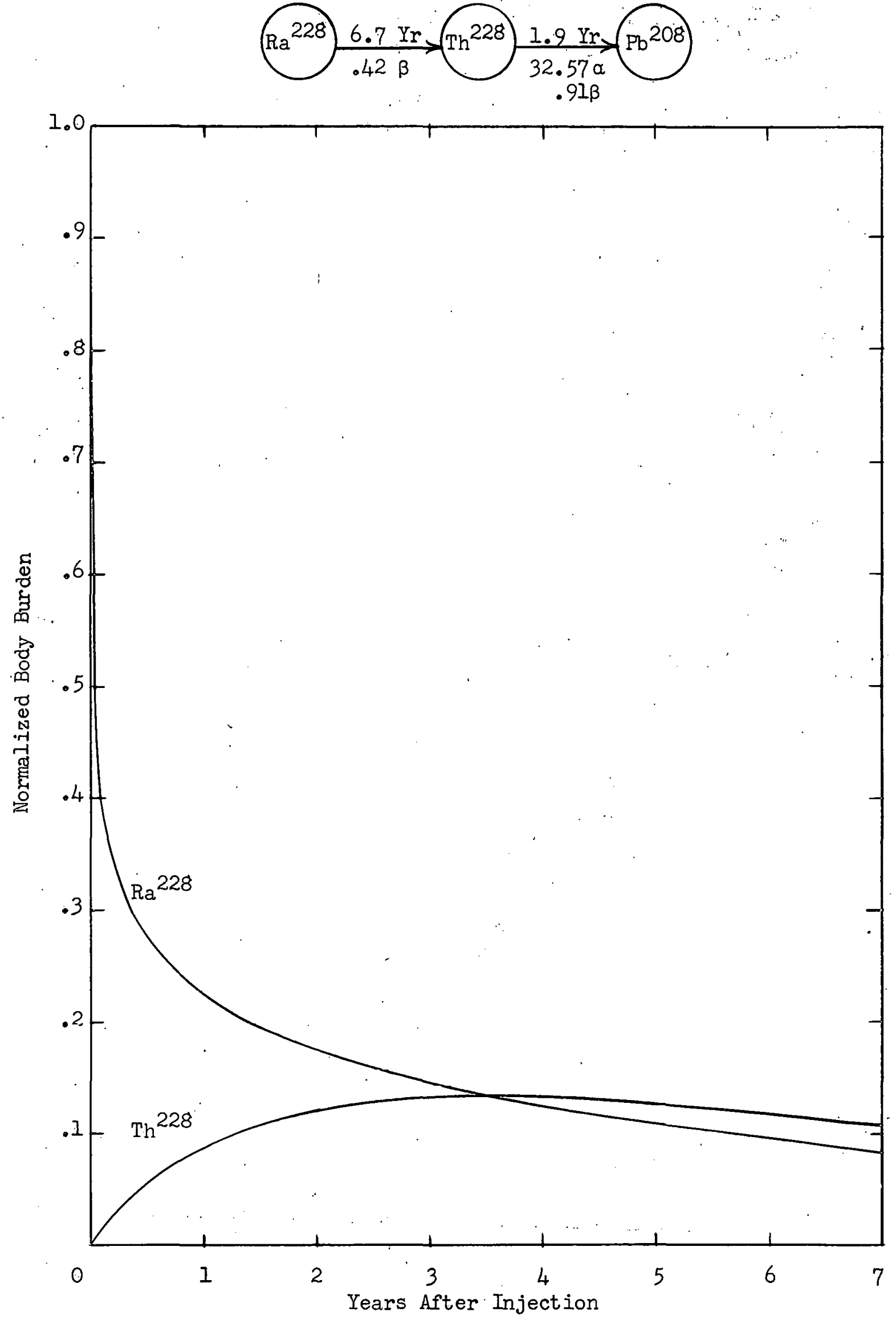
STRONT IUM AND DAUGHTER BODY BURDENS VS. TIME
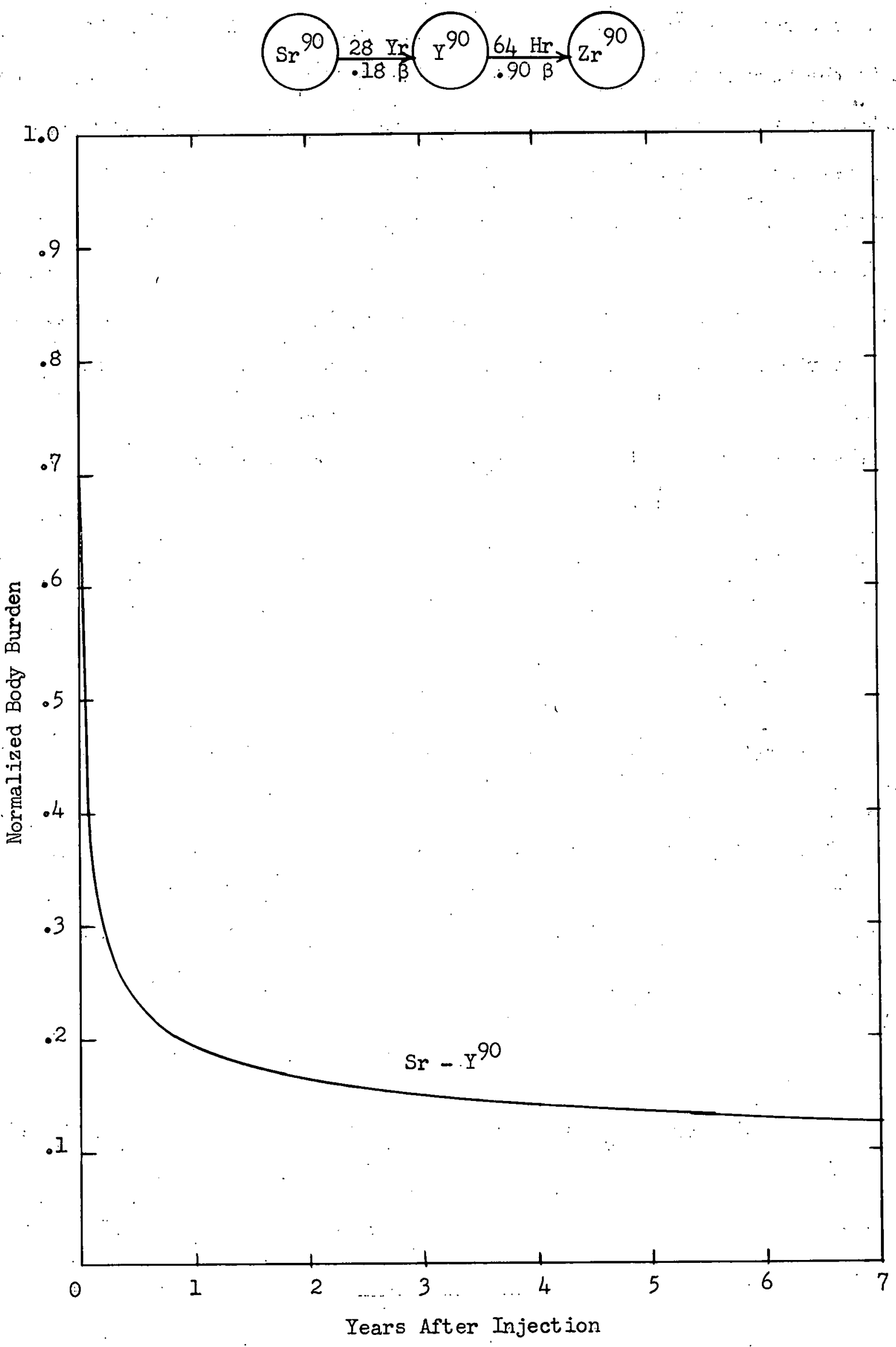


\section{CALCULATION OF DOSE RATE}

If the body burden of each isotope in a decay series is knowm, the average dose rate to the bone in rads per year for the 1-level dogs in each injection group can be computed. (I rad corresponds to the absorption from ionizing radiation of 100 ergs of energy per gram of material.) Only alpha plus recoil nucleus plus beta dose has been computed, as in comparison, gamma dose is negligible. Bone is assumed to make up $1 / 10$ of body weight. To find the dose rate for the $5,4,3,2,1.7,1.5$, and 0.5 levels multiply the $1-1$ level dose rate by $162,54,18,6,3,2$, and $1 / 3$ respectively.

In plutonium, 73\% of the body burden is assumed to be in the skeleton. 1-level plutonium dogs are injected with $0.0159 \mu \mathrm{c} / \mathrm{kg}$ body weight.

In radium and daughters, 100\% of the body burdens are assumed to be in the skeleton. I-level radium dogs are injected with $0.0572 \mu \mathrm{c} / \mathrm{kg}$ body weight.

In radiothorium, skeletal burden of $\mathrm{Th}^{228}$. is assumed to be $73 \%$ of the injected dose corrected for decay. $A: 17$ the $\mathrm{Ra}^{224}$ burden is assumed to be in the skeleton. Skeletal loss of $\mathrm{Tn}^{220}$ is assumed to be twice the exhaled Thoron. 1-level radiothorium dogs are injected with $0.0159 \mu \mathrm{c} / \mathrm{kg}$ body weight.

In mesothorium, 90\% of the energy of ingrown $\mathrm{Th}^{228}$ and daughters is assumed delivered to the skeleton. I-level mesothorium dogs are injected with $0.057 \mu \mathrm{c} / \mathrm{kg}$ body weight. Dose rate has been calculated for $15 \%, 3 \%$ and $0.6 \%$ RdTh contamination in the injection solution, and is shown on a separate graph.

In strontium, 100\% of the body burdens are assumed to be in the skeleton. 1-level strontium dogs are injected with $0.572 \mu \mathrm{c} / \mathrm{kg}$ body weight。

\section{SAMPLE CONPUTATION:}

DOSE RATE $=\left[\right.$ INJECTED $\left.\frac{\mu \mathrm{C}}{\mathrm{Kg}}\right]$ (SKELETAL BURDEN] (DISLINTEGRATION IVEV) (187 $\left.\frac{\mathrm{RAD}}{\mathrm{YEAR}}\right)$ for a lollevel plutonium dog one year after injection

DOSE RATE $=[.0159)\left[\begin{array}{ll}.73 & (.90-.0036 \times 365.54)\end{array}\right][5.23]\left(187 \frac{\mathrm{RAD}}{\mathrm{YEAR}}\right)=9.2 \frac{\mathrm{RADS}}{\mathrm{YEAR}}$ 
DOSE RATES TO I-IEVEL BEAGLES

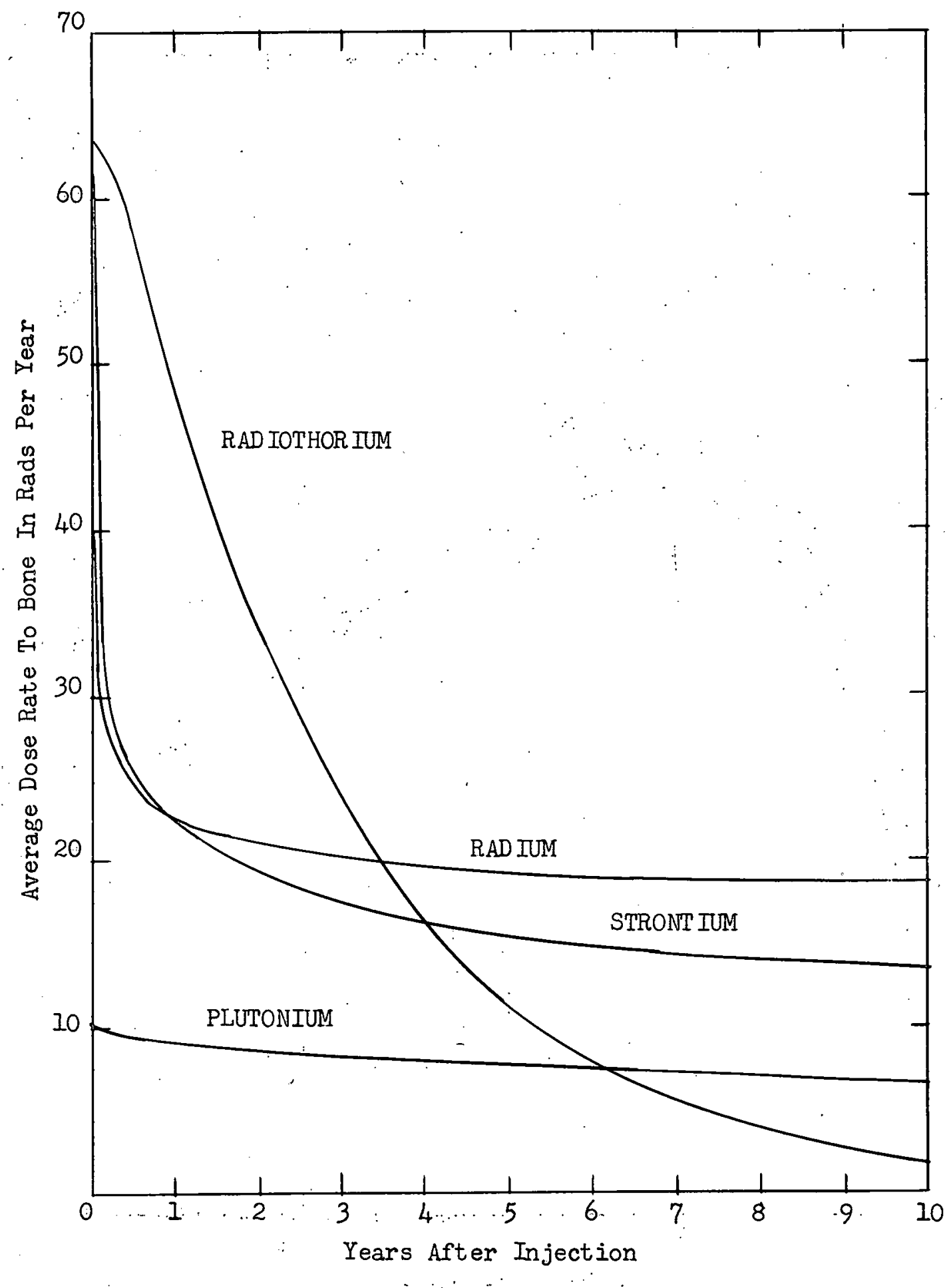


DOSE RATES TO I-IEVEL MsTh BEAGLES

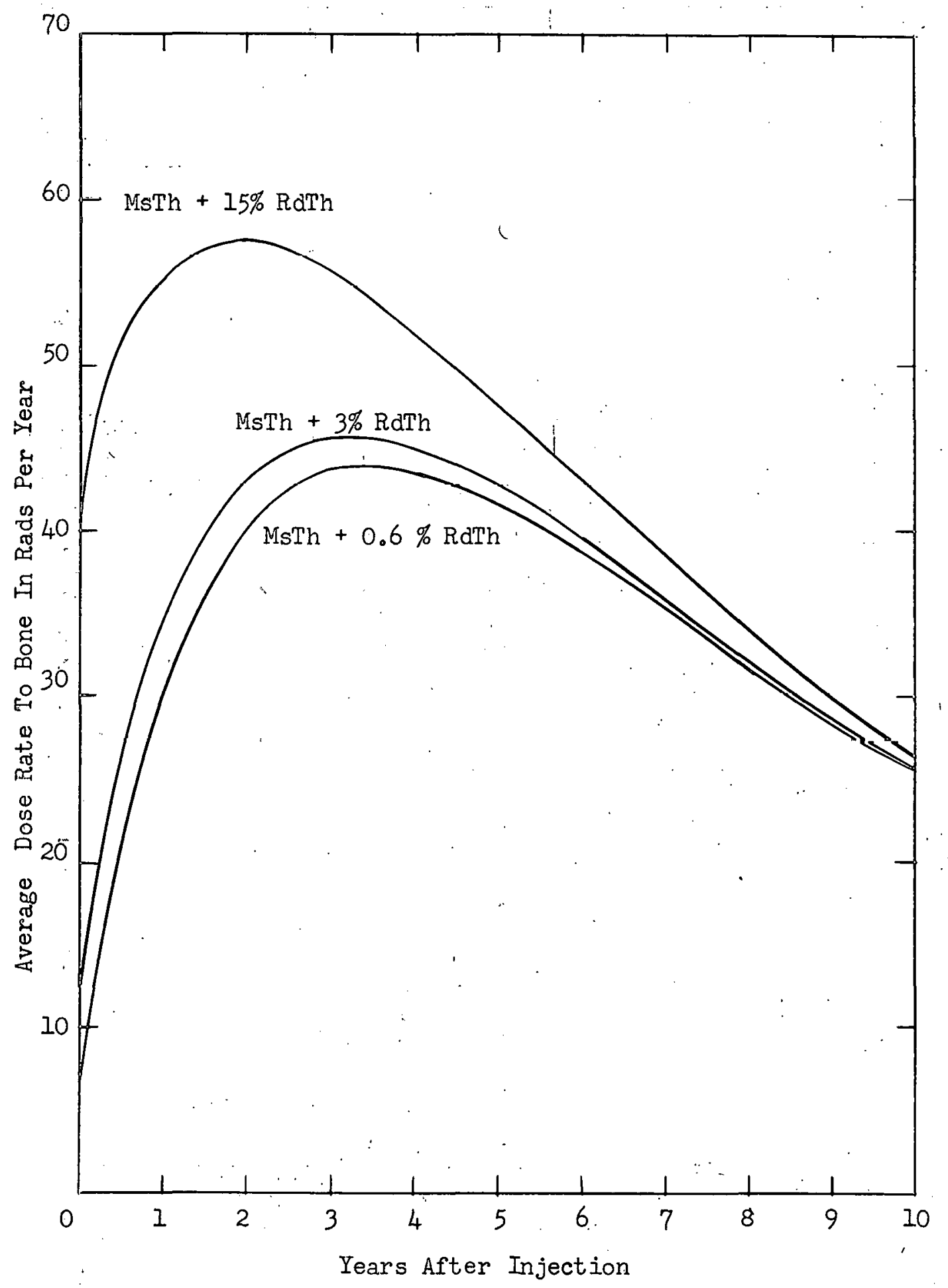




\begin{abstract}
A whole body gamma scintillation detector designed to admit a living dog has been completed.
\end{abstract}

The new detector is four times more sensitive than the earlier model (K-9) it replaces.

Natural potassium 40 and fallout cesium 137 are being measured in dogs and humans.

Design: The design of $\mathrm{K}-9$ Bark II is similar to the design of $\mathrm{K}-9^{I}$ the previous model and the Los Alamos human counter ${ }^{2}$.

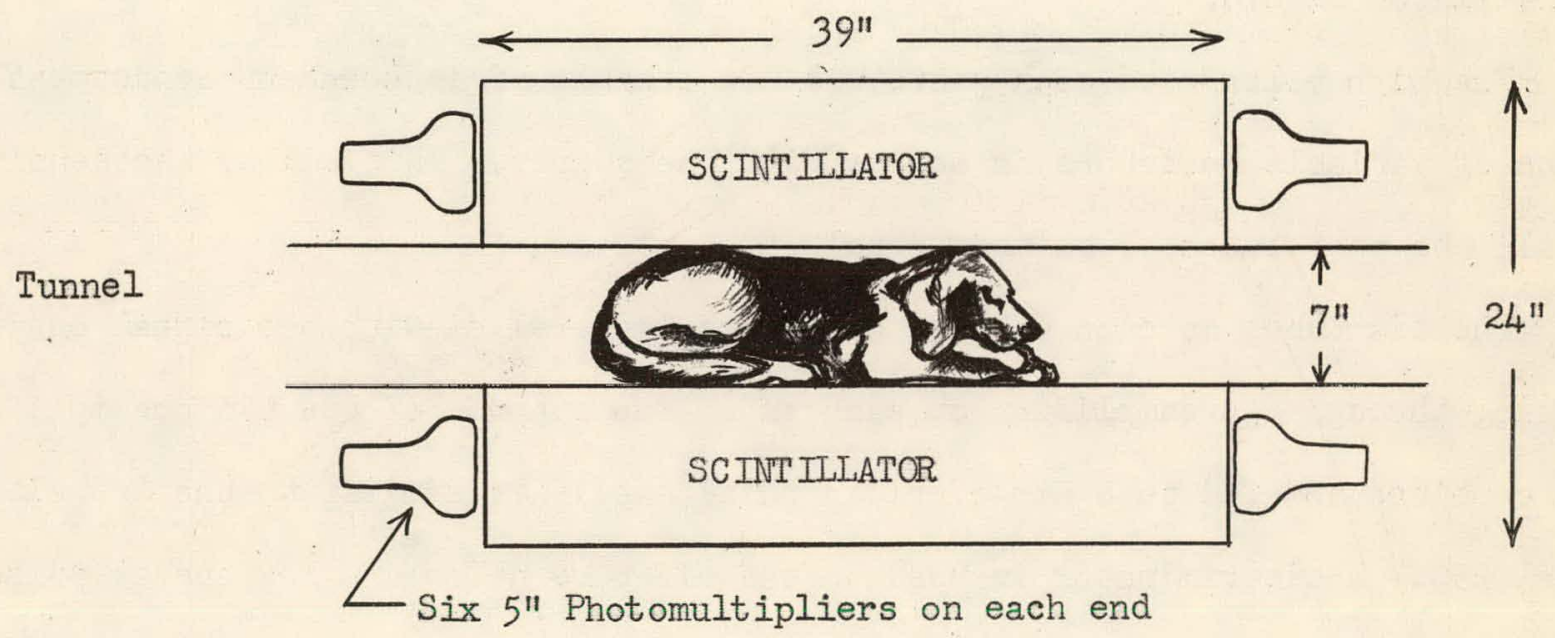

K-9 Bark II is an annular cylinder 39 inches long, 24 inches in diameter with a 7 inch diameter tunnel through the long axis.

The liquid scintillator is contained inside a steel shell 3/16 inches thick with end plates $3 / 8$ inches thick in which are welded threaded inserts which receive the plastic viewing ports and light tight compartments.

The seven inch diameter tunnel has a wall thickness of 0.032 inches. It passes through the center of the end plates and traverses the length of the counter. 
The tunnel projects 10 inches beyond each end to facilitate easy entrance of materials to be counted.

This arrangement provides a liquid layer 8.5 inches thick and 39 inches long.

The interior (part occupied by scintillator) was sand blasted and painted with a paint composed of Epon Resin Formulation $\mathrm{XA}-200$ containing anatase $\mathrm{TiO}_{2}$ as the reflecting pigment ${ }^{3}$.

The plastic ports are discs of CR-39 plastic $41 / 8$ inches thick mounted in pretreated neoprene "o" rings ${ }^{5}$. The photomultipliers are not yet optically coupled to the plastic ports but coupling with a transparent viscous fluid is planned.

Six 5 inch Dumont phototubes are arranged on each end and are situated in light tight compartments against CR-39 plastic ports through which scintillations are viewed.

The arrangement is such that the tubes may be removed without disturbing the scintillator liquid.

The high voltage to each phototube is capable of independent adjustment by means of variable resistors in series with the supply. This allows the sensitivity of a.II the phototubes to be made equal.

The six tubes at each end are connected in parallel with the signal output passing through a preamplifier at each end. The outputs of the two preamplifiers are combined and fed to a non-overload pulse amplifier similar to the Los Alamos model 250. A discriminator is used to cut off tube noise and low energy pulses. The pulses are then counted by both a scaler and precision count rate meter.

The volume of this counter is 70 gallons. Analytical reagent grade toluene with $5 \mathrm{gms} /$ liter of p-terphenyl and $0.2 \mathrm{gms} /$ liter of "POPOP" is the scintillator. This liquid was bubbled with 200 cubic feet of argon to sweep out dissolved oxygen. This was done to reduce the light quenching action of oxygen.

The counter is housed within a hollow steel cylinder 5 feet long and 5 feet in diameter with a 5 inch wall thickness. Five foot diameter disks of steel three inches thick close the ends. 
The arrangement of the counter in its enclosure allows $3 / 4$ of the space to be used to accomodate human subjects or space in which to carry out other measurements which require a low level of background.

The steel compartment is effective in reducing the background of a sodium iodide crystal counter by a factor of 20 for the energy range 0.25 to 1.00 M.E.V.

At this time an upper gate is being prepared for use with this counter. It should reduce that portion of background attributable to high-energy cosmic ray particles. This is expected to lower the total background appreciably.

Measurements: Dogs to be counted are anesthetized and placed in a plastic bag (open at the head end) to keep the counter clean, then slid on a cloth sling into the tunnel for gamma counting.

The upper limit of dog size is about $15 \mathrm{~kg}$ (33 Ibs.) which is well above our colony average of about $10 \mathrm{~kg}$.

The geometry for the counting of humans is not as good as it is for dogs, since humans must be counted outside the tank. The counter is, however, able to count potassium 40 and cesium 137 in humans to a reașonable accuracy.

The optimum counting condition to reduce the effect of purely statistical errors when the source is weak compared to background is to make the ratio $\mathrm{S}^{2} / \mathrm{B}$ a maximum. Where $S$ is the net count rate of the source and $B$ is the background count rate.

However, an operating point of slightly lower sensitivity was chosen to reduce tube noise, which experience has shown to be erratic. Efficiency: The figure on the following page shows the variation in counting efficiency with position along the axis for two unshielded gamma sources. 'If the average length of a dog $(70 \mathrm{~cm})$ is compared to the sensitivity curve shown, it will be seen that the dog is contained within the linear response region of the curve. This minimizes errors due to isotope distribution in the dog. 


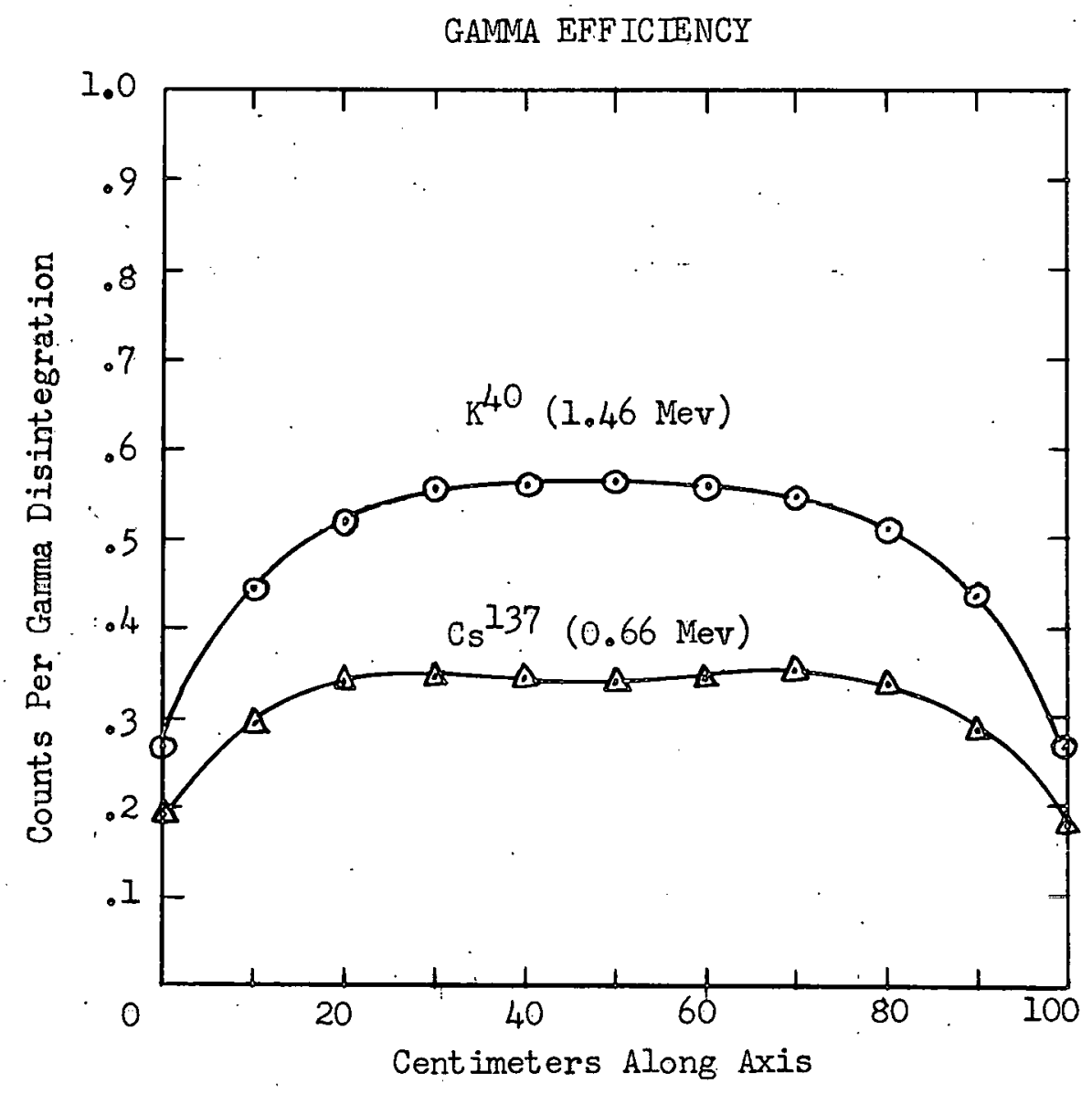

For a background of 70,000 c.p.m. samples giving count rates of 700 counts per minute (1/100 background) can be counted with a statistical standard deviation of $\pm 10 \%$ in a counting time of three minutes when using a three minute background count.

Non-statistical errors such as electronic drift tend to make the total error greater than the statistical error. However, for low level samples and short counting times the chief error is statistical.

The activity of several emitters which give a count rate of 700 counts per minute ( $1 / 100$ background) are 1isted. The recorded counts per parent atom disin : tegration are also tabulated. 


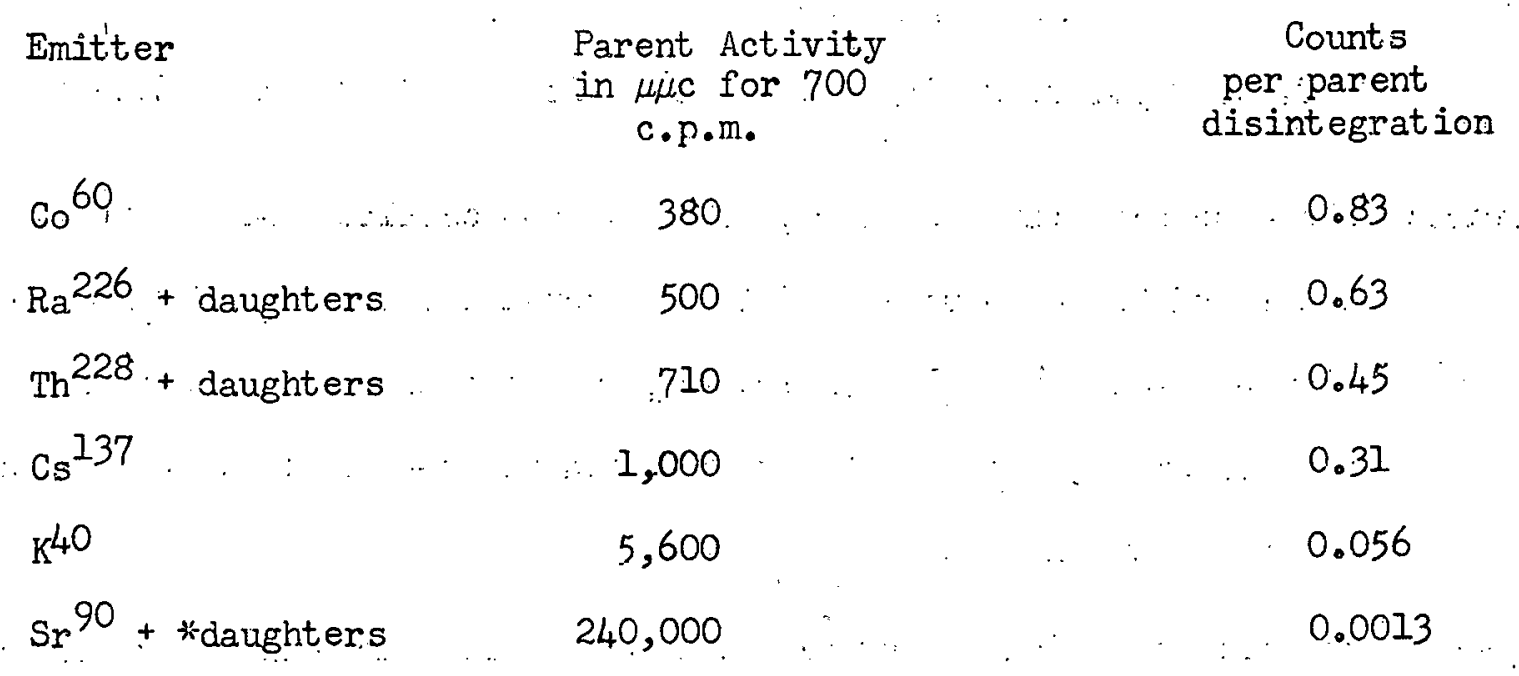

* Deposited in bone in a $10 \mathrm{~kg}$ beagle.

The sensitivity of this instrument increases with increasing gamma ray energy as is shown in the preceding table and the gamma efficiency curves.

\section{Surmary:}

1. An improved live dog gamina counter häs been completed.

2. A $5 \times 10^{-10}$ curie radium source in equilibrium with its daughters can be: measured to within a statistical standard deviation of $\pm 10 \%$ in only three minutes of of counting time.

3. Natural $\mathrm{K}^{40}$ and fallout $\mathrm{Cs}^{137}$ burdens are being measured in uninjected dogs and humans.

References and footnotes:

1. K-9: A large 4П Gamma-Ray Detector。 Nucleonics, September 1954, Vol.12, No. 9, Pgs。22-27.

2. The Los Alamos Human Counter, Nucleonics, January 1956, Vol. 14, No. I, Pgs. 26-29.

3. Glidden's Zopaque SD in Shell Chemical Companys Epon Resin Formulation XA-200.

4. CR-39: A product of Cast Optics Corporation Hackensack, New Jersey.

5. "O" rings soaked in toluene for three days before use. 
MEASUREMENT OF X-RAY DOSAGE TO DOGS

\section{W. Mays, D. H. Taysum, G. N. Taylor* and M. A. Van Dilla $* *$ *}

Abstract: The bone dose (in rads per year) from two complete $x$-ray examinations was found to be about $75 \%$ of the internal emitter dose in a l-level plutonium dog. In all control dogs and the lowest toxicity level dogs in each group, the $x$-ray dose has been reduced to about $30 \%$ of the l-level plutonium dose.

Introduction: All injection series plus $1 / 2$ the control dogs have been given a series of diagnostic $x$-rays twice a year. These x-rays form an extremely valuable record of bone changes, but considerable concern has arisen as to whether the $x-r a y$ dose may modify the changes caused by internal emitters in low level animals.

Technique: Dosage was measured with a Victoreen r-meter (I) which had been calibrated against $25 \mathrm{r}$ and $100 \mathrm{r}$ chambers at various dosage rates. Correction was made for temperature and pressure.

Entrance and exit dose was measured on the dog F5R5 during a regular x-ray examination. The meter was placed on top of the dog to measure entrance dose and underneath the animal to measure exit dose. Average dose to the exposed part was taken as the average of entrance and exit dose.

Average dose to the exposed part times the fractional part of the dog exposed gives equivalent whole body dose per shot. The sum of equivalent whole body doses per shot gives the total equivalent whole body dose in roentgens. Multiplying: equivalent whole body dose by the energy absorption coefficient for bone gives the average $x$-ray dose to the bone in rads.

(I) 1-r chamber model 227, Victoreen Instrument Company, 5806 Hough Ave. Cleveland, Ohio * Now at Michigan State University, Department of Veterinary Pathology. ** Now at Los Alamos Scientific Laboratories. 
On the suggestion of L. D. Marinelli of the Argonne National Laboratory, the effect of self-shielding due to the high $x$-ray absorption coefficient : of bone was investigated. Due to the thinness of dog bones, average dose to the exposed part is close to the average of entrance and exit dose. In a larger animal, such as the elephant, self-shielding would materially reduce the bone dose.

Results: 'X-rays were taken with a Westinghouse $x$-ray machine (style 981625). with $1.5 \mathrm{~mm}$ Al filter, $100 \mathrm{ma}, 1 / 5 \mathrm{sec}$, and 31 inch focal-film distarice except for shot \#2 where the focal-film distance was 15 . inches.

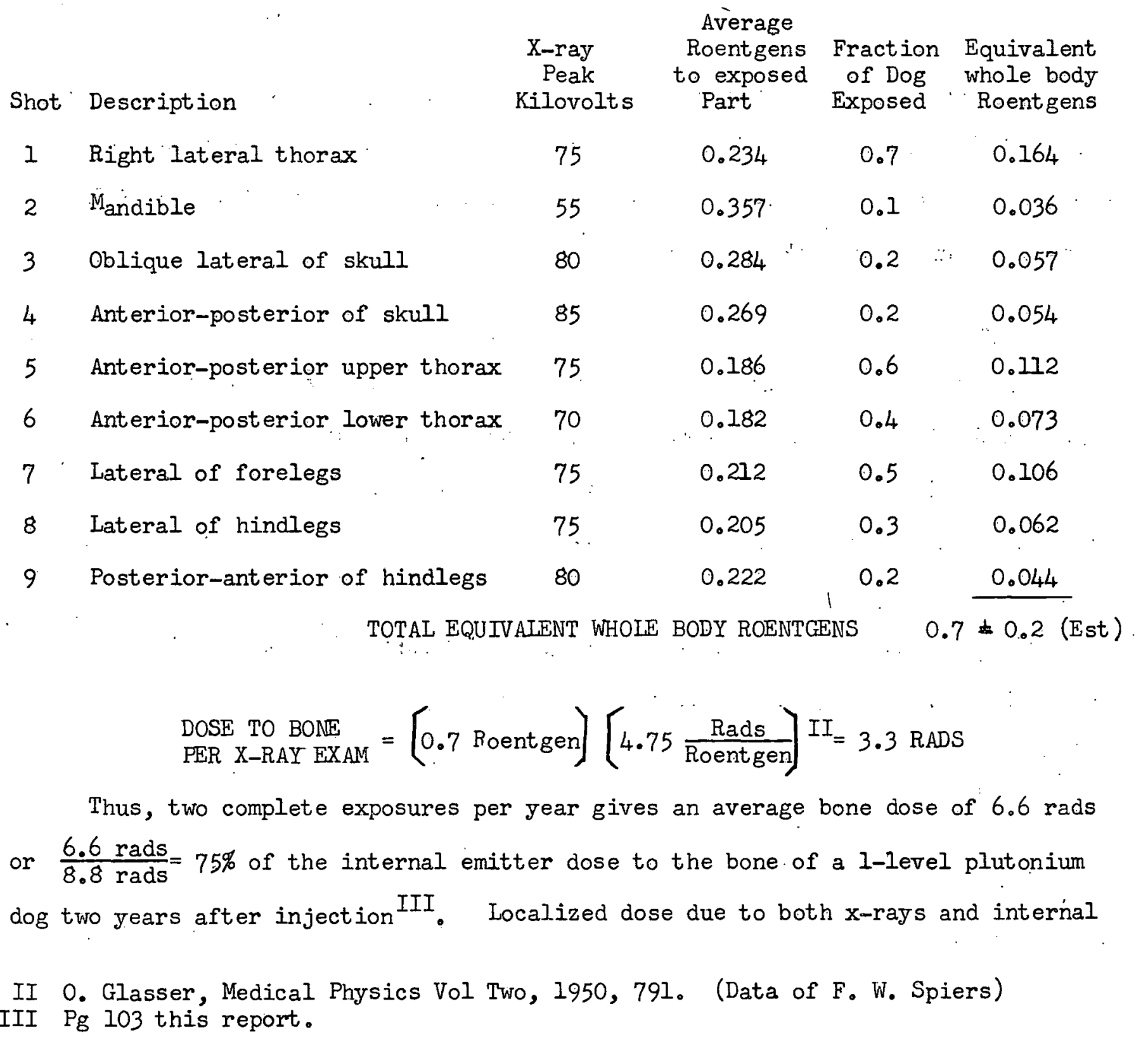


emitters varies considerably from the average dose due to the difference between entrance and exit dose and non uniform isotope deposition.

Reduction of $x$-ray dose: By limiting the $x$-ray beam-to parts of the animal directly over the film, dose is reduced to about $2 / 3$ of its original value. In addition, one of the two complete $\mathrm{x}$-ray examinations per year has been replaced with an abbreviated examination consisting of the lateral thorax, mandible, and lower foreleg in the controls, and 1-level dogs ( 0.5 level for Radiothorium). This reduces dose in these dogs to about $30 \%$ of the l-level plutonium internal emitter dose to the bone. The higher level dogs still receive the two complete examinations per year.

Dose could be still further reduced by using thicker filters and high kilovoltage but at the price of loss of contrast in the films. Good contrast is needed to detect minimal changes in bone architecture. We feel that poor films defeat the purpose of taking x-rays.

\section{Conclusions:}

1. With two $x$-ray examinations per year, the $x$-ray dose is uncomfortably close to the internal emitter dose in the lowest level animals.

2. By improved technique and reduction in exposures, the $x$-ray dose to control and lowest level dogs has been reduced to about $30 \%$ the 1 -level plutonium dose.

3. Continued effort will be directed toward further reduction of $x$-ray dose while maintaining high quality radiograms. 
FURTHER THORON EXHALAT ION MEASUREMENTS

$$
\text { C. W. Mays and I. W. Blake }
$$

Abstract: Using the technique previously described (Annual Report March 56 pg 81), breath thoron measurements have been continued in the radiothorium dogs and started in the "pure" mesothorium series.

Exhaled thoron in radiothorium dogs: Exhaled thoron was measured by having the dog breathe into a large tank in which the thoron decay atoms were collected on $a$ negatively-charged steel rod, whose activity was measured later. Values were adjusted to a standard ventilation rate of $3.33 \frac{\text { liter. }}{\text { min. }}$

Total thoron produced in the body was calculated by subtracting $\mathrm{Ra}^{224}$ excretion from the $\mathrm{Th}^{228}$ retention equation, (see pg 96: this report). (After 100 days this becomes a constant $73 \%$ of the injected $\mathrm{Th}^{228}$ corrected for decay). Because body-produced thoron is greater than was originally assumed, and due to more accurate calibration; the thoron exhalation values previously reported. (Annual Report March 1956) are too high.

Based on 76 measurements, the percent of thoron atoms formed in the body which are exhaled from 1 to 1000 days after injection may be expressed as:

2- and lower levels $\quad P=8 \% t-.11$
3--level
4-level

where $t$ is the number of days after injection.

\section{Comments:}

1.. The percent of thoron exhaled is small and becomes even smaller as. burden time increases. This is caused by the short half life of thoron (54 seconds), and the burial of parent atoms in locations less accessable to the circulation.

2. High level ( $3 \& 4$ ) dogs exhale a smaller percent of their thoron, while there is no significant difference among the 2 or lower level dogs. This effect 
becomes more pronounced as burden time increases and may indicate impaired circulation in areas of radiation damage.

Exhaled thoron in mesothorium dogs: The M4M, F5M, M6M and F7M groups were chosen for measurement because of the low $(0.6 \%)$ radiothorium contamination in their injection solutions. 24 dogs in dose levels 1 through 5 were measured.

Exhaled thoron produced from injected mesothorium was found by estimating (based on previous RdTh dogs) the exhaled thoron due to contamination of RdTh in the injection solution, and subtracting this from the measured total exhaled thoron. Calculation of the fraction of thoron exhaled: Total mesothorium produced thoron activity was assumed to be $90 \%$ of the ingrown radiothorium activity. Ingrown rad10thorium was computed assuming mesothorium ( $\mathrm{Ra}^{228}$ ) was retained like radium ( $\mathrm{Ra}^{226}$ ) (MsTh $=.8 t^{-.2} \mathrm{e}^{-.0284 t}$ ) and that in vivo produced radiothorium is not excreted. The radiothorium build up equation, $\operatorname{RdTh}=.0008 e^{-.001 t} \int_{.06}^{t} t-.2 e .00716 t d t$ was evaluated on a Datatron model 204 digital computer, the results of which appear on page 100 of this report.

Results: From 50 to 200 days after injection, $1.8 \neq 0.6 \%$ of the mesothoriumproduced thoron atoms formed in the body are exhaled.

This is only about $1 / 3$ as great as the percent of thoron exhaled by low level radiothorium dogs with the same burden time. The scatter in data prevents detection of the effects of time after injection and dose level.

Conclusion: We believe that the smaller fractional thoron exhalation in mesothorium injected dogs is due to failure of ingrown radiothorium to translocate appreciably from injected radium deposition sites (mineral bone) to injected thorium deposition sites from which escape of thoron is presumably easier. 
FURTHER STUDIES ON RADON RETENTION,

C.W. Mays, M。A. Van. Dilla, W. S.S. Jee, D。R.Atherton, J。 Watkins, D。 Barton, L. Blake and W. Stevens

Abstract: This is a continuation of work reported in the March, 1957 Annual Report. Conclusions remain unchanged except that fractional radon retention in mature, as well as in growing, bone formed after injection is smaller than that in pre-injection bone. Ethelyene diamine soxhlet extraction greatly increases radon retention.

Method: Fractional radon retention was measured by the method previously described pages 156-157 Annual Progress Report, March 1957.

Radon retention in post-injection bone: We have found that fractional radon retention in bone grown after injection (hereinafter called "post-injection bone"). is smaller than that in pre-injection bone. In an earlier Progress Report (March 1956, pp71) the reverse was (erroneously) reported. The discrepancy was solved by exhuming the frozen skeletons of F3R4 and MIR5 and measuring radon retention in dead bone kept moist and exposed to air at room temperature. Fractional radon retention was measured by comparing radon activity in the air-exposed sample to. equilibrium radon activity in the sealed sample. Due to absence of circulation, retention in dead bone is always greater than in live bone. By a rare stroke of luck the previously measured rib samples from F3R4 were discovered and remeasured in their original container。

The following data show that the previously reported retention values in post-injection bone are much too high, while the values for pre-injection bone are probably about correct.

$\begin{array}{ccccc}\text { Part of } & \begin{array}{c}\text { Reported } \\ \text { in vivo } \\ \text { Retention }\end{array} & \begin{array}{c}\text { Exhumed } \\ \text { sample } \\ \text { Retention }\end{array} & \begin{array}{c}\text { Remeasured original } \\ \text { sample } \\ \text { Retention }\end{array} \\ \text { F3R4 } & \text { Tip (Post-inj) } & 29 \%(?) & 18.0 \% & 18.1 \% \\ \text { F3R4 } & \text { Shaft (Pre-inj) } & 16 & 20.3 & 22.0 \\ \text { MZR5 } & \text { Tip (Post-inj) } & 36(?) & 18.5 & -\infty \\ \text { MZR5 } & \text { Shaft (Pre-inj) } & 23 & 23.1 & -\infty\end{array}$


The reason for the high values originally reported in post-injection bone seems to be the shift of the center of radiation in the containing vial due to diffusion of radon from the small porous rib tips which thawed while being serially counted. The well type counter used in the original measurement was unfortunately quite geometry dependent.

Lower fractional radon retention in post-injection bone is confirmed by the following measured values for live bone.

RIB SAMPIE

Tip (Post-inj)

Hot line

Shaft (Pre-inj)
FRACTIONAL RADON

TI2R5 . T13R5. M4R5 M2R5

$11.9 \%$

$12.7 \%$

$17.2 \%$

$17.0 \%$

15.5

15.9

20.7

22.2

$16.2 \quad 15.8$

20.7

21.2

Since post-injection bone has a smaller radium burden time than bone existing at injection, these results are in line with the observed increase in whole body fractional radon retention with burden time. Hot line retention is the same as shaft retention.

Erroneous carcass measurements of T8R5 and T9R5: Using the method just described, suspected measured values of whole body radon retention for T\&R5 and T9R5 (SemiAnnual Report September 1955, page 15) were proved to be in error. Representative bones were removed from the frozen skeletons and fractional radon retention was measured in these samples which were kept moist and exposed to air at room temperature.

Fractional radon retention in the exhumed bones is listed and compared with in vivo values for the humeri and carcasses made at the time of death. 
FRACTIONAL RADON RETENTION

SAMPLE

Femur shaft

Rib shaft

7th lumbar vertebra

Calvarium (top of skull)

Pelvis

Average (air expósed)

In vivo humerus

In vivo carcass
T8R5

$14.2 \%$

23.3

15.6

18.9

14.2

17.3

13.7

20.3

(?)

\section{T9R5}

$16.8 \%$

12.5

15.1

15.2

12.2

14.4

13.8

31.7 (?)
TIOR 5 Controi $16.1 \%$

13.2

9.3

15.8

10.8

13.1

12.2

10.0

Due to lack of circulation in dead bone, true in vivo radon retention is less than dead bone radon retention. Hence, the suspected values of in vivo radon retention, being higher, are wrong.

In contrast, the humeri retention values, measured by an independent method at time of death appear to be correct, and form the best available estimate of true whole body retention for these dogs.

Bones from TlOR5, whose measured whole body retention was unquestioned served as a control.

We do not know why the in vivo carcass values of T8R5 and T9R5 were so high. Both dogs were measured on the same days in $\mathrm{K}-9$, a whole dog gamma counter.

Effect of time after injection: Whole body fractional radon retention values at time of death for 16 beagles\% are presented' in tabular form and graphically. For comparison some retention values from other authors for ráts and humans are also plotted.

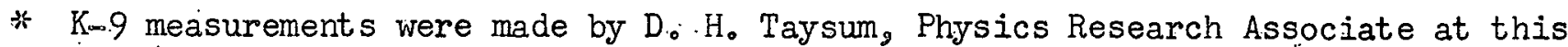
Laboratory and R. L。Floyd, now Associate Scientist at Linfield Research Institute, McMinnville, Oregon. 


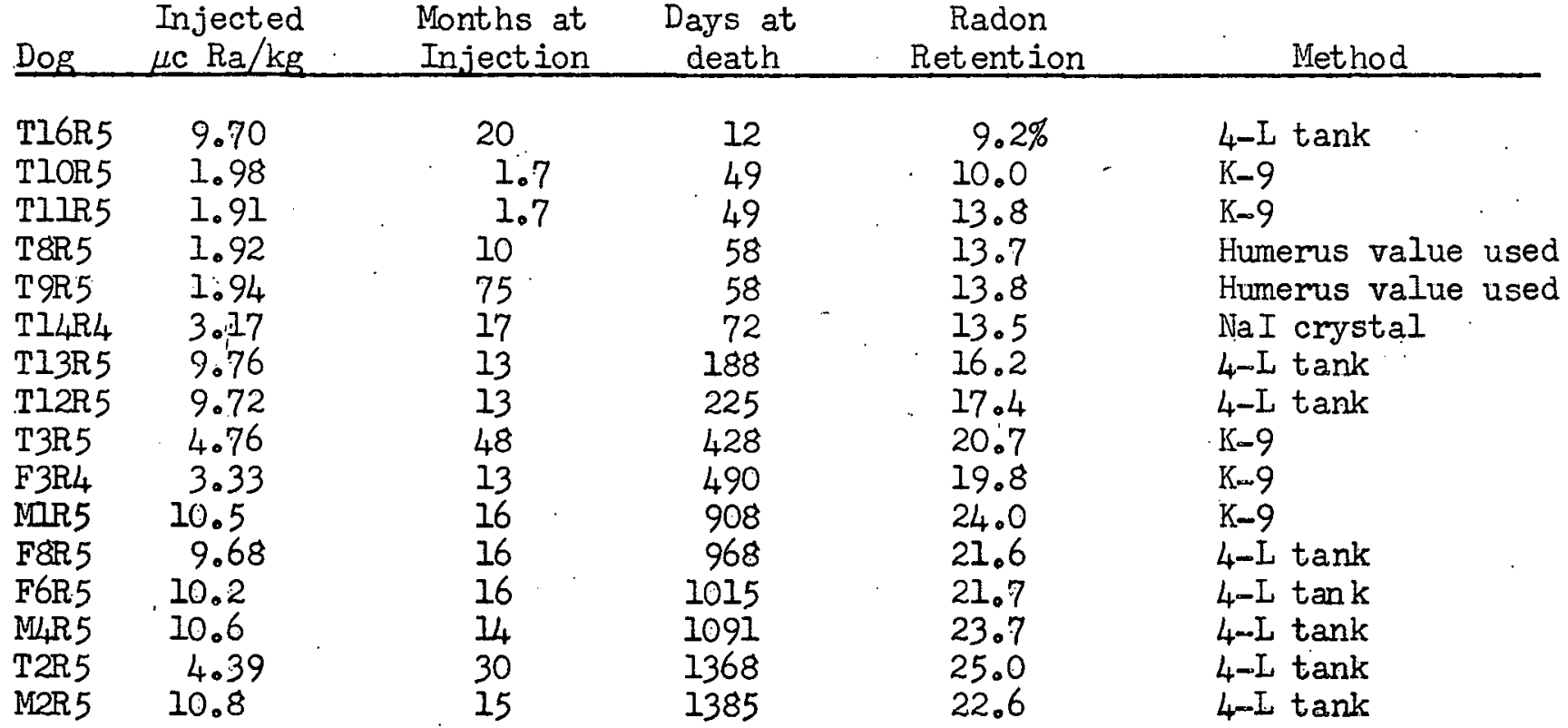

FRACT IONAL RADON RETENTION VS. TTME

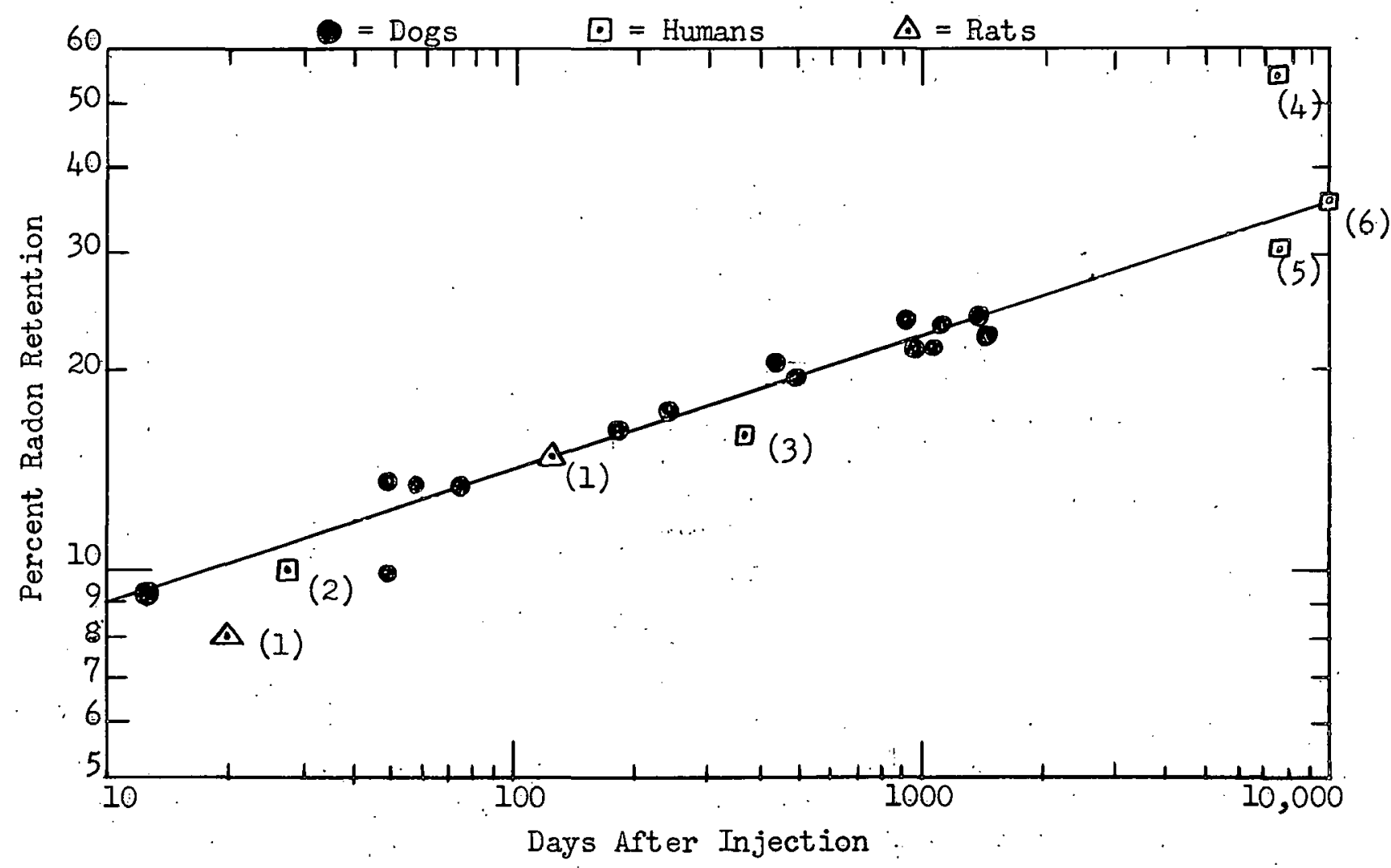

$151 \quad 119$ 
The following relations are evident from the preceeding data:

(a)., Fractional radon retention increases with time after radium injection and for beagles may be expressed as:

$F=5.7 \% t^{20} \quad \ldots$ where $t$ is the number of days after injection.

(b) Fractional, radon retention is similar in rats, dogs, and humans at the same time after injection.

(c) Fractional radon retention seems independent of dose level (from $1.91 \mu \mathrm{c} / \mathrm{kg}$ to $10.8 \mu \mathrm{c} / \mathrm{kg}$ ) and age at injection (from 1.7 months to 75 months).

Radon retention in whole bones: Fractional radon retention at time of death has been measured in individual whole bones from the 8 radium dogs whose bones were counted in the 4-liter scintillator tank. The most striking fact was the similarity in fractional radon retention from bone to bone in a particular animal. In any one dog, there is a definite tendency for retention to fall in the same sequence. Average retention values are presented by bone, and correspond to a burden time of 500 days.

BONE

Mandible (jaw bone)

Calvarium (top of skull)

Pelvis

Humerus and Femur (upper leg bones)

Cervical vertebra (neck bones)

Scapula (shoulder blade)

Lumbar vertebra. (lower backbone)

Hyoid bones (small bones in throat)

- Thorac ic vertebra (upper backbone)

Foot bones

Ribs

Sternum (breast bone)

Coccyx (tail)
Average

Fractional radon retention

$22.0 \%$

21.4

20.6

20.3

19.6

19.3

19.3

19.1

18.8

18.6

18.1

18.0

17.1 
The similarity of radon retention among individual whole bones and different: parts of whole bones suggests that whole body fractional radon retention could be closely estimated from a small bone sample. Our Pathologist, Dr. T. H. Cochran, has observed that small bone samples are often removed in the course of normal surgery and that we can expect radium poisoned humans to require surgery more often than non poisoned persons. Measurement of radon retention in these samples would be simpler than whole body gamma counting, and breath radon measurements, and yet might be more accurate.

Low radon retention in teeth: The similarity. of individual bone retention to skeletal retention does not apply to teeth where much lower retention has been found. Six canine teeth and two molar teeth have been measured from 5 dogs.: In four of the canine teeth, the pulp cavity and its lining were cored out to test whether retention might be different near the pulp cavity (extremely high radium concentration) than in the remainder of the tooth (diffuse radium concentration). Results show tooth retention is only about half of skeletal retention for these dogs.

$\begin{array}{lcc}\text { DOG } & \text { SKEIETAL RETENTION } & \text { TOOTH RETENT ION DESCR } \\ \text { TIR5 } & 23.0 & \\ \text { TRR5 } & 23.0 & 10.9 \% \text { whole canine } \\ \text { T2R5 } & 25.0 & 8.8 \text { whole molar } \\ \text { F6R5 } & 21.7 & 11.0 \text { whole molar } \\ \text { MLR5 } & \therefore & 11.2 \text { cored canine } \\ \text { M4R5 } & 23.7 & 13.5 \text { cored canine } \\ \text { M2R5 } & 23.7 & 13.3 \text { cored canine } \\ \text { M2R5 } & 22.6 & 9.7 \text { cored canine } \\ \text { M } & 22.6 & 12.9 \text { whole canine }\end{array}$

It is ironic that teeth, having the lowest radon retention, grow in jawbones which average the highest radon retention among the whole bones.

This suggests a fundamental difference in crystal size or composition between bone and teeth. It may be that the narrowest dimension in bone crystals is about twice that in teeth. X-ray diffraction and electron microscope studies may amplify this speculation.

Retention in bone tumors: Fractional radon retention was measured in samples taken from the exterior and interior of the calcified bone tumor on the lumbar vertebrae $151 \quad 121$ 
of MLR5. Retention in the exterior sample (17.7\%) was lower than retention in the older interior sample $(20.2 \%)$ which in turn was lower than retention in the lumbar vertebrae (21.7\%).

In F8R5 fractional radon retention was measured in a sample from the sightly calcified, extremely rapidly growing tumor on the right foreleg. The tumor retention of $6.5 \%$ was much less than the skeletal retention of $21.6 \%$.

These results are in line with our idea that fractional radon retention in: creases wlth the length of timo aftor radium deposition.

Radon retention in mineral bone: The organic fraction was removed from 10 radium bone samples from the dog TI2R5 using a soxhlet extractor with $80 \%$ ethylene diamine (EDA) for 3 days. The samples were then flushed with water for 3 days and the radon allowed to equilibrate in the air exposed samples for $2=4$. weeks at various temperature and humidity conditions. Mineral fraction was taken as the ratio of sample weight at $230^{\circ} \mathrm{C}$ (assumed $100 \%$ mineral) to the sample weights at other conditions. The samples represented cortical and trabecular bone from the long bones and vertebrae, and post and pre-injection bone from the rib. No significant differences existed between individual and average retentions in the EDA treated samples. Temperature, average mineral fraction and average fractional radon retention are presented in the same order measurements were taken. 


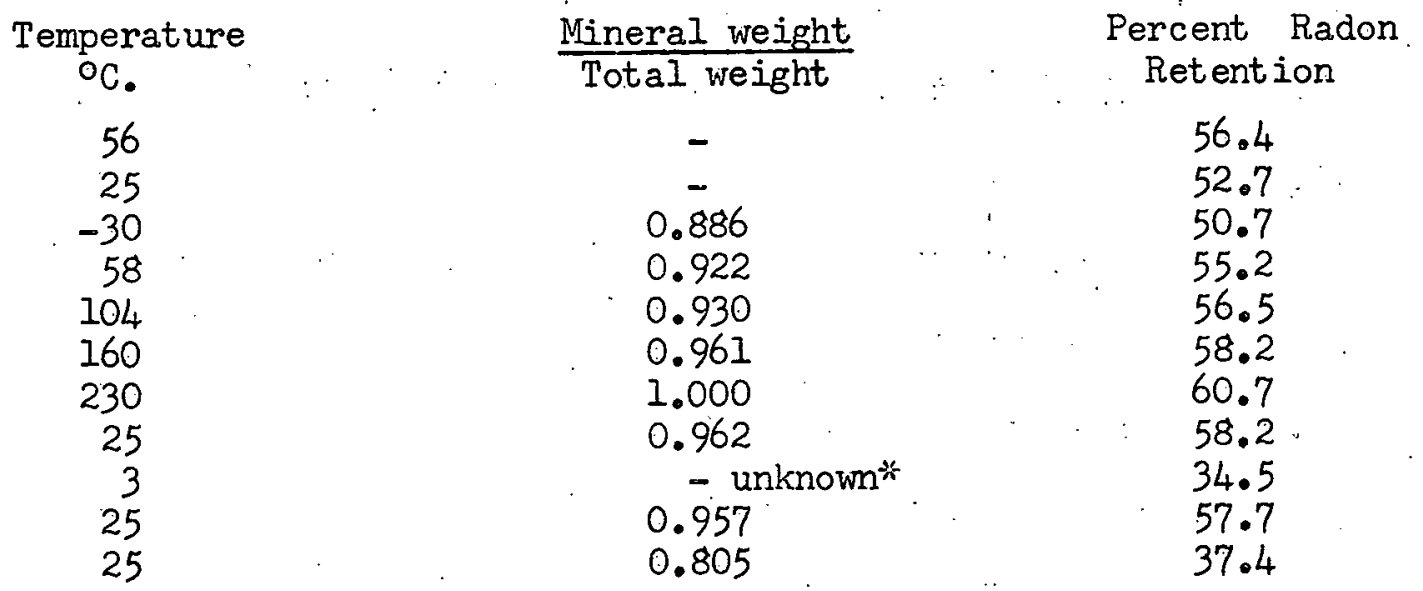

* Samples soaked in water, exact mineral fraction unknown.

RADON RETENTION VS. MINERAL FRACTION

IN EDA EXTRACTED BONE

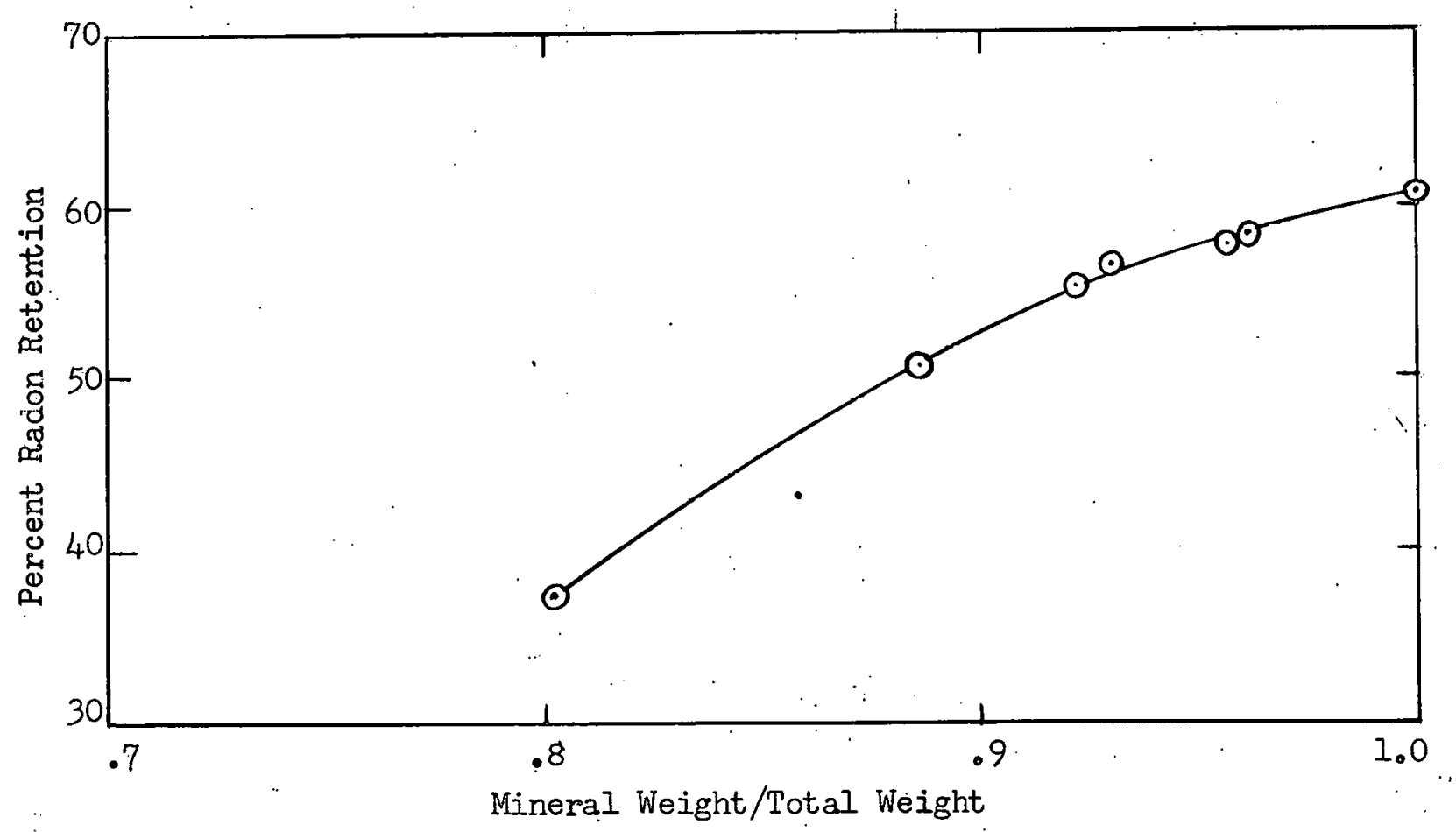

$151 \quad 123$ 
The increase of radon retention with increasing temperature was initially a surprise as temperature alone, by increasing molecular kinetic energy normally increases diffusion and hence should produce a decrease in radon retention. Temperature however, was not acting alone but was causing air-exposed bone samples to gain or lose water from the atmosphere. This altered the mineral fraction and it was this change in mineral fraction which accounts for the change in radon retention.

The lack of a pure temperature effect was proved by changing the temperature from $230^{\circ}$ to $25^{\circ} \mathrm{C}$ while keeping the samples as dry as possible in a large sealed vessel. Radon retention at a temperature of $25^{\circ} \mathrm{C}$, and a mineral fraction of 0.962 was the same as retention at $160^{\circ} \mathrm{C}$ and the same mineral fraction. Hence, under the conditions tested, temperature acting along does not measurably alter radon retention in EDA treated bone.

However, when the water content (and hence mineral fraction) was altered while the temperature was held constant radon retention changed significantly. The sequence of runs shows that these effects are reversable.

Part of the increase of radon retention with increasing mineral fraction can be explained on the basis of more recoiling radon atoms stopping inside crystals from which diffusion is difficult, and fewer in water from which diffusion is easy, but this is not enough to completely account for the observed changes. We do not know the complete explanation for increase of radon retention with increasing mineral fraction in EDA treated bone. This relation does not necessarily exactly apply to change of radon retention with mineral fraction in vivo where the crystals are always water saturated.

Another puzzle remains. In the live animal, fractional radon retention was $17 \%$. Before EDA extraction, retention in air exposed samples was $22 \%$. But after extraction, retention more than doubled! It is clear that EDA Soxhlet extraction changes at least one property of mineral bone, $\dot{i}_{0} e_{0}$, its ability to retain radon, but we do not know whether this is caused by effective increase in crystal size 
or a decreased diffusion coefficient produced by modifications in crystal structure.

Our results on mineral bone agree with the more extensive work done by $R$. E.

Rowland $(7)$ at the Argonne National Laboratory:

SUMMARY OF RADON EXPER IMENTAL RESULTS TO DATE

Fractional radon retention:

1. Is similar for the rat, $\operatorname{dog}_{9}$ and human at equal times after radium injection.

2. In dogs is independent of injected dose, age at injection, sex, state of health, rate of circulation, weight and fat content.

3. Increases with time after radium deposition.

a) Is lower in post injection bone.

b) Is lower in areas of rapid bone growth:

c) Is lower in rapidly growing bone tumors.

4. Is similar among different whole bones, tending to be slightly smaller in the smaller bones.

5. Is only half as large in teeth as in bone.

6. Is increased to about $90 \%$ in water saturated, frozen bone.

7. Is increased by EDA soxhlet extraction.

8. Increases as the mineral fraction increases.

Correlation with theory: Because of lack of exact knowledge of the true shape of bone crystals, retention equations have been worked out for a tablet, cylinder and sphere assuming radon recoil range was large compared to the smallest dimension of the crystal and that the diffusion coefficient was uniform throughout the crystal. The derivation for the tablet case has been worked out in detail previously (Annual Progress Report March 1957)。The other derivations are similar. Assuming bone crystals are long thin cylinders:

$$
F=M\left(I-\frac{2}{x} \quad \frac{I_{1}(x)}{I_{0}(x)}\right)
$$


Assuming bone crystals are thin tablets:

$$
F=M\left(I-\frac{\tanh (x)}{x}\right)
$$

Assuming bone crystals are spheres:

$$
F=M\left(1+\frac{3}{x^{2}} \frac{-3 \operatorname{Coth}(x)}{x}\right)
$$

where

$F=$ fractional radon retention

$M=\frac{\text { mineral density within recoil range }}{\text { tota]. density within recoil range }}$

$x=r \sqrt{\frac{\lambda}{\mathrm{D}}}$

$$
\begin{aligned}
& \text { (half thickness of tablet } \\
& \text { (radius of cylinder } \\
& \text { (radius of sphere }
\end{aligned}
$$

$\lambda=$ decay constant of radon

$D=$ diffusion coefficient of radon in bone crystal

$I(x)=$ Hyperbolic Bessel function (tabulated in Handbook of Chemistry and Physics)

Radon retention is regarded as chiefly a function of three variables, $M_{9}, r_{2}$ and $D$. As bone ages, the mineral fraction (M) increase, crystal size ( $r$ ) increases and as the crystal matures and becomes more nearly perfect the diffusion coefficient (D) probably decreases.

Each indicated change in these variables tends to increase fractional radon retention $(F)$ in all three equations. This predicted increase in fractional radon retention with time after radium deposition is observed experimentally.

A logical question is why is there no effect of age at injection? We think the answer is that most of the radium atoms deposit in growing areas. In these areas the crystals are young regardless of the age of the animal, and these young crystals mature at about the same rate. The similarity of radon retention in rats, dogs, and humans suggests a basic species uniformity in the sizes of bone crystals and the rate at which they mature. 


\section{References}

1. W. P. Norris, et alog Argonne National Laboratory Report on Biological Medicine and Biophysics Programs, July 1954 (ANL 5288).

2. F. E. Hoecker, J. Ind. Hyg and Toxicol 26, 1944 .

3. H. Schlundt, et alog Am。 Jo Roentgenol and Rad. Therápy 1933, 30 .

4. R. D. Evans, J. Indust. Hyg and Toxicol, 25, 1943.

5. W. P. Norris, et al., Am。J. Roentgenol and Rad. Therapy, 73, No. 5, May 1955.

6. W. B. Looney, et al. gm. J: Roentgenol and Rad Therapy 73, No. 6, June 1955.

7. R. E. Rowland, Personal comminication. 